\title{
Tigliane Diterpenoids with Larvicidal, Antifungal and $\alpha$-Glucosidase Inhibitory Activities from Croton damayeshu
}

Zhi-Yong Jiang, ${ }^{*}, \dagger, \downarrow$, Jin-E Feng, ${ }^{\S}$ Li-Kun Duan, ${ }^{\S}$ Chun-Jiang Liu, ${ }^{\dagger}$ Xiao-Fei Li,${ }^{\dagger}$ Chun-Qiu Huang, ${ }^{\perp}$ Sheng-Li Shi, ${ }^{\|}$Rui-Rui Wang, ${ }^{* \dagger}{ }^{\dagger}$ Ai-Xue Zuo, ${ }^{* \dagger}$ Hong-Ping $\mathrm{He}^{*, \dagger, t}$

${ }^{\dagger}$ School of Ethnic Medicine, Yunnan University of Chinese Medicine, Kunming 650500, Yunnan, People's Republic of China

${ }^{\ddagger}$ Key Laboratory of Modern Research on Ethnic Medicine in Colleges of Yunnan Province, Kunming 650500, Yunnan, People's Republic of China

${ }^{\S}$ Key Laboratory of Chemistry in Ethnic Medicinal Resources, State Ethnic Affairs Commission \& Ministry of Education, Yunnan Minzu University, Kunming 650500, Yunnan, People's Republic of China

${ }^{\perp}$ Yunnan Phytopharmaceutical Co. Ltd. Kunming 650505, Yunnan, People’s Republic of China

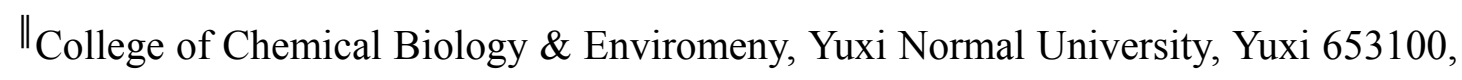
Yunnan, People's Republic of China 


\section{Supporting Information}

\begin{aligned} \hline Contents page \\ \hline\end{aligned}

S1. Isolation procedure of the known compounds.

Figure S1. The structures of the known compounds.

Figure S2. The structures of the new compounds.

Figure S3. The larvicidal activities against $P$. xylostella of tested compounds. 4

Figure S4. The HRESIMS (+) of compound 1

Figure S5. The IR spectrum of compound 1

Figure S6. The ${ }^{1} \mathrm{H}$ NMR (400 MHz) spectrum of compound $\mathbf{1}$ in $\mathrm{CDCl}_{3}$. 7

Figure S7. The enlarged ${ }^{1} \mathrm{H}$ NMR (400 MHz) spectrum of compound $\mathbf{1}$ in $\mathrm{CDCl}_{3}$. 8

Figure S8. The ${ }^{13} \mathrm{C}$ NMR $(100 \mathrm{MHz})$ spectrum of compound $\mathbf{1}$ in $\mathrm{CDCl}_{3}$. 9

Figure S9. The enlarged ${ }^{13} \mathrm{C}$ NMR $(100 \mathrm{MHz})$ spectrum of compound $\mathbf{1}$ in $\mathrm{CDCl}_{3}$. 10

Figure S10. The HSQC spectrum of compound $\mathbf{1}$ in $\mathrm{CDCl}_{3}$. 11

Figure S11. The $\mathrm{HMBC}$ spectrum of compound $\mathbf{1}$ in $\mathrm{CDCl}_{3} \quad 12$

Figure S12. The ${ }^{1} \mathrm{H}-{ }^{1} \mathrm{H}$ COSY spectrum of compound $\mathbf{1}$ in $\mathrm{CDCl}_{3}$

Figure S13. The ROESY spectrum of compound $\mathbf{1}$ in $\mathrm{CDCl}_{3}$. 14

Figure S14. The HRESIMS (+) of compound $2 \quad 15$

Figure S15. The IR spectrum of compound $2 \quad 16$

Figure S16. The ${ }^{1} \mathrm{H}$ NMR (400 MHz) spectrum of compound 2 in $\mathrm{CDCl}_{3}$. 17

Figure S17. The enlarged ${ }^{1} \mathrm{H}$ NMR (400 MHz) spectrum of compound 2 in $\mathrm{CDCl}_{3}$. 18

Figure S18. The ${ }^{13} \mathrm{C}$ NMR $(100 \mathrm{MHz})$ spectrum of compound 2 in $\mathrm{CDCl}_{3}$. 19

Figure S19. The enlarged ${ }^{13} \mathrm{C}$ NMR $(100 \mathrm{MHz})$ spectrum of compound $\mathbf{2}$ in $\mathrm{CDCl}_{3}$. 20

Figure S20. The HSQC spectrum of compound $\mathbf{2}$ in $\mathrm{CDCl}_{3} \quad 21$

Figure S21. The $\mathrm{HMBC}$ spectrum of compound $\mathbf{2}$ in $\mathrm{CDCl}_{3}$

Figure S22. The ${ }^{1} \mathrm{H}-{ }^{1} \mathrm{H}$ COSY spectrum of compound $\mathbf{2}$ in $\mathrm{CDCl}_{3}$

Figure S23. The ROESY spectrum of compound $\mathbf{2}$ in $\mathrm{CDCl}_{3}$

Figure S24. The HRESIMS (+) of compound $3 \quad 25$

Figure S25. The IR spectrum of compound $3 \quad 26$

Figure S26. The ${ }^{1} \mathrm{H}$ NMR (400 MHz) spectrum of compound 3 in $\mathrm{CDCl}_{3} \quad 27$

Figure S27. The ${ }^{13} \mathrm{C}$ NMR $(100 \mathrm{MHz})$ spectrum of compound 3 in $\mathrm{CDCl}_{3} \quad 28$

Figure S28. The enlarged ${ }^{13} \mathrm{C}$ NMR $(100 \mathrm{MHz})$ spectrum of compound 3 in $\mathrm{CDCl}_{3}$

Figure S29. The HSQC spectrum of compound 3 in $\mathrm{CDCl}_{3}$. 30

Figure S30. The $\mathrm{HMBC}$ spectrum of compound $\mathbf{3}$ in $\mathrm{CDCl}_{3}$. 31

Figure S31. The ${ }^{1} \mathrm{H}-{ }^{1} \mathrm{H}$ COSY spectrum of compound $\mathbf{3}$ in $\mathrm{CDCl}_{3}$

Figure S32. The ROESY spectrum of compound $\mathbf{3}$ in $\mathrm{CDCl}_{3}$

Figure S33. The HRESIMS (+) of compound $4 \quad 34$

Figure S34. The IR spectrum of compound $4 \quad 35$

Figure S35. The ${ }^{1} \mathrm{H}$ NMR (600 MHz) spectrum of compound $\mathbf{4}$ in $\mathrm{CDCl}_{3} \quad 36$

Figure S36. The ${ }^{13} \mathrm{C}$ NMR $(150 \mathrm{MHz})$ spectrum of compound $\mathbf{4}$ in $\mathrm{CDCl}_{3}$

Figure S37. The enlarged ${ }^{13} \mathrm{C}$ NMR (150 MHz) spectrum of compound $\mathbf{4}$ in $\mathrm{CDCl}_{3} \quad 38$

Figure S38. The HSQC spectrum of compound $\mathbf{4}$ in $\mathrm{CDCl}_{3}$

Figure S39. The HMBC spectrum of compound $\mathbf{4}$ in $\mathrm{CDCl}_{3}$.

Figure S40. The ${ }^{1} \mathrm{H}-{ }^{1} \mathrm{H}$ COSY spectrum of compound $\mathbf{4}$ in $\mathrm{CDCl}_{3}$. 41 
Figure S41. The ROESY spectrum of compound $\mathbf{4}$ in $\mathrm{CDCl}_{3}$

Figure S42. The HRESIMS (+) of compound 5. 43

Figure S43. The IR spectrum of compound 5

Figure S44. The ${ }^{1} \mathrm{H}$ NMR (600 MHz) spectrum of compound 5 in $\mathrm{CDCl}_{3}$. 45

Figure S45. The ${ }^{13} \mathrm{C}$ NMR (150 MHz) spectrum of compound 5 in $\mathrm{CDCl}_{3}$

Figure S46. The enlarged ${ }^{13} \mathrm{C}$ NMR $(150 \mathrm{MHz})$ spectrum of compound 5 in $\mathrm{CDCl}_{3} \quad 47$

Figure S47. The HSQC spectrum of compound 5 in $\mathrm{CDCl}_{3}$. 48

Figure S48. The HMBC spectrum of compound 5 in $\mathrm{CDCl}_{3}$. 49

Figure S49. The ${ }^{1} \mathrm{H}-{ }^{1} \mathrm{H}$ COSY spectrum of compound 5 in $\mathrm{CDCl}_{3} \quad 50$

Figure S50. The ROESY spectrum of compound 5 in $\mathrm{CDCl}_{3}$

Figure S51. The HRESIMS (+) of compound 6

Figure S52. The IR spectrum of compound 6

Figure S53. The ${ }^{1} \mathrm{H}$ NMR (600 MHz) spectrum of compound 6 in $\mathrm{CDCl}_{3}$

Figure S54. The ${ }^{13} \mathrm{C}$ NMR $(150 \mathrm{MHz})$ spectrum of compound 6 in $\mathrm{CDCl}_{3}$. 55

Figure S55. The enlarged ${ }^{13} \mathrm{C}$ NMR $(150 \mathrm{MHz})$ spectrum of compound 6 in $\mathrm{CDCl}_{3} \quad 56$

Figure S56. The HSQC spectrum of compound $\mathbf{6}$ in $\mathrm{CDCl}_{3}$

Figure S57. The HMBC spectrum of compound 6 in $\mathrm{CDCl}_{3} \quad 58$

Figure S58. The ${ }^{1} \mathrm{H}-{ }^{1} \mathrm{H}$ COSY spectrum of compound 6 in $\mathrm{CDCl}_{3}$

Figure S59. The ROESY spectrum of compound 6 in $\mathrm{CDCl}_{3} \quad 60$

Figure S60. The HRESIMS (+) of compound 7.

Figure S61. The IR spectrum of compound 7 62

Figure S62. The CD spectrum of compound 7

Figure S63. The ${ }^{1} \mathrm{H}$ NMR (600 MHz) spectrum of compound 7 in $\mathrm{CDCl}_{3}$

Figure S64. The ${ }^{13} \mathrm{C}$ NMR $(150 \mathrm{MHz})$ spectrum of compound 7 in $\mathrm{CDCl}_{3}$

Figure S65. The enlarged ${ }^{13} \mathrm{C}$ NMR $(150 \mathrm{MHz})$ spectrum of compound 7 in $\mathrm{CDCl}_{3} \quad 66$

Figure S66. The HSQC spectrum of compound 7 in $\mathrm{CDCl}_{3}$. 67

Figure S67. The HMBC spectrum of compound 7 in $\mathrm{CDCl}_{3} \quad 68$

Figure S68. The ${ }^{1} \mathrm{H}-{ }^{1} \mathrm{H}$ COSY spectrum of compound 7 in $\mathrm{CDCl}_{3}$.

Figure S69. The ROESY spectrum of compound 7 in $\mathrm{CDCl}_{3} \quad 70$

Figure S70. The HRESIMS (+) of compound 8

Figure S71. The IR spectrum of compound 8. 72

Figure S72. The CD spectrum of compound 8

Figure S73. The ${ }^{1} \mathrm{H}$ NMR (400 MHz) spectrum of compound 8 in $\mathrm{CDCl}_{3} \quad 74$

Figure S74. The ${ }^{13} \mathrm{C}$ NMR (100 MHz) spectrum of compound 8 in $\mathrm{CDCl}_{3}$

Figure S75. The enlarged ${ }^{13} \mathrm{C}$ NMR (100 MHz) spectrum of compound 8 in $\mathrm{CDCl}_{3} \quad 76$

Figure S76. The HSQC spectrum of compound 8 in $\mathrm{CDCl}_{3}$. 77

Figure S77. The HMBC spectrum of compound 8 in $\mathrm{CDCl}_{3} \quad 78$

Figure S78. The ${ }^{1} \mathrm{H}-{ }^{1} \mathrm{H}$ COSY spectrum of compound 8 in $\mathrm{CDCl}_{3}$

Figure S79. The ROESY spectrum of compound 8 in $\mathrm{CDCl}_{3} \quad 80$

Figure S80. The HRESIMS (+) of compound 9

Figure S81. The IR spectrum of compound 9

Figure S82. The CD spectrum of compound 9. 83

Figure S83. The ${ }^{1} \mathrm{H}$ NMR (600 MHz) spectrum of compound 9 in $\mathrm{CDCl}_{3}$

Figure S84. The ${ }^{13} \mathrm{C}$ NMR (150 MHz) spectrum of compound 9 in $\mathrm{CDCl}_{3}$ 
Figure S85. The enlarged ${ }^{13} \mathrm{C}$ NMR (150 MHz) spectrum of compound 9 in $\mathrm{CDCl}_{3}$.

Figure S86. The HSQC spectrum of compound 9 in $\mathrm{CDCl}_{3}$.

Figure S87. The $\mathrm{HMBC}$ spectrum of compound 9 in $\mathrm{CDCl}_{3}$.

Figure S88. The ${ }^{1} \mathrm{H}-{ }^{1} \mathrm{H}$ COSY spectrum of compound $\mathbf{9}$ in $\mathrm{CDCl}_{3}$

Figure S89. The ROESY spectrum of compound 9 in $\mathrm{CDCl}_{3} \quad 90$

Figure S90. The HRESIMS (+) of compound $\mathbf{1 0} 91$

Figure S91. The IR spectrum of compound $10 \quad 92$

Figure S92. The CD spectrum of compound 10.

Figure S93. The ${ }^{1} \mathrm{H}$ NMR (400 MHz) spectrum of compound $\mathbf{1 0}$ in $\mathrm{CDCl}_{3}$

Figure S94. The ${ }^{13} \mathrm{C}$ NMR (100 MHz) spectrum of compound 10 in $\mathrm{CDCl}_{3}$. 95

Figure S95. The enlarged ${ }^{13} \mathrm{C}$ NMR (100 MHz) spectrum of compound 10 in $\mathrm{CDCl}_{3}$

Figure S96. The HSQC spectrum of compound 10 in $\mathrm{CDCl}_{3}$

Figure S97. The $\mathrm{HMBC}$ spectrum of compound $\mathbf{1 0}$ in $\mathrm{CDCl}_{3}$

Figure S98. The ${ }^{1} \mathrm{H}-{ }^{1} \mathrm{H}$ COSY spectrum of compound $\mathbf{1 0}$ in $\mathrm{CDCl}_{3}$

$\begin{array}{ll}\text { Figure S99. The ROESY spectrum of compound } \mathbf{1 0} \text { in } \mathrm{CDCl}_{3} & 100\end{array}$ 


\section{S1. Isolation of the known compounds 11-37.}

The dried leaves $(10 \mathrm{~kg})$ of Croton damayeshu were extracted with 90\% EtOH (90 L) for three times at room temperature $(12 \mathrm{~h}$ each time). The combined $90 \% \mathrm{EtOH}$ extract was evaporated in vacuo to give a black syrup, which was partitioned between water and petroleum ether, followed by partitioning between water and EtOAc to give petroleum ether $(350 \mathrm{~g})$ and EtOAc fractions $(200 \mathrm{~g})$.

The petroleum ether fraction was subjected to silica gel $\mathrm{CC}$ with gradient elution (petroleum ether-acetone, 100:0, 98:2, 95:5; 90:10, 80:20; 70:30; 60:40; 50:50; v/v, each 8L) to afford five major fractions (Fr.s A-E). Fr.B (25.4 g) was purified on a silica gel column (petroleum ether-EtOAc, 90:10, 80:20, 70:30: 60:40) to yield four fractions (Fr.B1-FrB4). Fr.B2 (5.4 g) was decolorized by a MCI gel column with a gradient elution $\left(\mathrm{MeOH}-\mathrm{H}_{2} \mathrm{O}, 80: 20,90: 10,100: 0\right)$ to yield three sub-fractions (Fr.B2.1- Fr.B2.3). Fr.B2.1 was subjected to silica gel column (petroleum ether-EtOAc, 90:10, 80:20, 70:30) and further purified by Rp-18 $\left(\mathrm{MeOH}-\mathrm{H}_{2} \mathrm{O}, 65: 35\right)$ to give compounds $\mathbf{1 1}(25.0 \mathrm{mg})$ and $\mathbf{1 7}(74.0 \mathrm{mg})$. Fr.B2.3 was purified by HPLC with an elution of $\mathrm{MeOH}-\mathrm{H}_{2} \mathrm{O}$ (63:37) to yield compounds 12 (2.7 mg), 20 (16 mg), 25 (3 mg). FrB3 (1.5 g) was chromatographed on a silica gel column (petroleum ether-aceton, 90:10, 80:20, 70:30: 60:40) to yield three fractions (FrB3.1- FrB3.3). FrB3.2 (0.52 g) was subjected on a Sephadex LH-20 and further purified by HPLC to get compounds $21(19 \mathrm{mg}), 24(22 \mathrm{mg})$ and $30(15 \mathrm{mg})$. Fr.C (35.2 g) was chromatographed over a silica gel column with gradient elution (petroleum ether-acetone, 80:20, 70:30, 60:40, 50:50, each 2L) to give six sub-fractions (Fr.C1Fr.C6), Fr.C2 (2.8 g) was subjected to a MCI gel column with an gradient elution of $\mathrm{MeOH}-\mathrm{H}_{2} \mathrm{O}(60: 40,70: 30,80: 20,90: 10,100: 0$, each $800 \mathrm{~mL})$ to give four fractions (Fr.C2.1-FrC2.4). Fr.C2.1 was purified on silica gel CC (petroleum ether-acetone, 80:20) to yield compounds $18(310 \mathrm{mg})$ and $19(9 \mathrm{mg})$. FrC2.3 was performed on a Sephadex LH-20 column $\left(\mathrm{MeOH} / \mathrm{H}_{2} \mathrm{O}, 1: 1\right)$ and further separated by HPLC $\mathrm{MeOH}-\mathrm{H}_{2} \mathrm{O}(61: 39)$ to provide compounds $13(3.2 \mathrm{mg}), 23(79 \mathrm{mg})$ and $25(6 \mathrm{mg})$. 
FrC2.4 was subjected to a silica gel column (petroleum ether-acetone, 85:15) to afford compounds $32(17.0 \mathrm{mg})$ and $34(45.6 \mathrm{mg})$.

Fr.D (28.7 g) was subjected to a silica gel column (petroleum ether-acetone, 80:20, 70:30: 60:40, 50:50) to give four fractions (Fr.D1- Fr.D4). Fr.D1 was decolorized on a MCI column and further purified by silica gel CC (petroleum ether-EtOAc, 75:25) to yield compounds 22 (54 mg), 31 (34 mg) and 35 (29 mg). Fr.D2 was subjected to a silica gel CC (petroleum ether-acetone, 80:20) followed by a HPLC purification to get compound $33(34.3 \mathrm{mg})$. Fr.D3 was performed on an Rp-18 gel column $\left(\mathrm{MeOH}-\mathrm{H}_{2} \mathrm{O}, 60: 40,70: 30,80: 20,90: 10\right.$, 100:0) to give three sub-fractions (Fr.D3.1- Fr.D3.3). Fr.D3.1 was purified on a Sephadex LH-20 $\left(\mathrm{CHCl}_{3}-\mathrm{MeOH}, 1: 1\right)$ to yield compounds $29(19.0 \mathrm{mg})$ and $37(2.1 \mathrm{mg})$. Fr.D3.2 was subjected to a silica gel column $\left(\mathrm{CHCl}_{3}-\mathrm{MeOH}, 95: 5\right)$ and followed by being purified with HPLC (MeOH-H $\left.{ }_{2} \mathrm{O}, 42: 58\right)$ to yield compounds 15 (11.1 mg), 27 (6.3 mg), 28 (84.2 $\mathrm{mg})$ and 36 (6.8 $\mathrm{mg})$. Fr.D3.3 was separated on a silica gel column $\left(\mathrm{CHCl}_{3}-\mathrm{MeOH}, 95: 5\right)$, followed by a Sephadex $\mathrm{LH}-20\left(\mathrm{CHCl}_{3}-\mathrm{MeOH}, 1: 1\right)$ and HPLC (MeOH-H $\left.{ }_{2} \mathrm{O}, 46: 54\right)$ purification to get compounds 14 (8.2 mg), 16 (11.0 mg), and 26 (46 mg). 
Figure S1. The structures of the known compounds isolated from $C$. damayeshu.

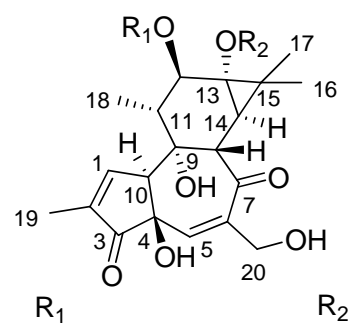

$\begin{array}{lll}11 & \text { tiglyl } & \text { 2-(methyl)butyl } \\ 12 & \text { tiglyl } & \text { isobutyryl } \\ 13 & \text { tiglyl } & \text { acetyl } \\ 14 & \text { H } & \text { 2-(methyl)butyl } \\ 15 & \text { tiglyl } & \text { H } \\ 16 & \text { 2-(methyl)butyl } & \text { H }\end{array}$

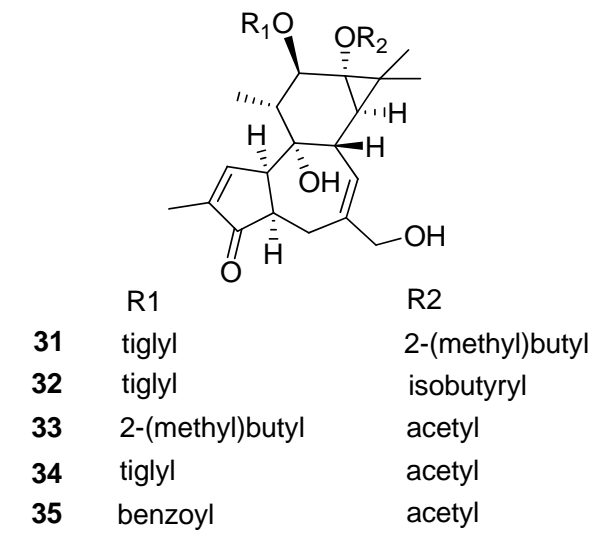

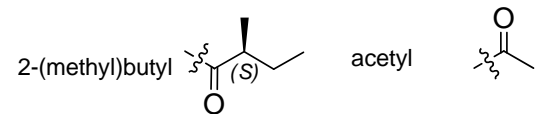

isobutyryl<smiles>CC(C)C(=O)C(C)(C)C</smiles>

octanoyl

benzoyl<smiles>CC(=O)c1ccccc1</smiles>

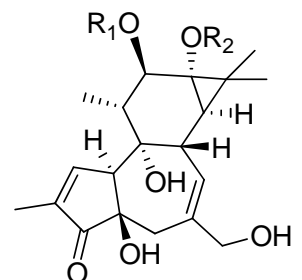

$$
\mathrm{R}_{1}
$$

tiglyl

tiglyl

2-(methyl)butyl

2-(methyl)butyl

tiglyl

2-(methyl)butyl

2-(methyl)butyl

tiglyl

tiglyl

$\mathrm{H}$

$\mathrm{H}$

tiglyl

2-(methyl)butyl

benzoyl

$\mathrm{R}_{2}$

isobutyryl

2-(methyl)butyl

decanoyl

acetyl

acetyl

2-(methyl)butyl

isobutyryl

decanoyl

octanoyl

2-(methyl)butyl

isobutyryl

$\mathrm{H}$

$\mathrm{H}$

2-(methyl)butyl

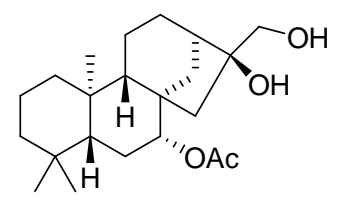

36

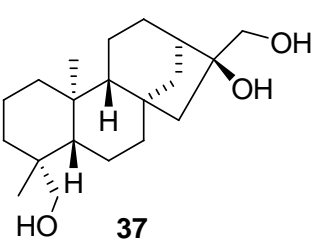

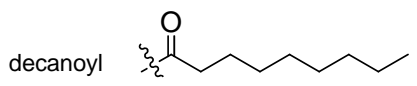

tiglyl<smiles>CC=C(C)C(C)=O</smiles> 
Figure S2. The structures of the new compounds isolated from $C$. damayeshu.

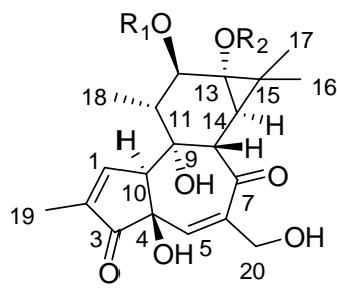

$\begin{array}{lll} & \mathrm{R}_{1} & \mathrm{R}_{2} \\ 1 & 2 \text {-(methyl)butyl } & \text { 2-(methyl)butyl } \\ \mathbf{2} & \text { 2-(methyl)butyl } & \text { isobutyryl } \\ \mathbf{3} & \text { 2-(methyl)butyl } & \text { acetyl } \\ \mathbf{4} & \text { tiglyl } & \text { octanoyl } \\ \mathbf{5} & \text { tiglyl } & \text { decanoyl } \\ \mathbf{6} & \text { 2-(methyl)butyl } & \text { decanoyl } \\ \mathbf{7} & \text { 2-(methyl)butyl } & \text { octanoyl } \\ \mathbf{8} & \text { 2-(methyl)butyl } & \text { (4Z)-decanoyl } \\ \mathbf{9} & \text { 2-(methyl)butyl } & \text { (4Z,7Z)-decanoyl-diene } \\ 10 & \text { tiglyl } & \text { (4Z)-decanoyl }\end{array}$

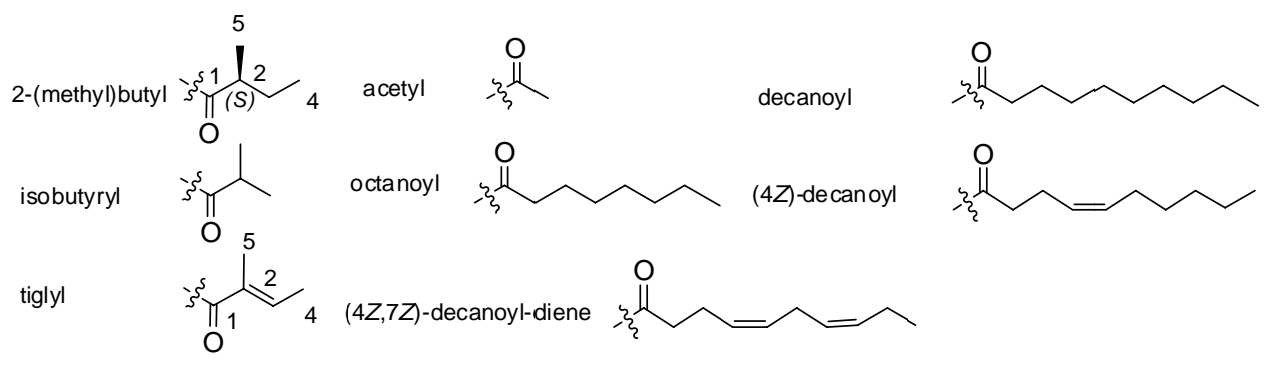

Figure S3. The larvicidal activities against $P$. xylostella of the tested compounds.

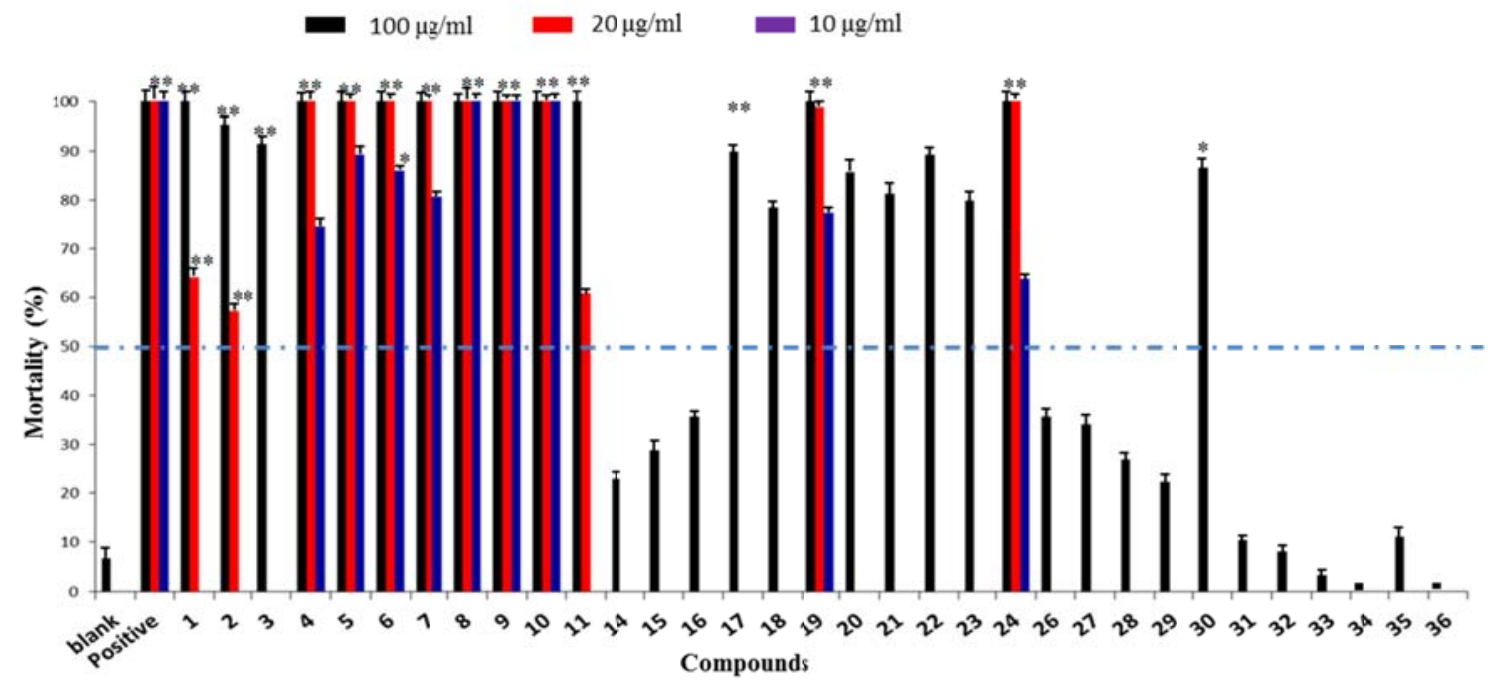

Note: Larvicidal activities against P. xylostella for compounds 1-11, 14-24, 26-36 at 100, 20 and 10 $\mu \mathrm{g} / \mathrm{ml}$ concentrations in EtOH. Only active compounds with mortality percentage of $100 \%$ at concentration of $10 \mu \mathrm{g} / \mathrm{ml}$ were selected to establish the $\mathrm{LC}_{50}$ values. Each value was expressed as mean \pm SD. $\left({ }^{*}\right) p<0.05,(* *) p<0.01$. The solvent ethanol and flubendiamide were employed as a blank and positive control, respectively. 


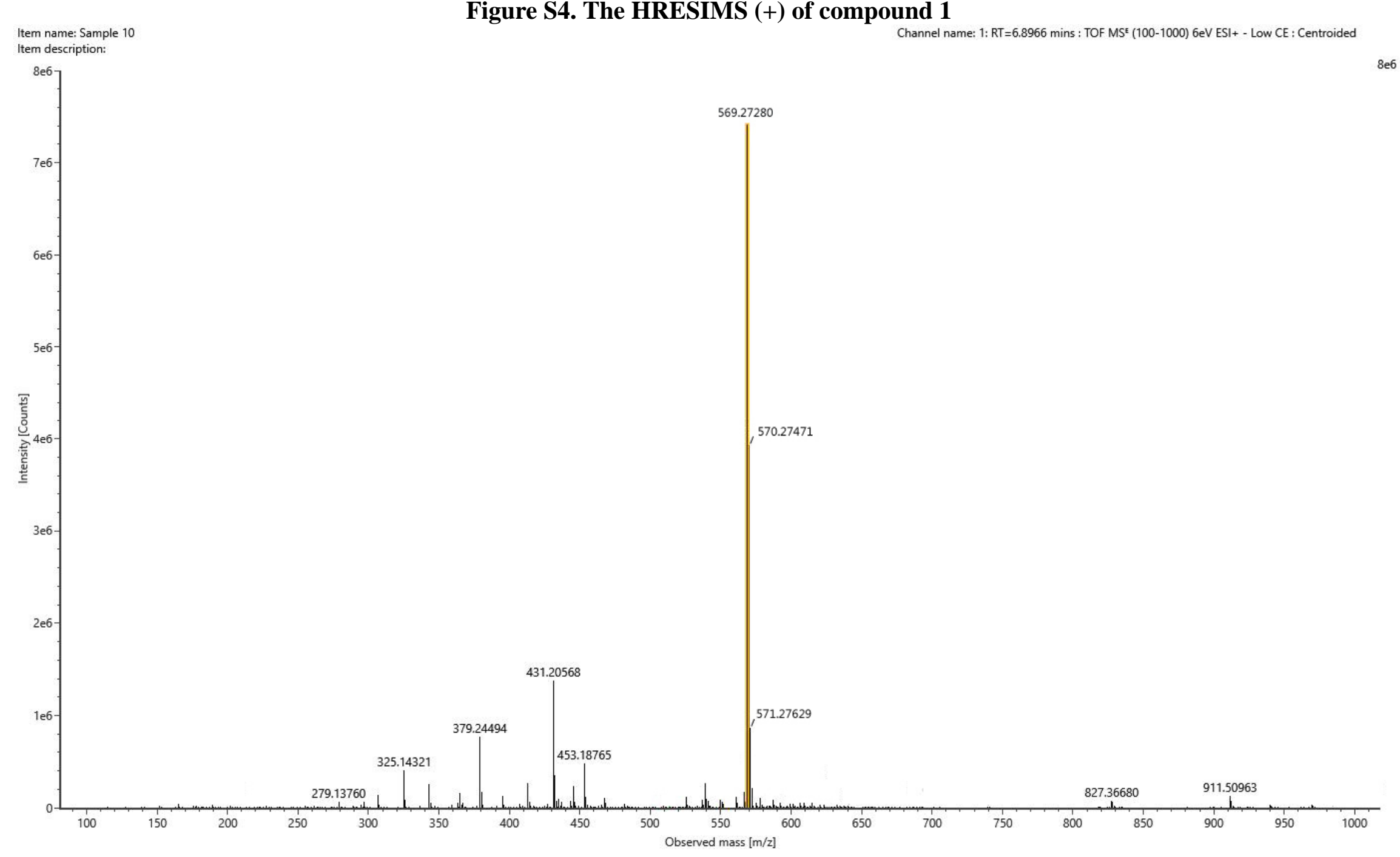




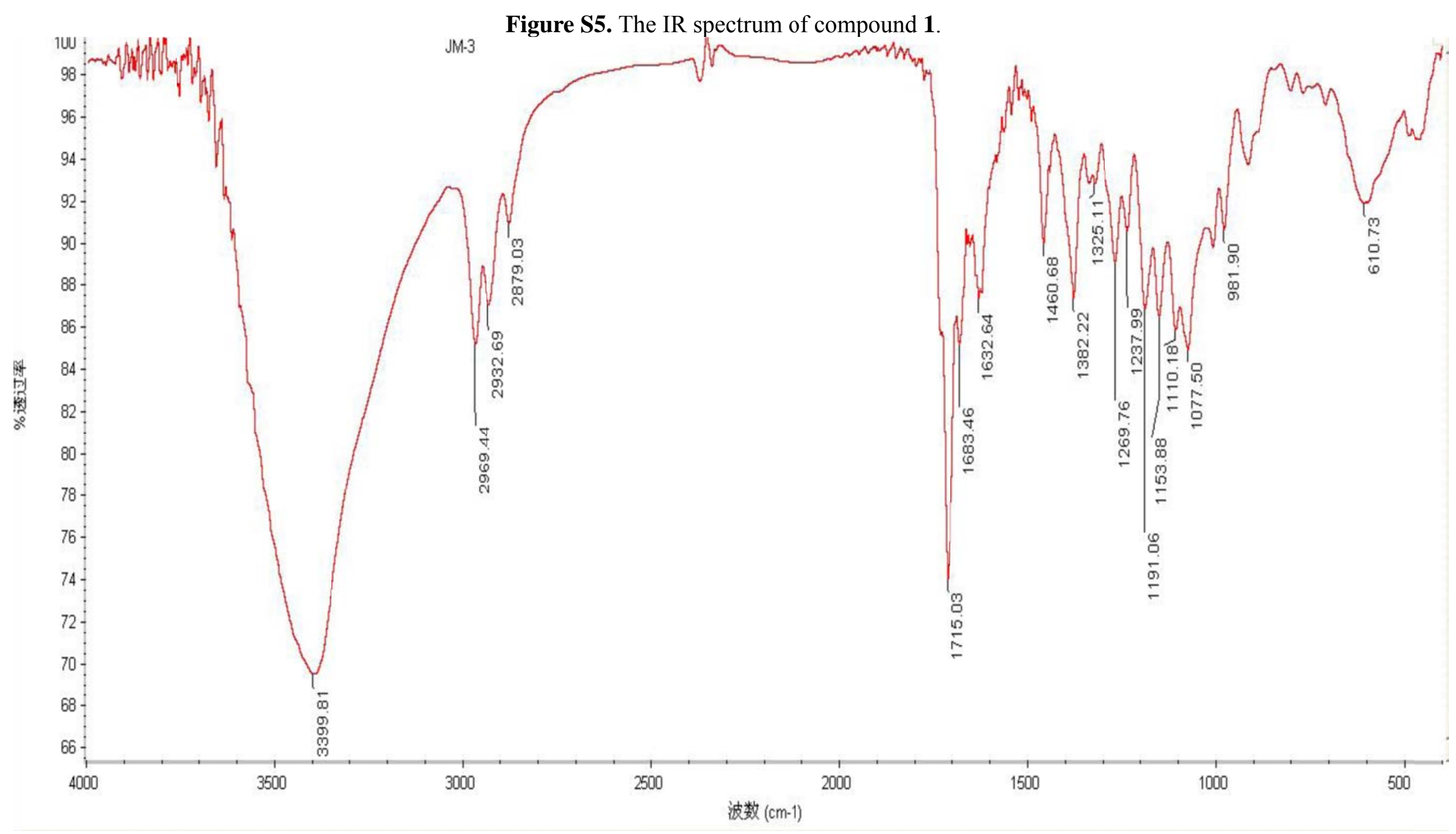




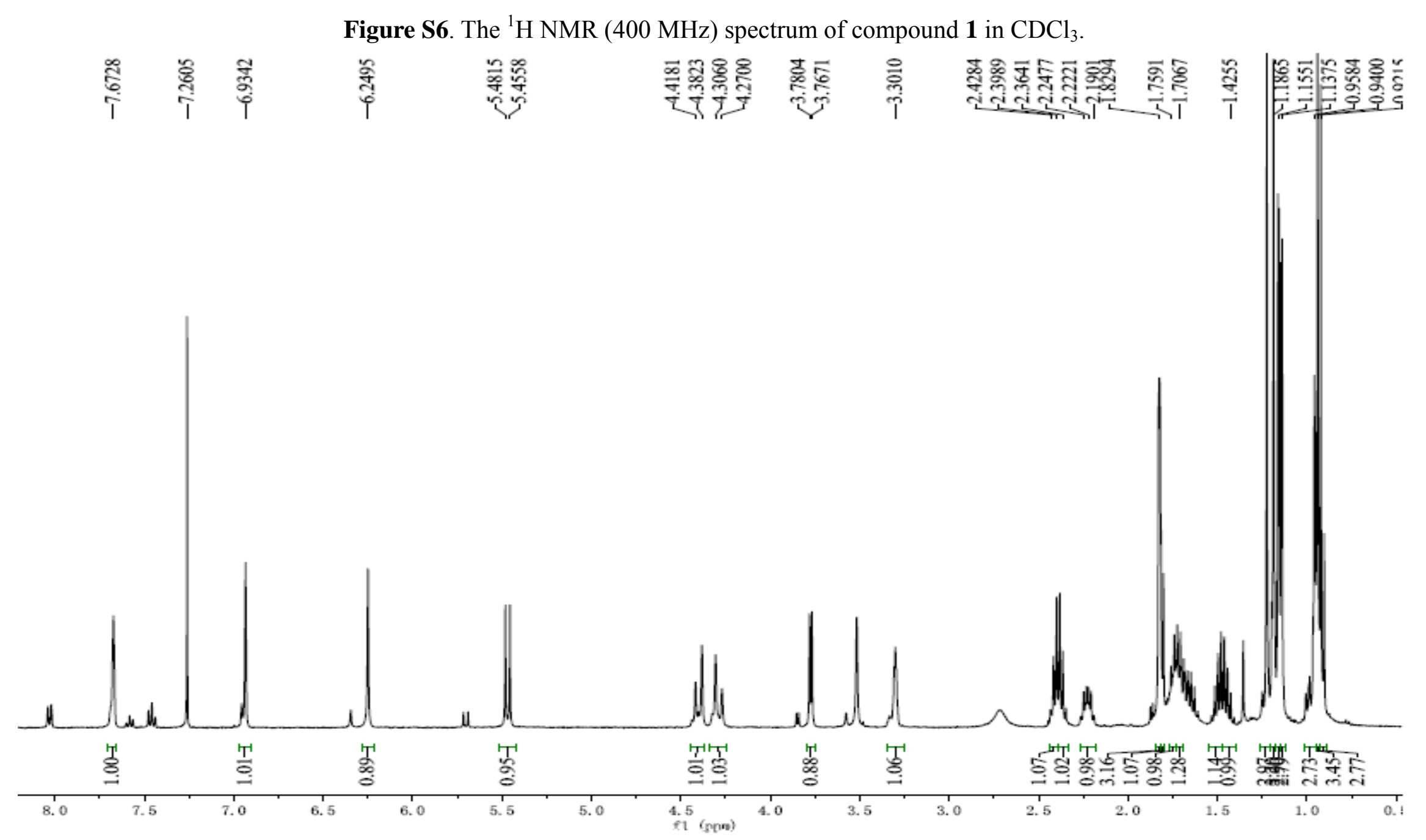


Figure S7. The enlarged ${ }^{1} \mathrm{H}$ NMR (400 MHz) spectrum of compound 1 in $\mathrm{CDCl}_{3}$.

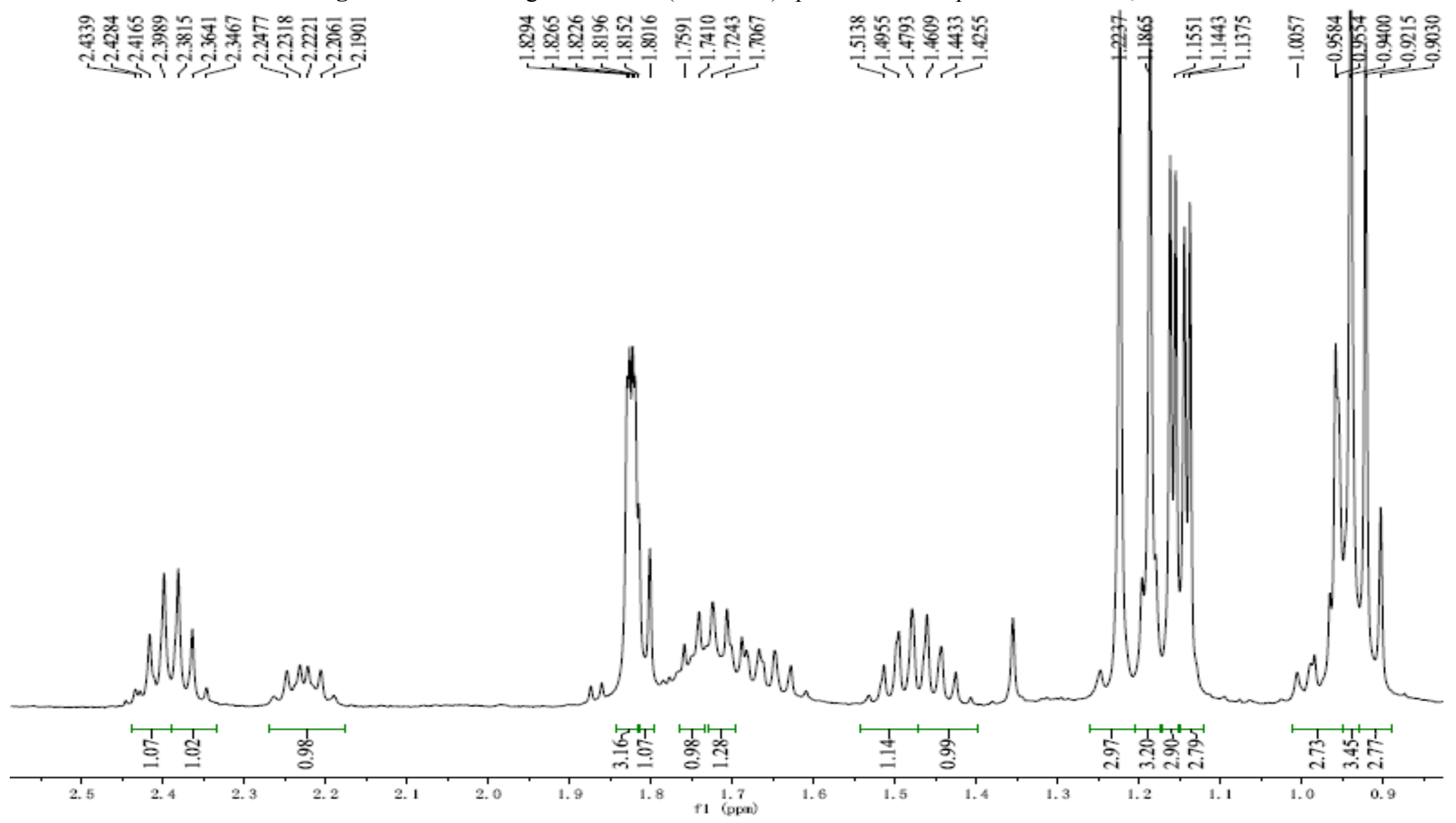


Figure S8. The ${ }^{13} \mathrm{C}$ NMR (100 MHz) spectrum of compound 1 in $\mathrm{CDCl}_{3}$.
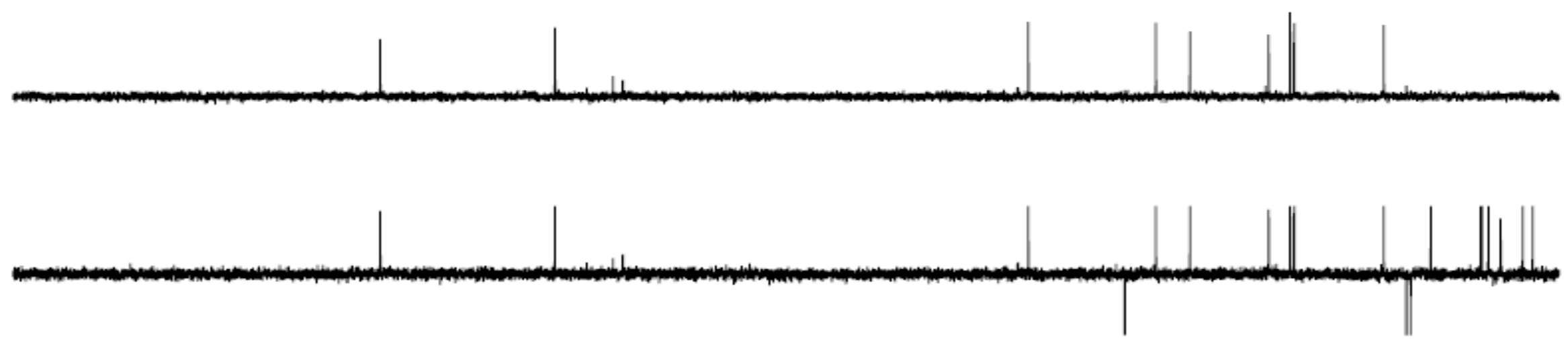

\begin{tabular}{|c|c|c|c|}
\hline 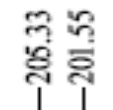 & $\frac{2}{\frac{8}{2}} \frac{1}{1}$ & $\frac{5}{\frac{8}{1}}$ & $\begin{array}{l}9 \\
\text { of } \\
\text { ơ } \\
\end{array}$ \\
\hline
\end{tabular}
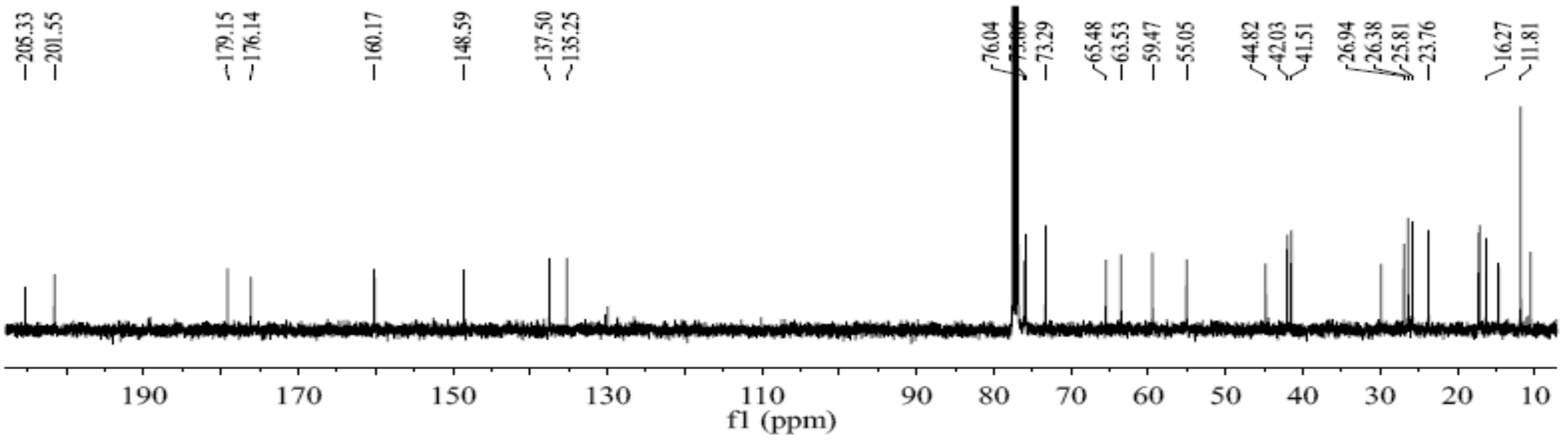
Figure S9. The enlarged ${ }^{13} \mathrm{C}$ NMR $(100 \mathrm{MHz})$ spectrum of compound $\mathbf{1}$ in $\mathrm{CDCl}_{3}$.

$\mathrm{JM}-3-\mathrm{C}$
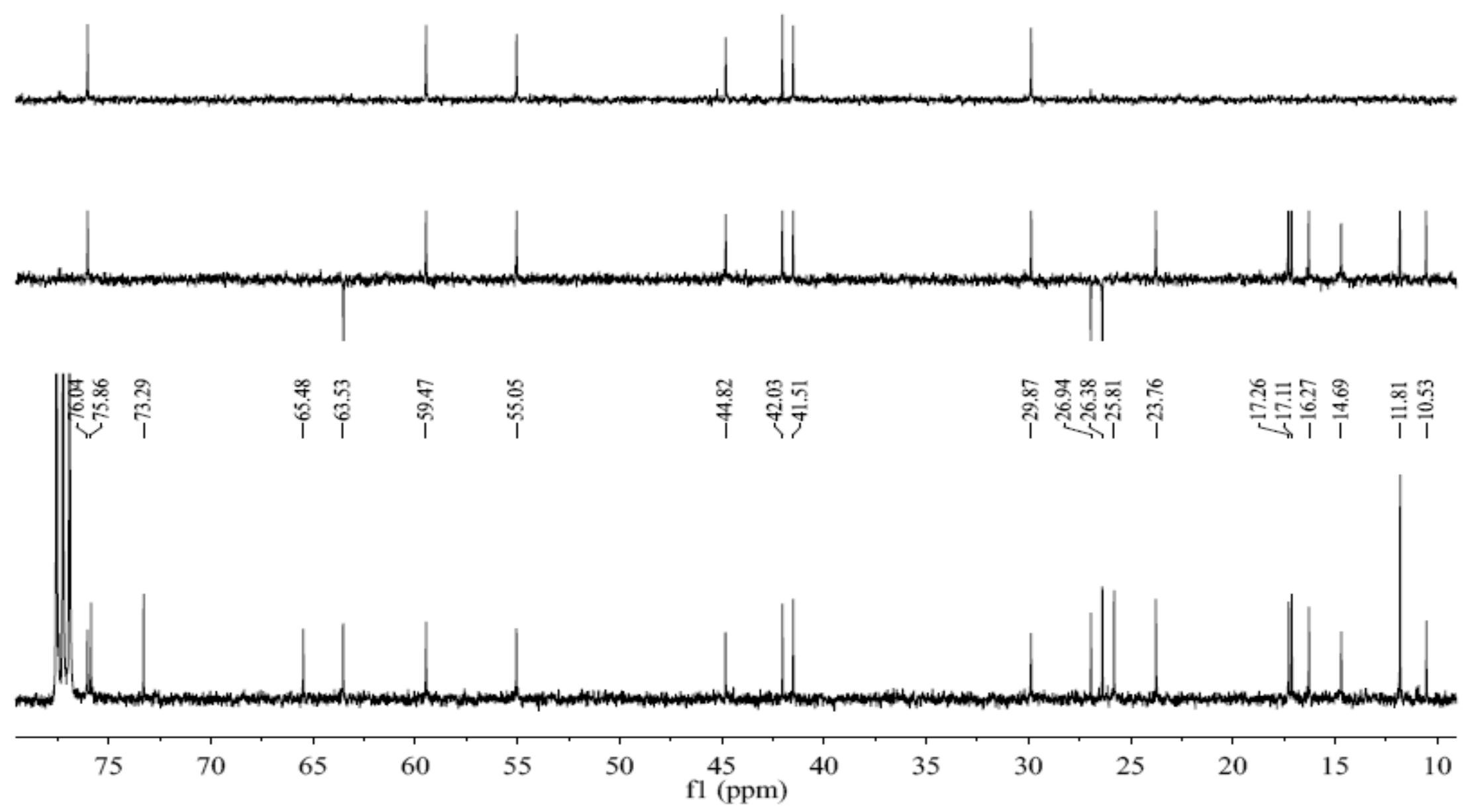
Figure S10. The HSQC spectrum of compound 1 in $\mathrm{CDCl}_{3}$.

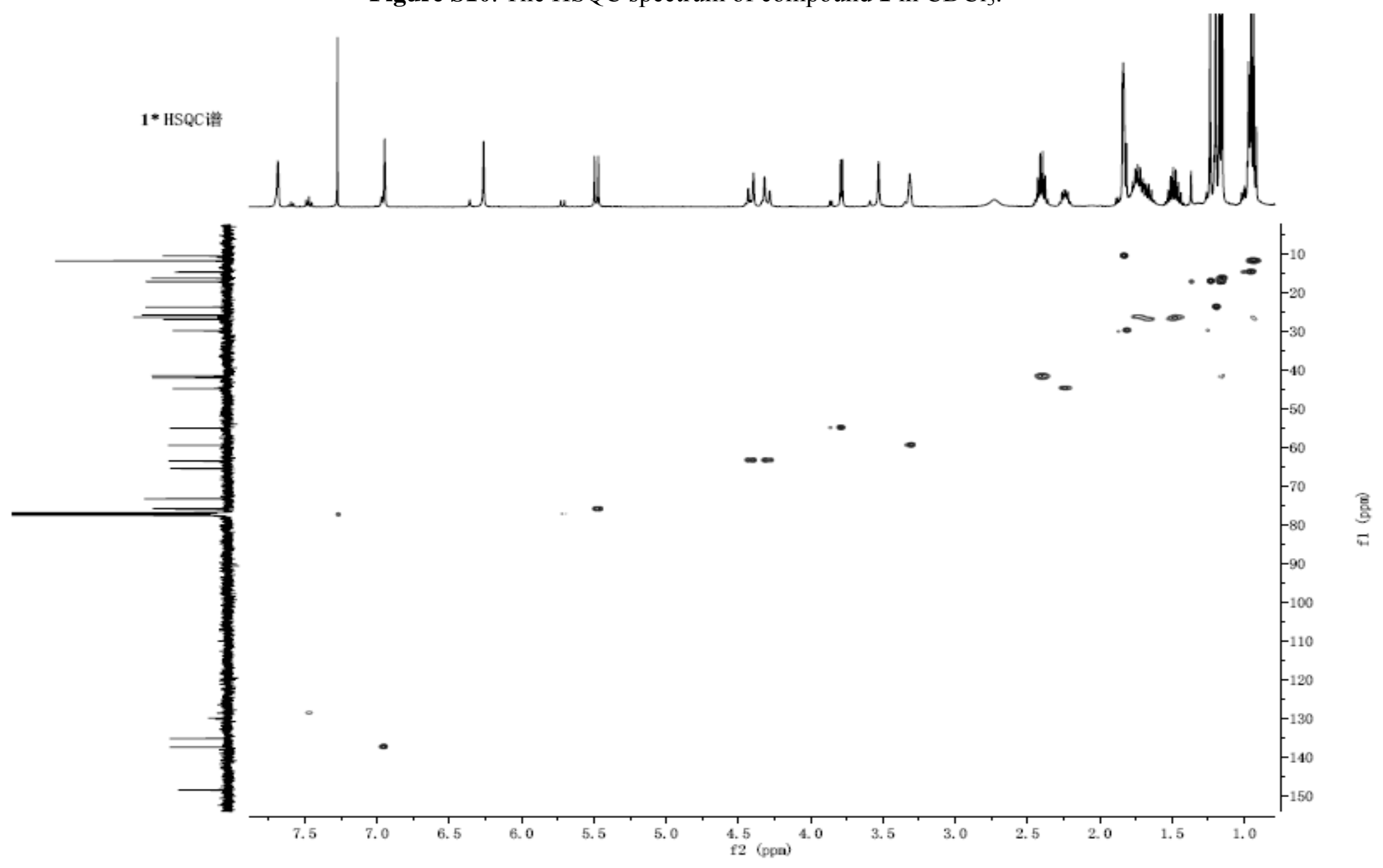


Figure S11. The HMBC spectrum of compound 1 in $\mathrm{CDCl}_{3}$.

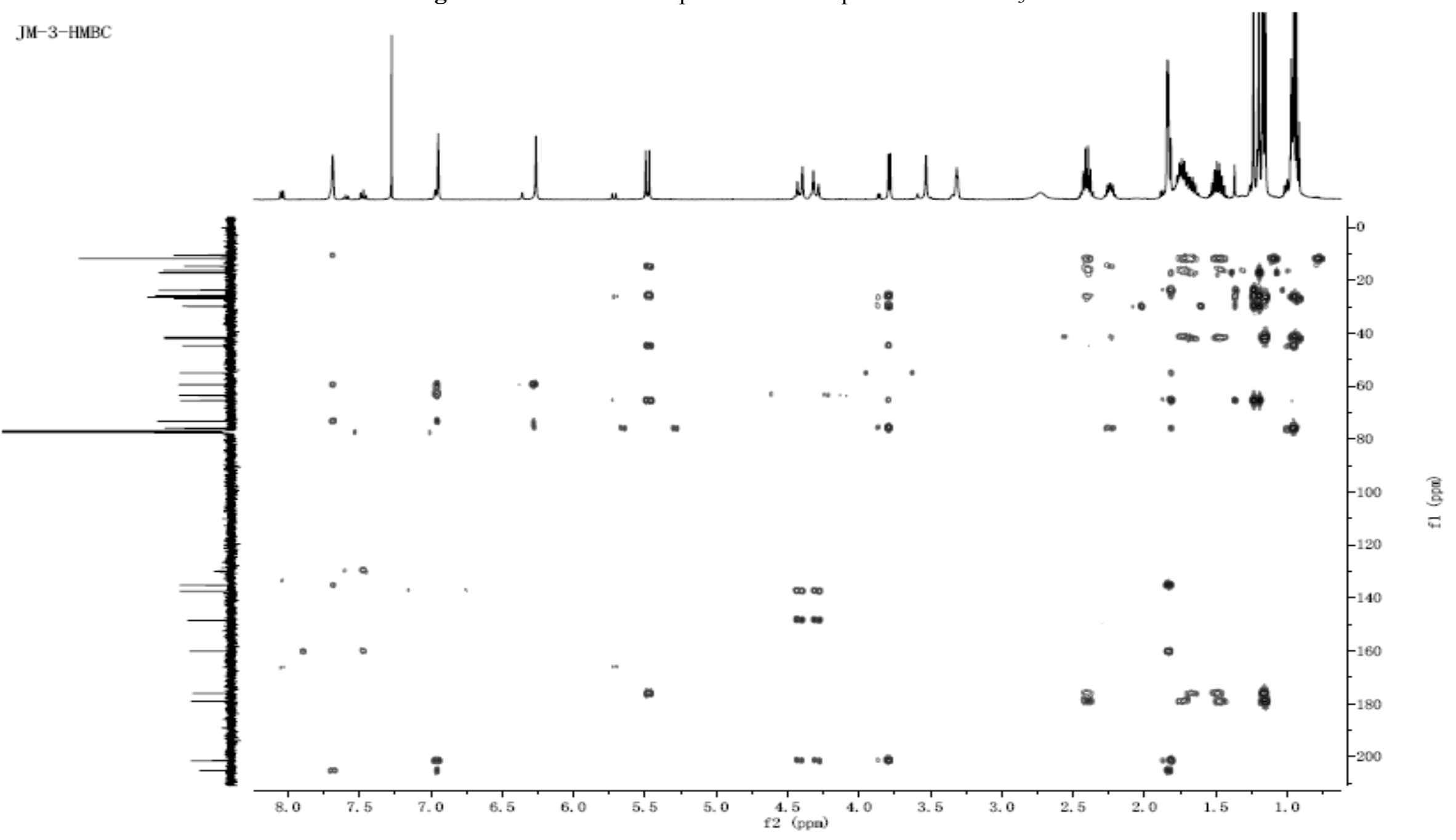


Figure S12. The ${ }^{1} \mathrm{H}-{ }^{1} \mathrm{H}$ COSY spectrum of compound 1 in $\mathrm{CDCl}_{3}$.

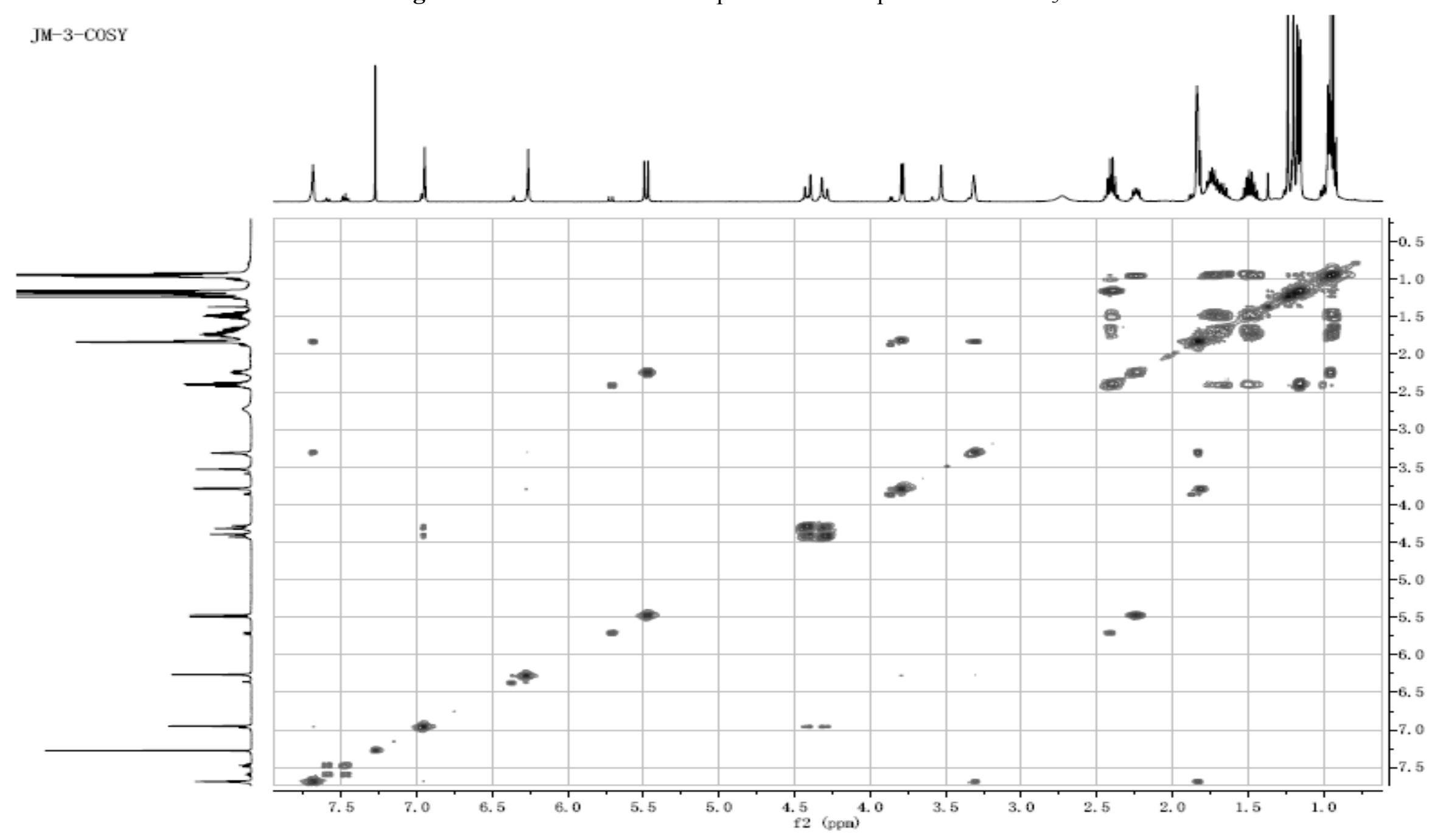


Figure S13. The ROESY spectrum of compound 1 in $\mathrm{CDCl}_{3}$.

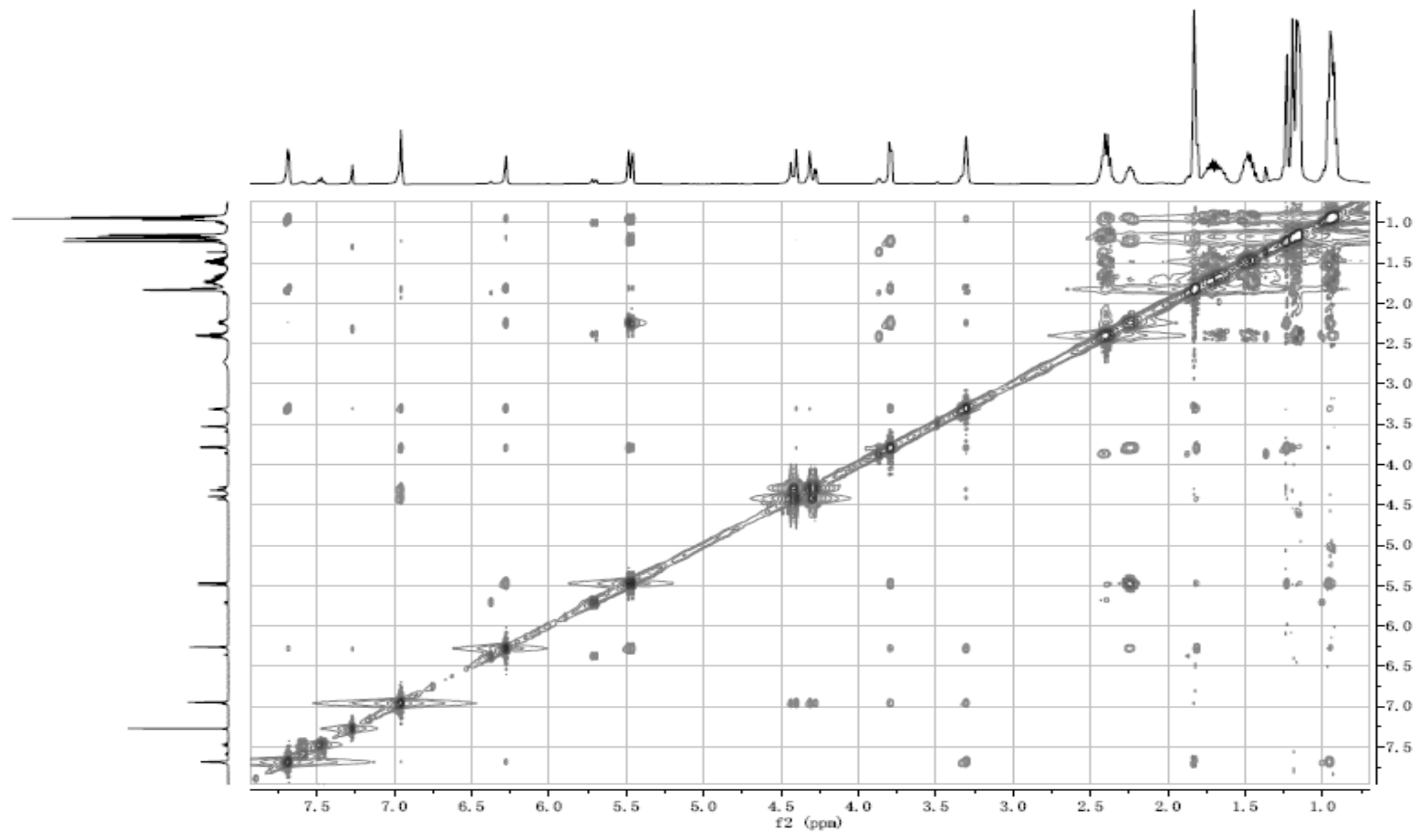




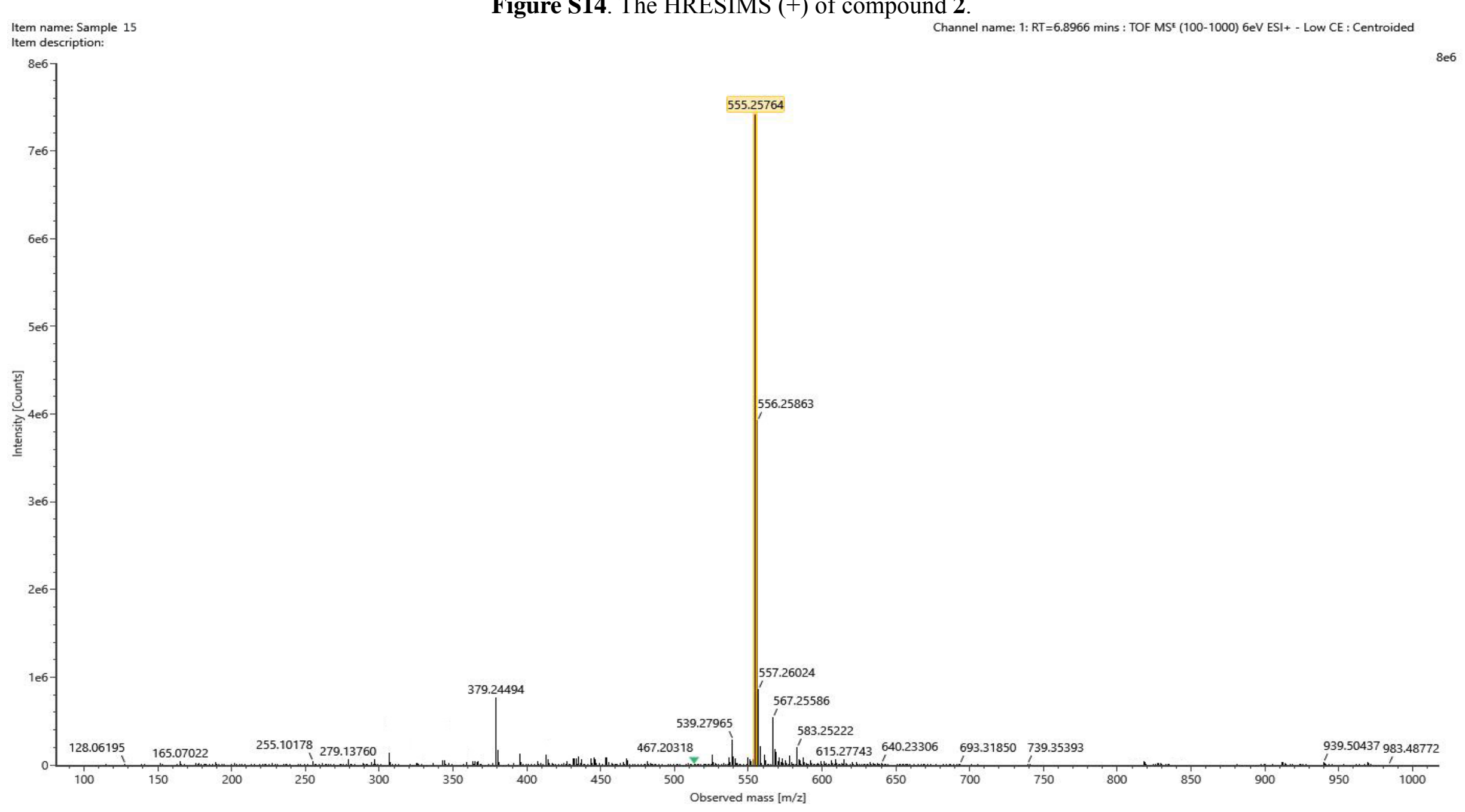


Figure S15. The IR spectrum of compound 2.

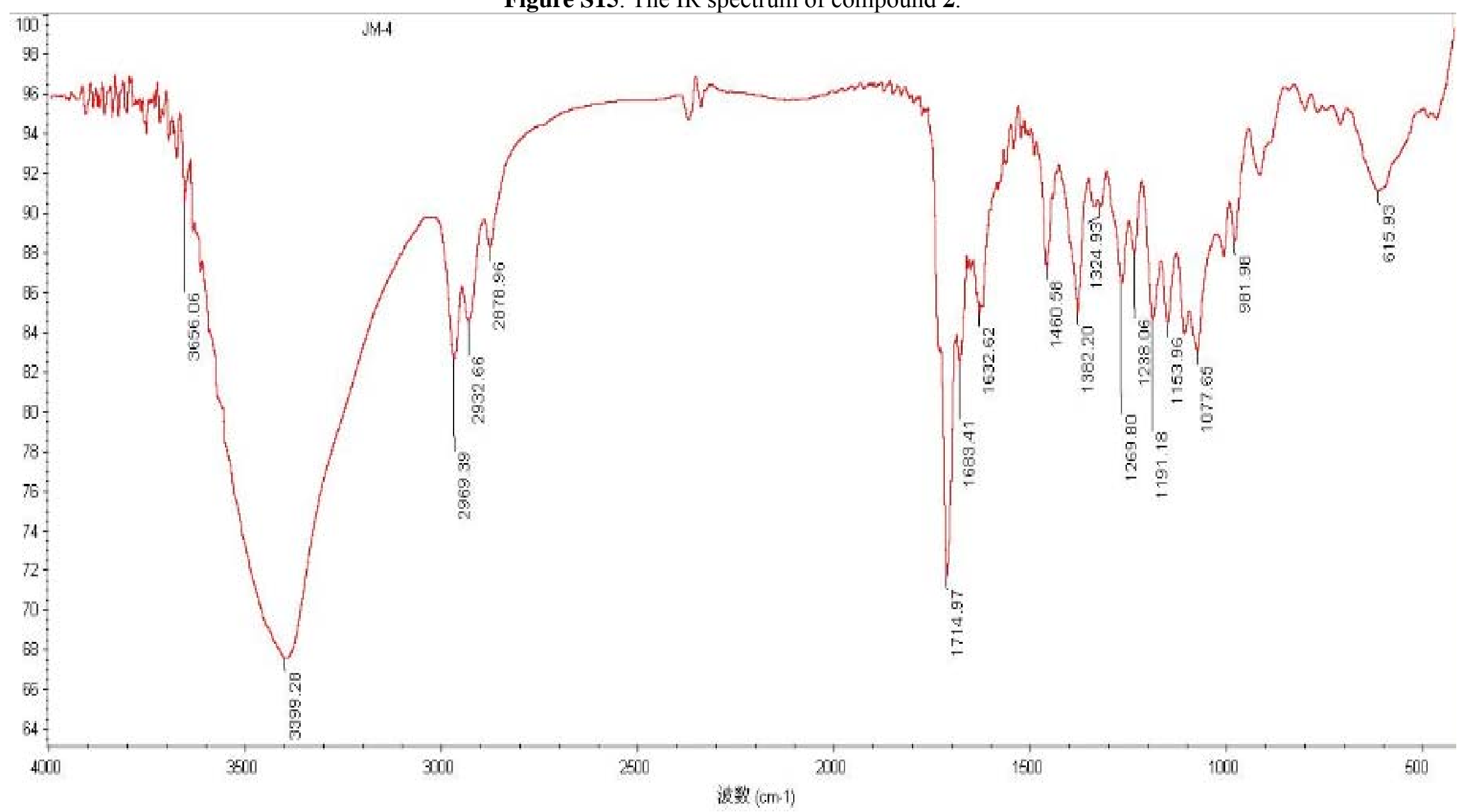


Figure S16. The ${ }^{1} \mathrm{H}$ NMR (400 MHz) spectrum of compound 2 in $\mathrm{CDCl}_{3}$.

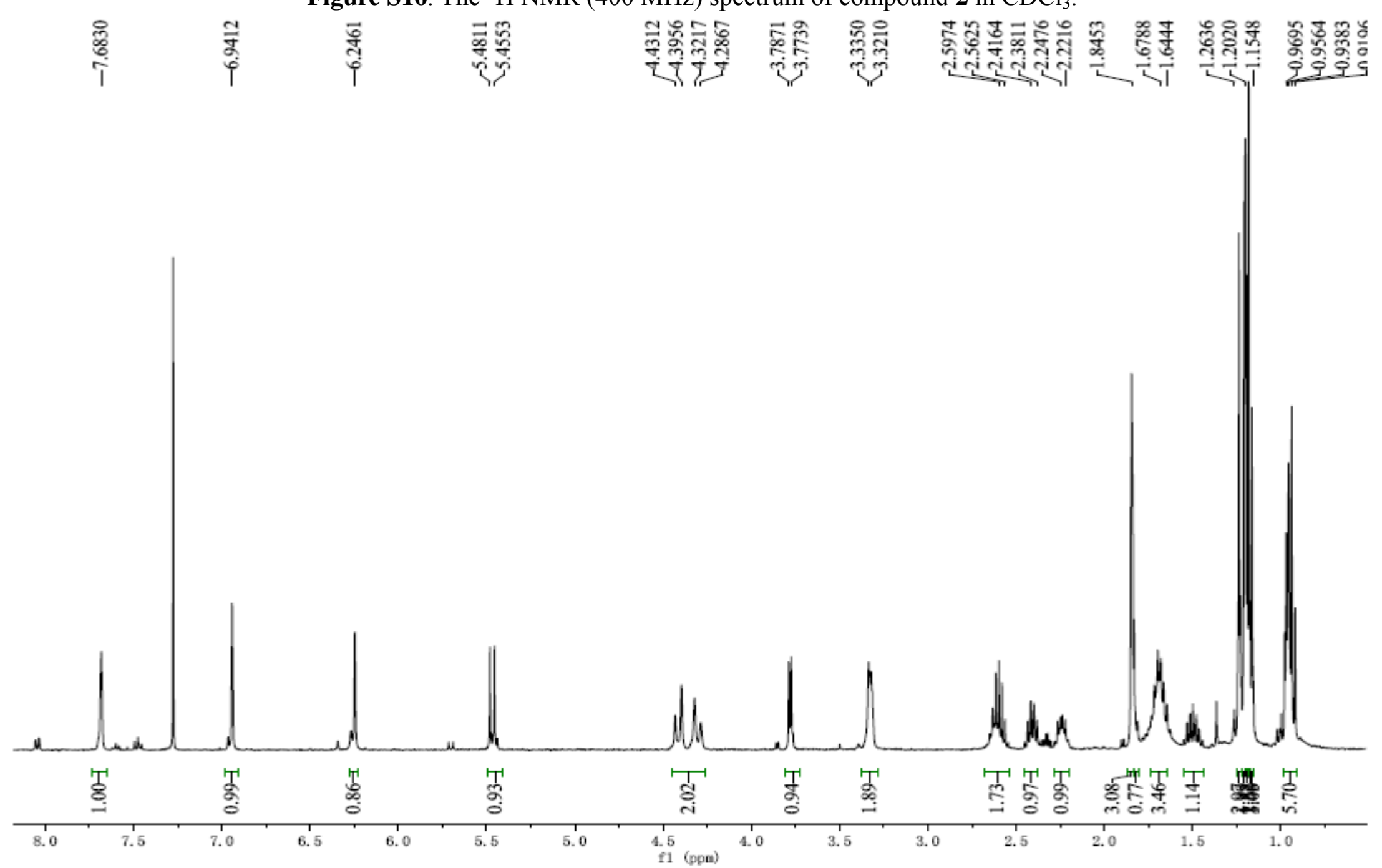


Figure S17. The enlarged ${ }^{1} \mathrm{H}$ NMR (400 MHz) spectrum of compound 2 in $\mathrm{CDCl}_{3}$.

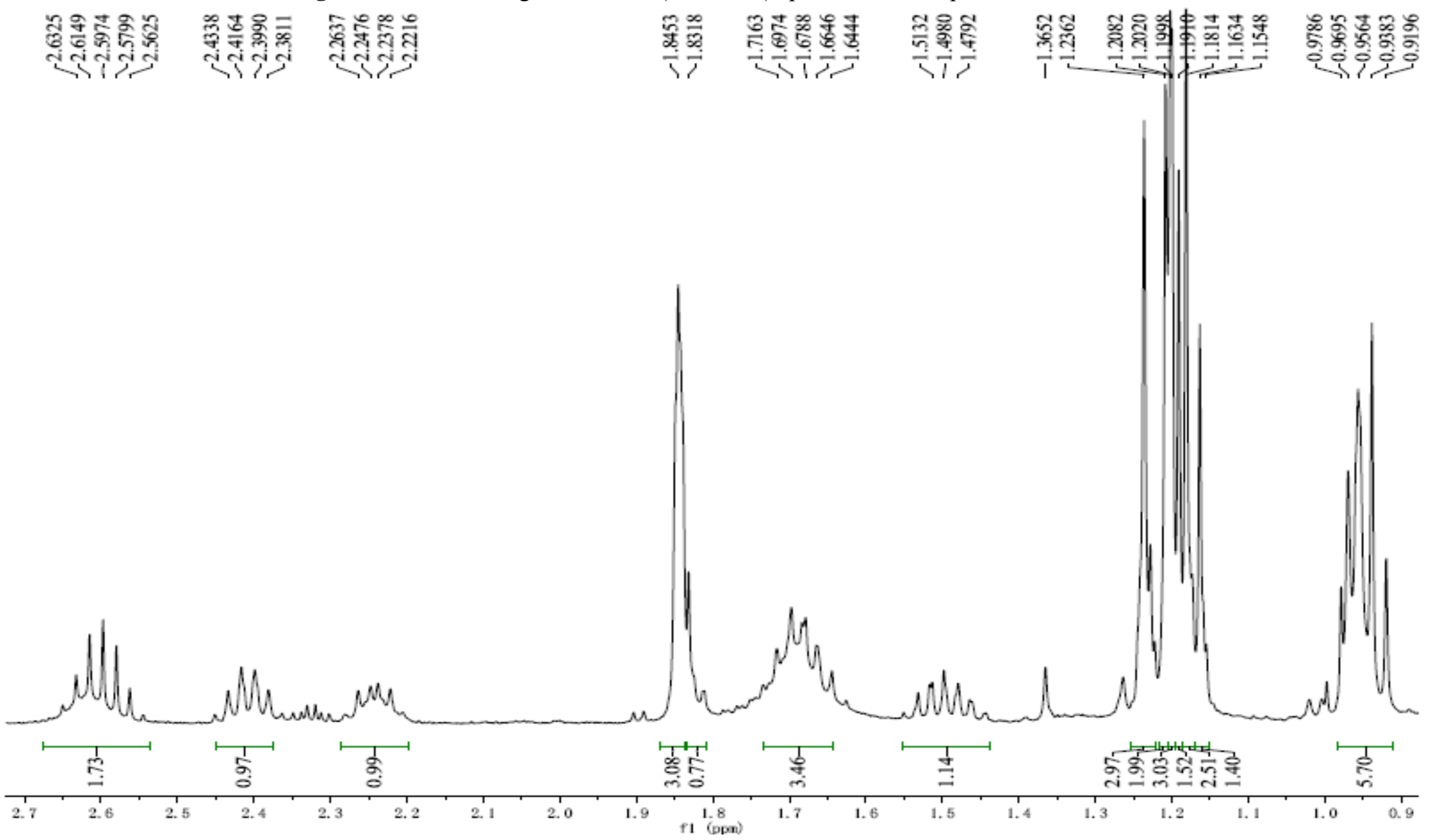


Figure S18. The ${ }^{13} \mathrm{C}$ NMR (100 MHz) spectrum of compound 2 in $\mathrm{CDCl}_{3}$.
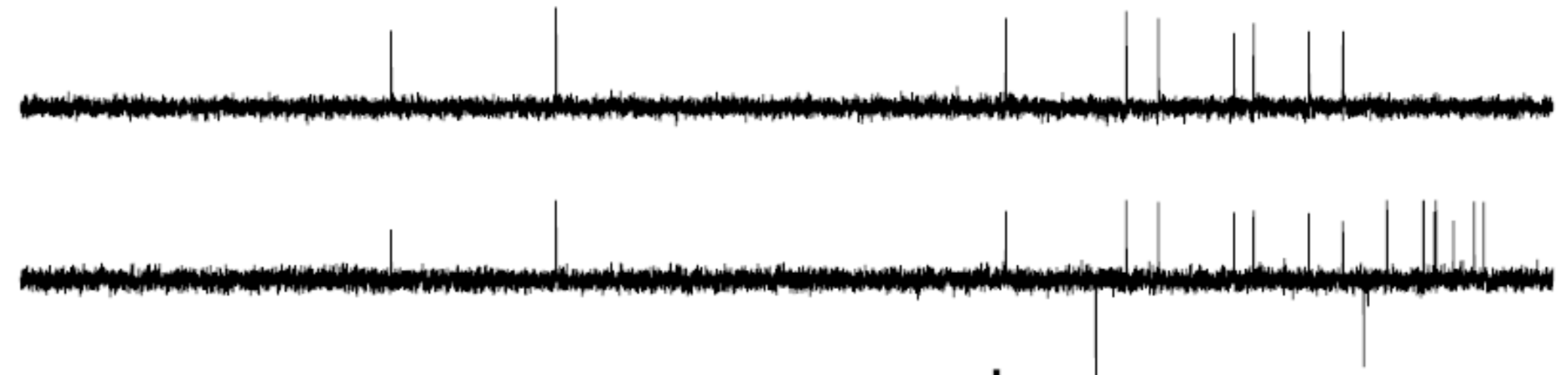

\begin{tabular}{|c|c|c|c|}
\hline 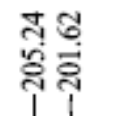 & 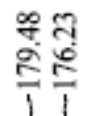 & $\begin{array}{l}8 \\
8 \\
8 \\
\end{array}$ & $\begin{array}{l}8 \\
\text { के } \\
\text { o } \\
\end{array}$ \\
\hline
\end{tabular}

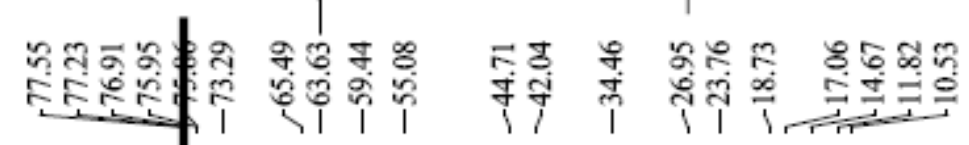
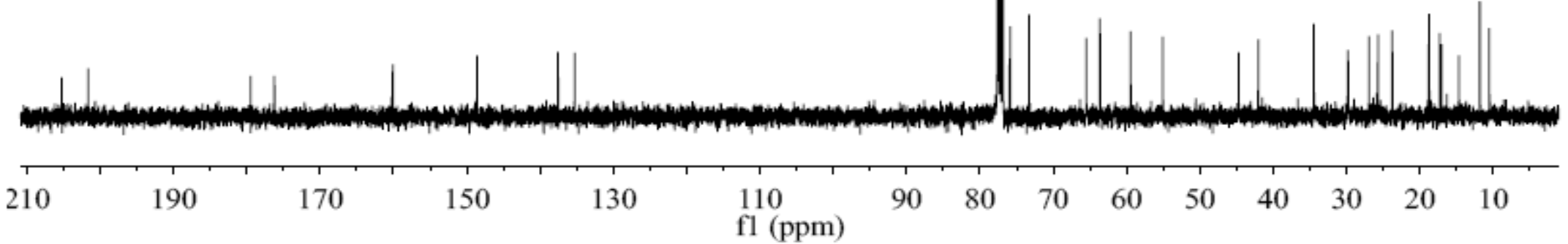

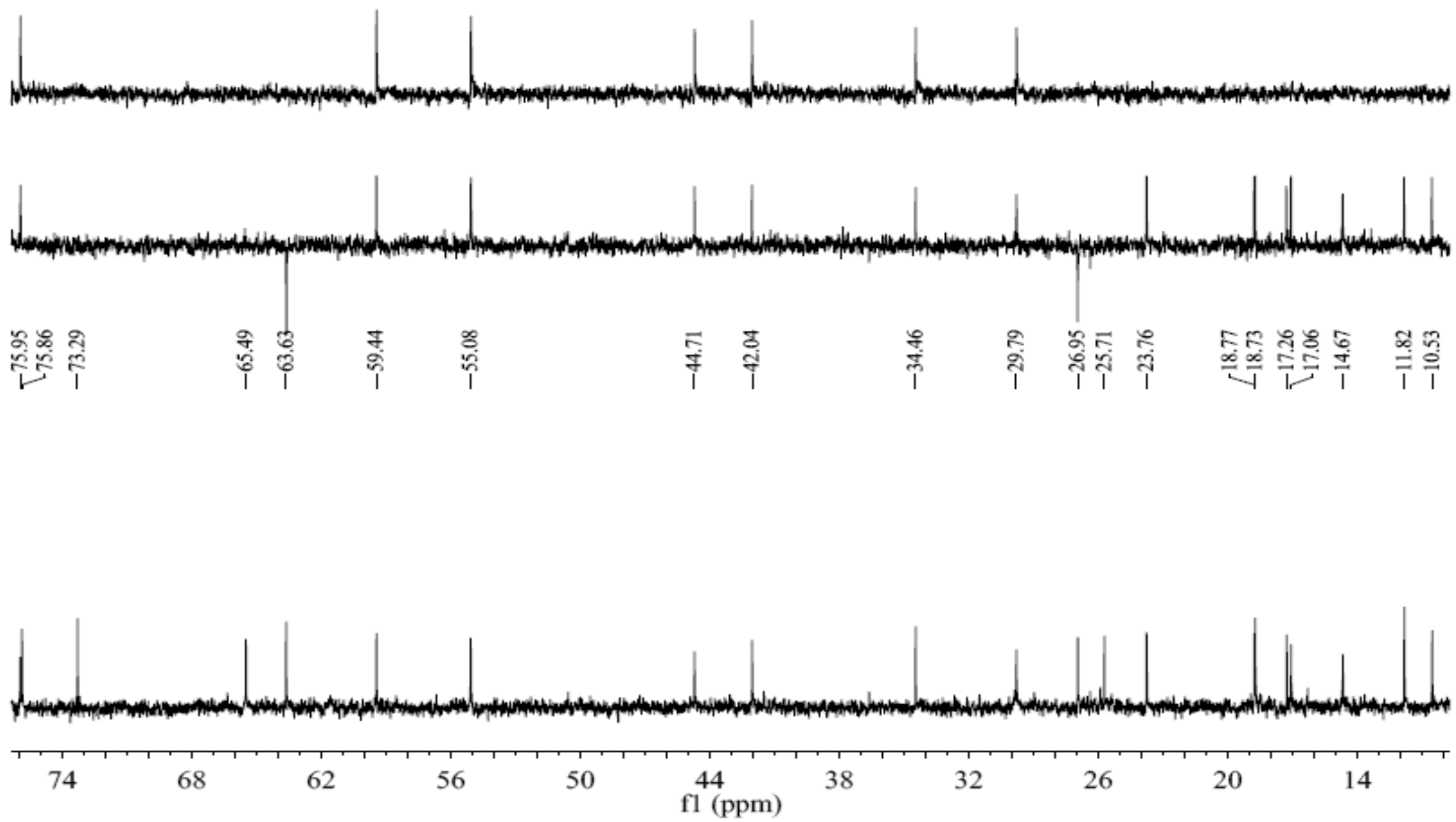
Figure S20. The HSQC spectrum of compound $\mathbf{2}$ in $\mathrm{CDCl}_{3}$.

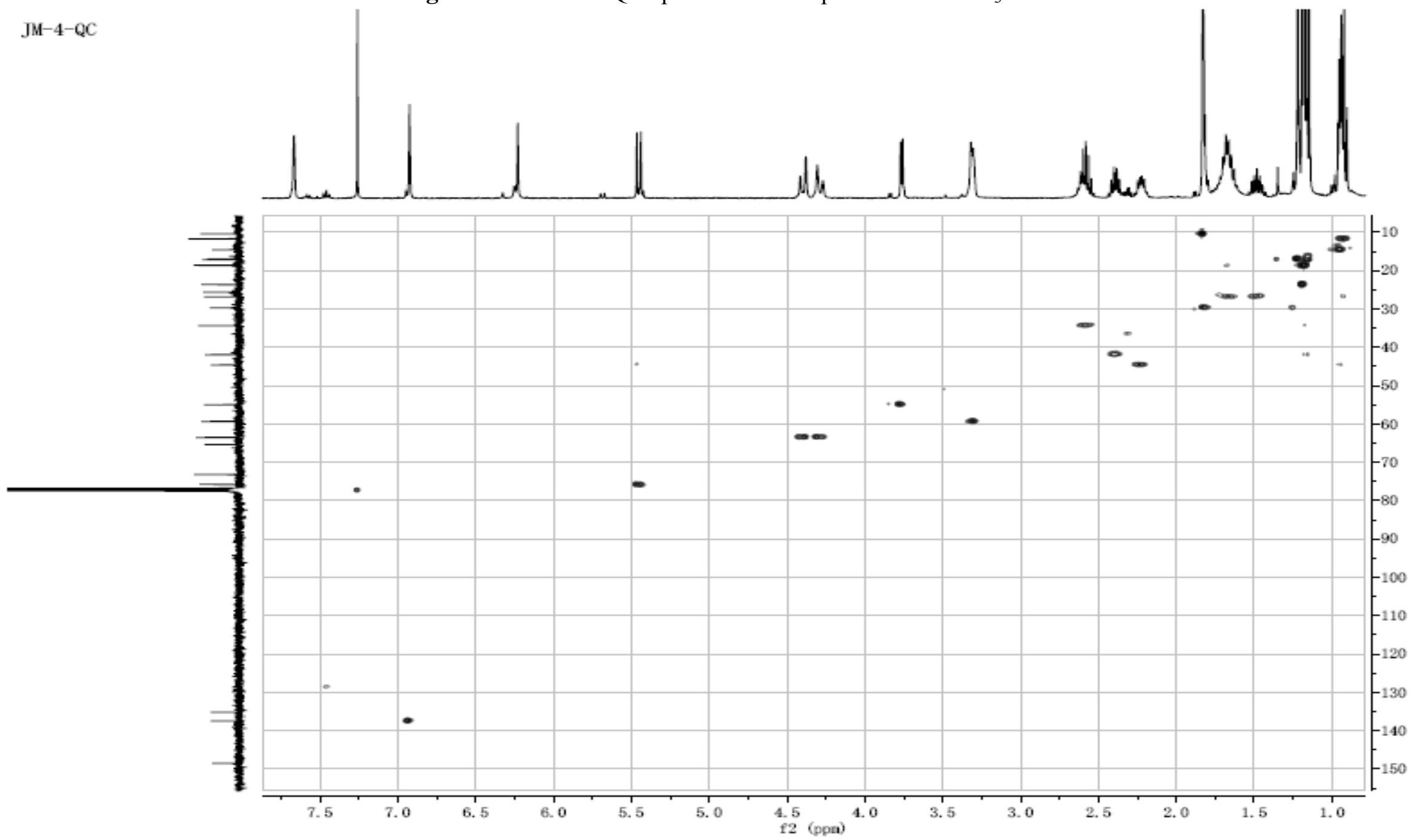


Figure S21. The HMBC spectrum of compound 2 in $\mathrm{CDCl}_{3}$.

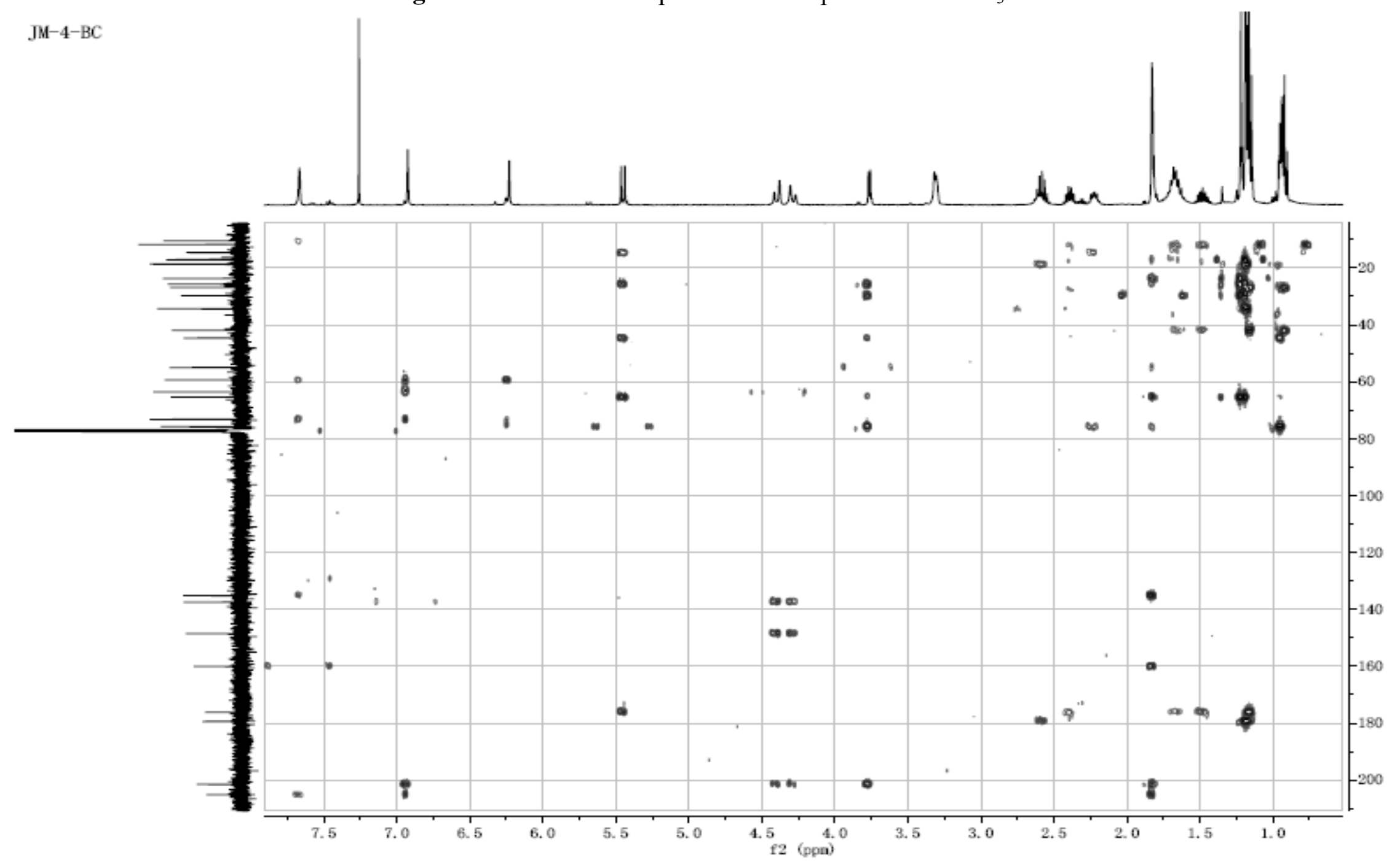


Figure S22. The ${ }^{1} \mathrm{H}-{ }^{1} \mathrm{H}$ COSY spectrum of compound 2 in $\mathrm{CDCl}_{3}$.

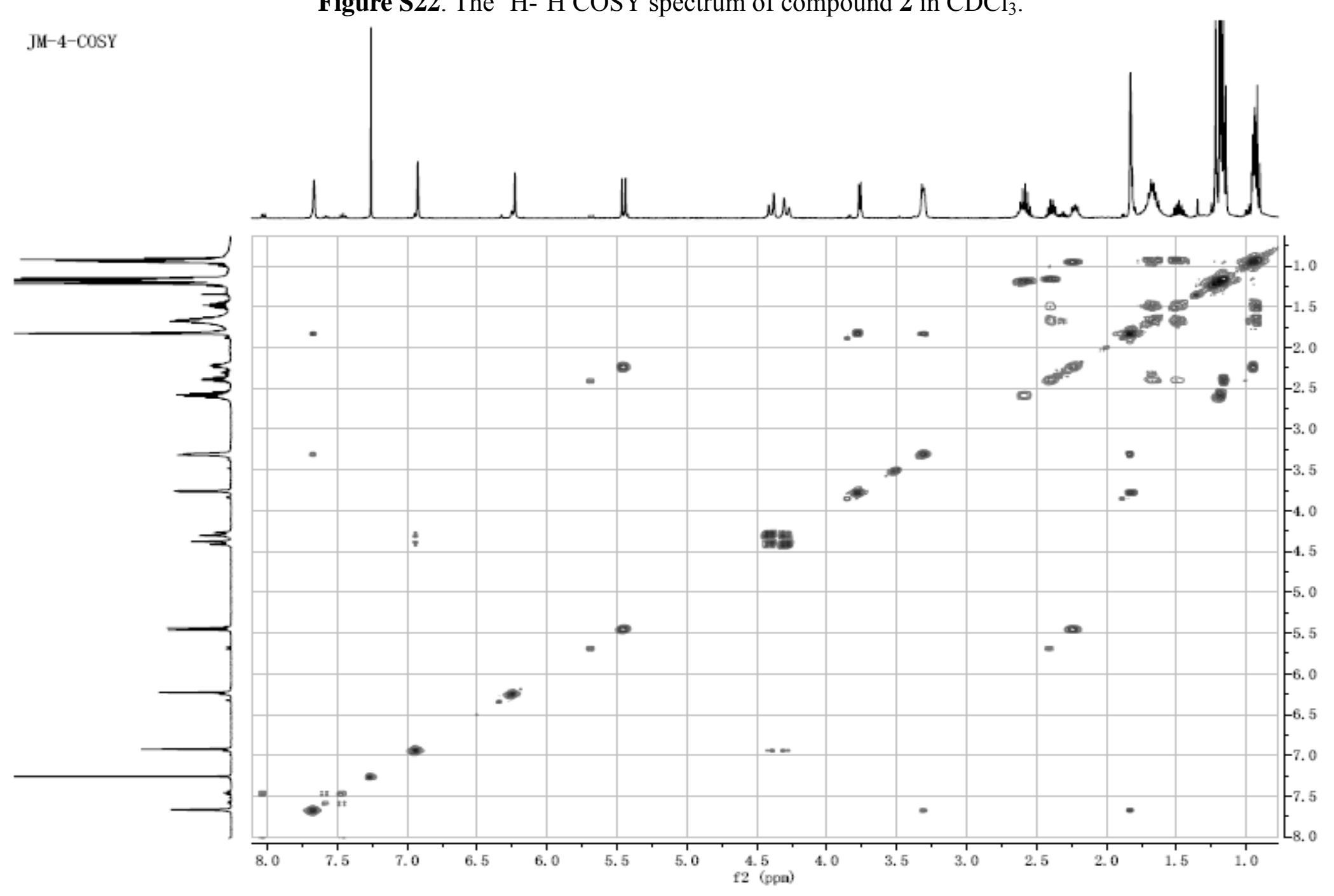


Figure S23. The ROESY spectrum of compound 2 in $\mathrm{CDCl}_{3}$.

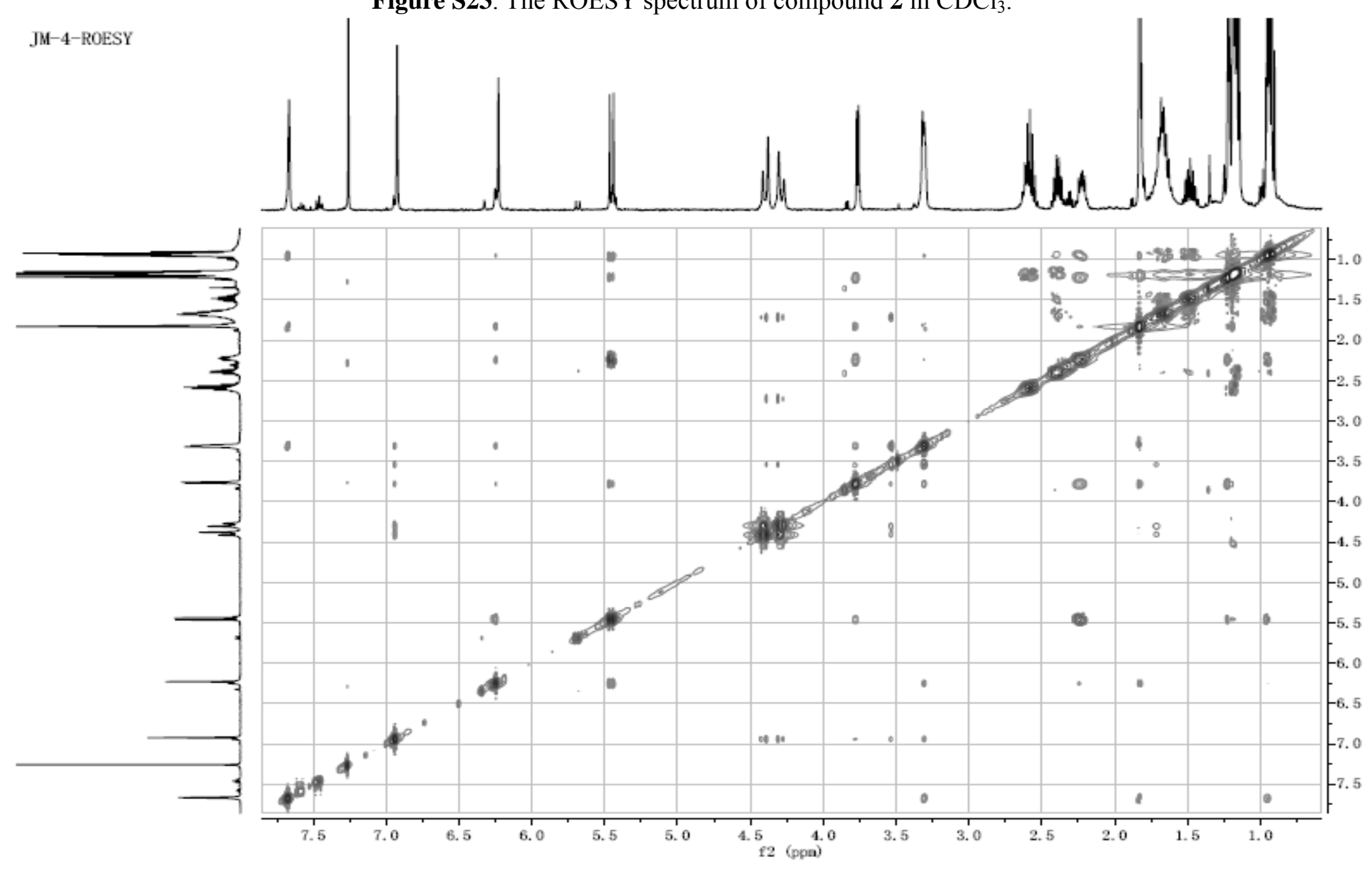


Figure S24. The HRESIMS (+) of compound 3.

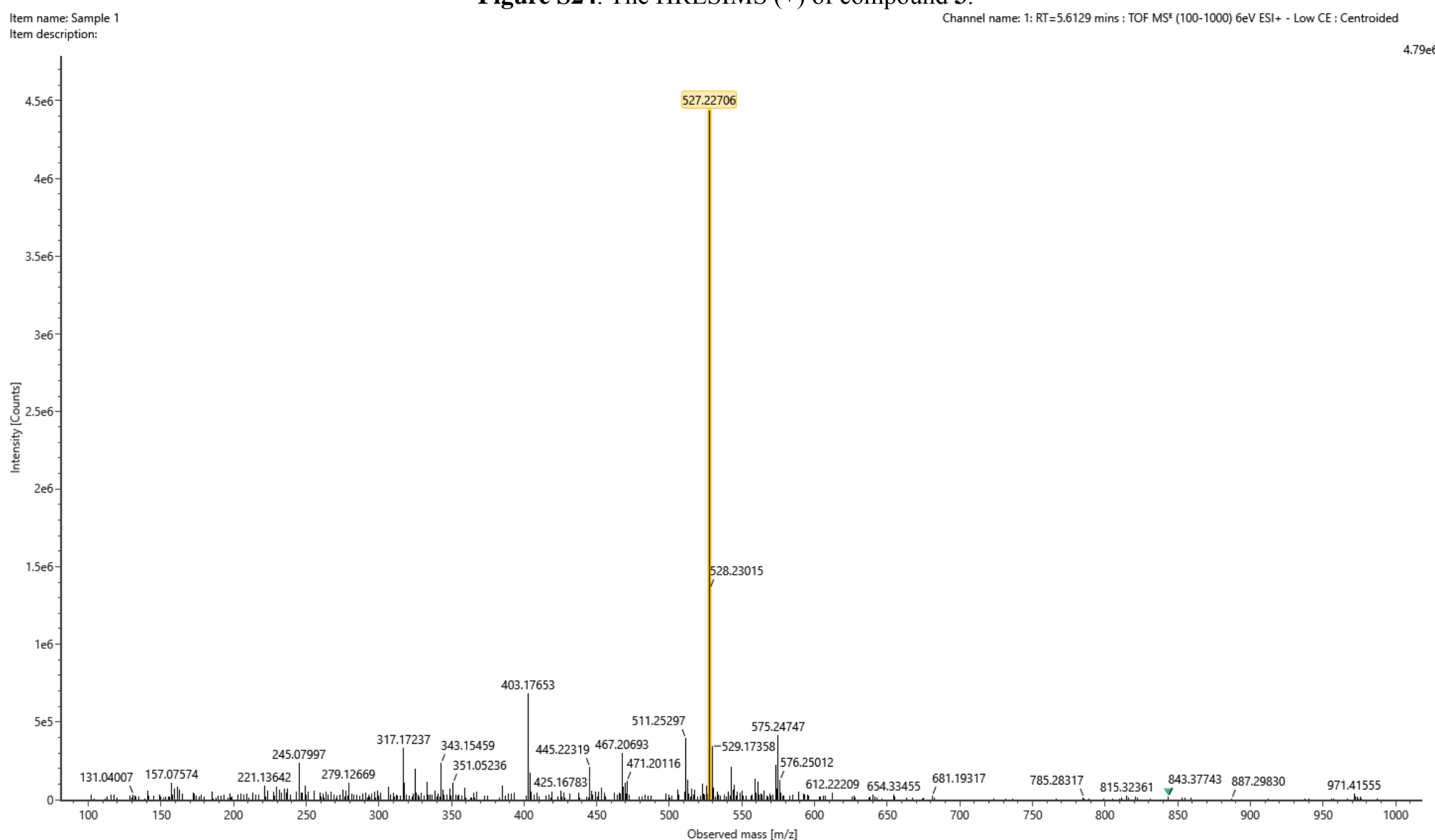


Figure S25. The IR spectrum of compound 3.

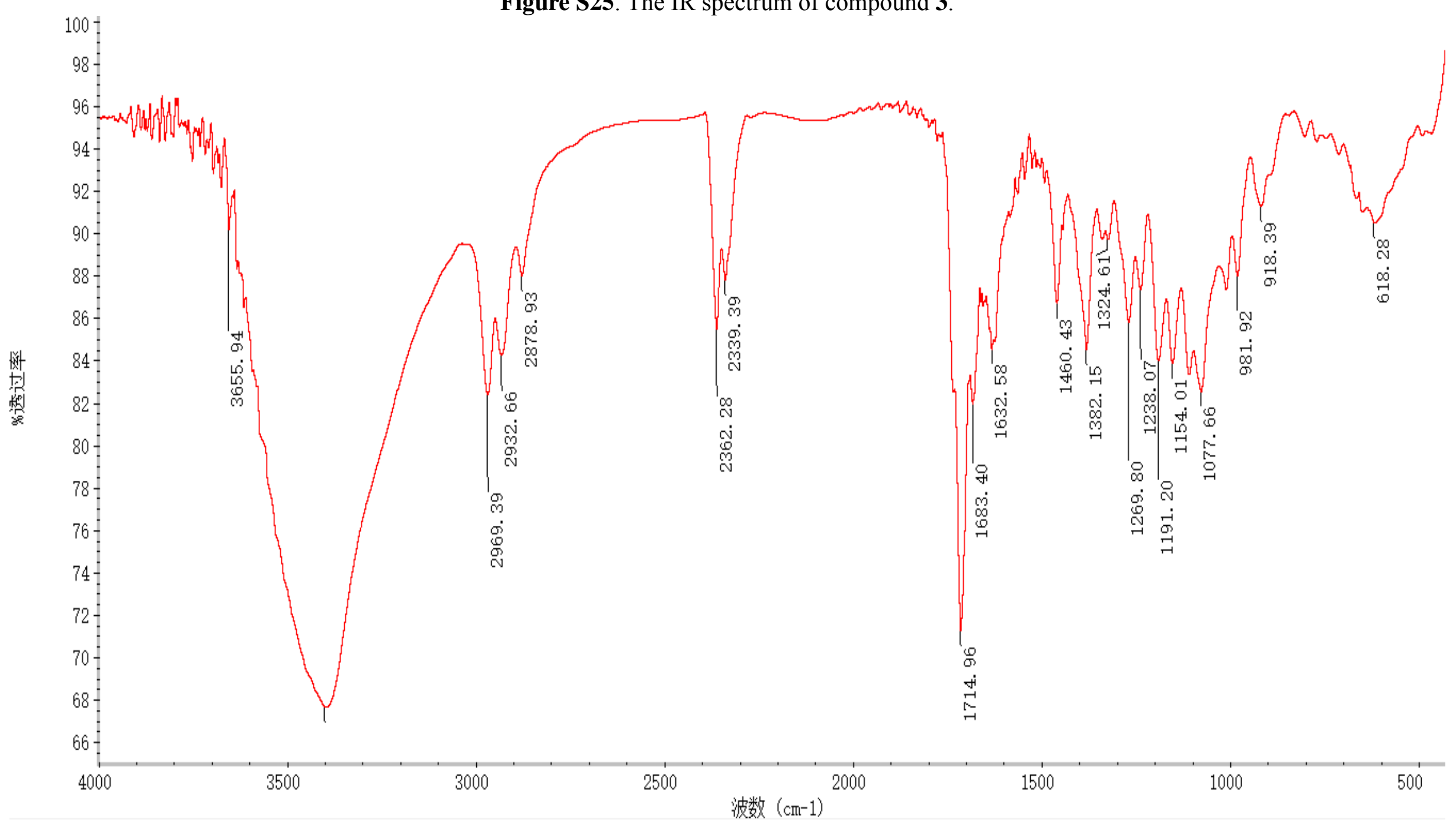


Figure S26. The ${ }^{1} \mathrm{H}$ NMR (400 MHz) spectrum of compound 3 in $\mathrm{CDCl}_{3}$.

JM-34-H 言 骂势

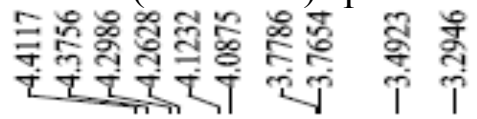
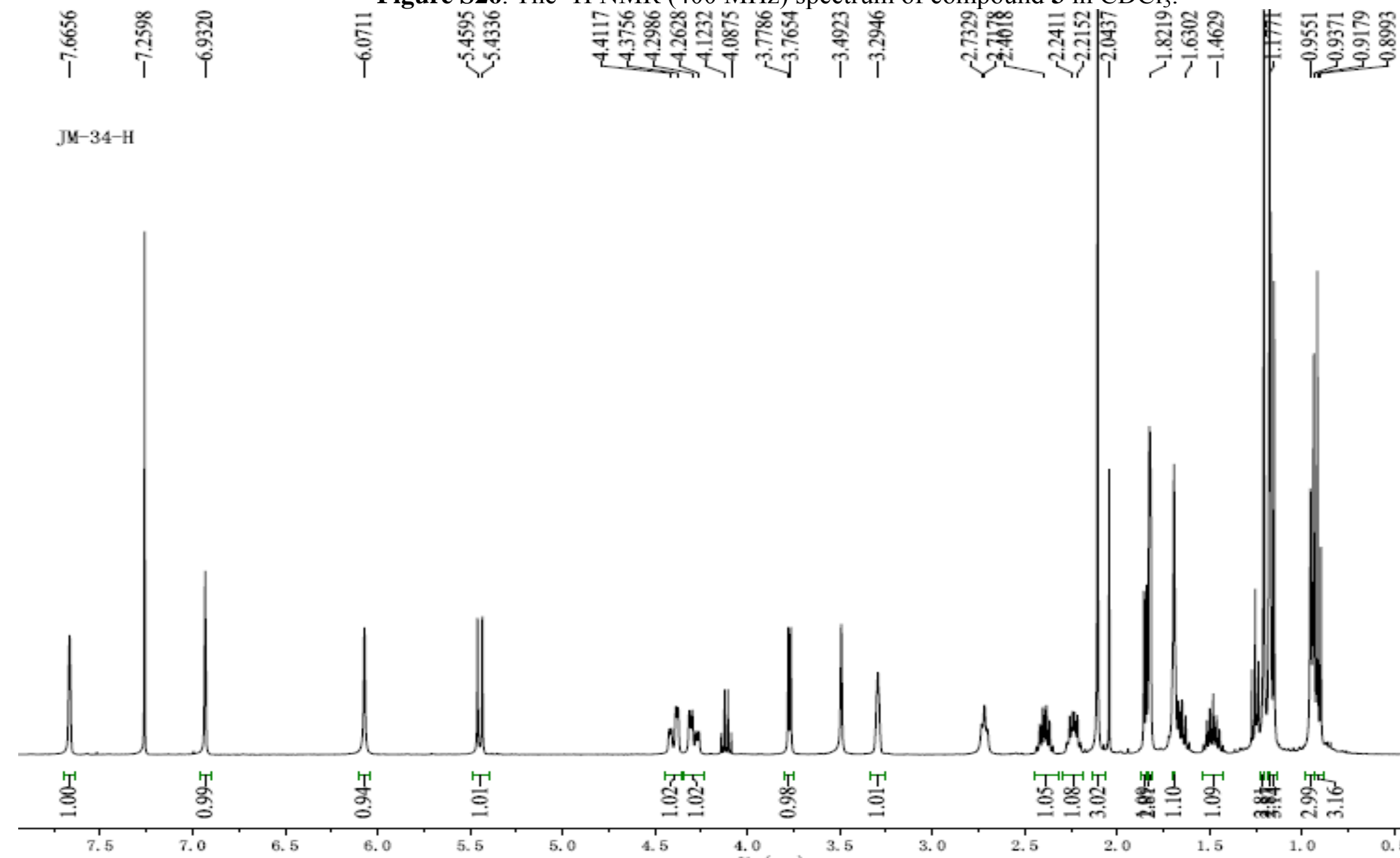

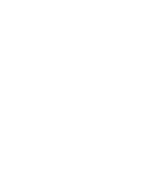



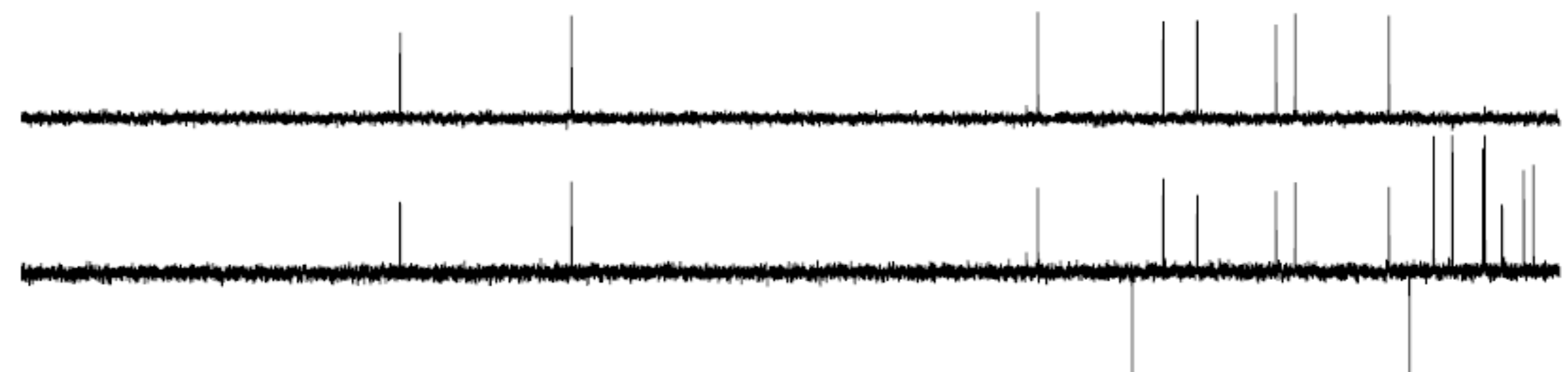

\begin{tabular}{|c|c|}
\hline 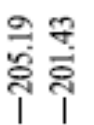 & 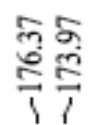 \\
\hline
\end{tabular}
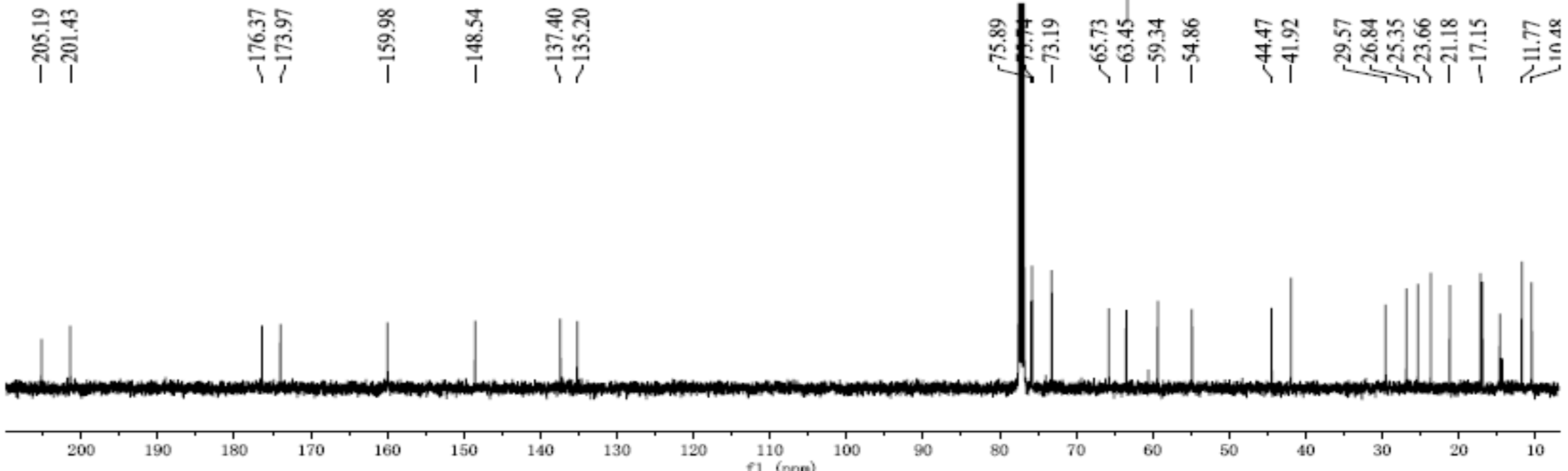

$80 \quad 70$

60

$50 \quad 40$

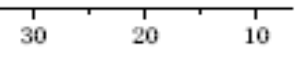


Figure S28. The enlarged ${ }^{13} \mathrm{C}$ NMR (100 MHz) spectrum of compound 3 in $\mathrm{CDCl}_{3}$.
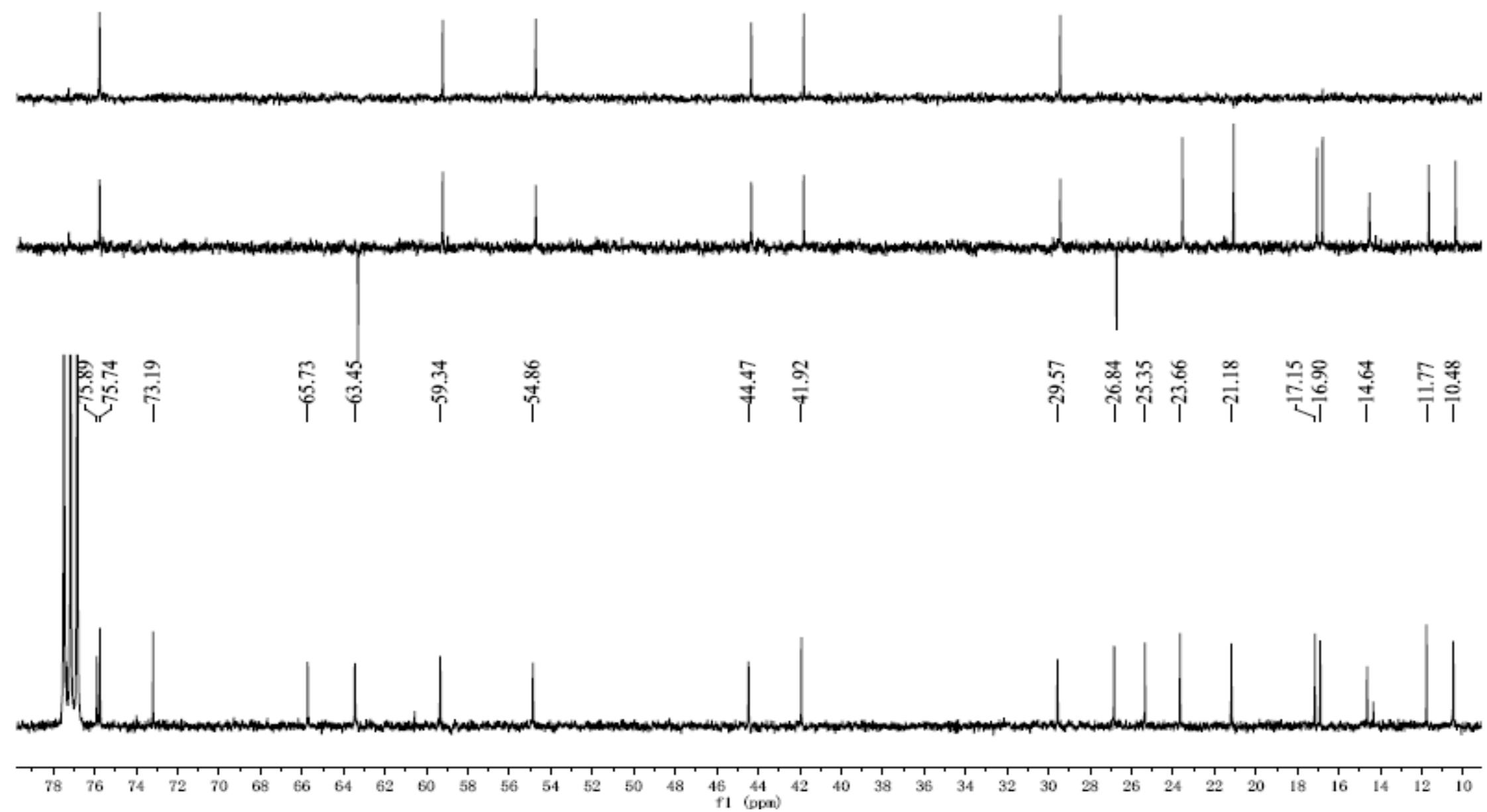
Figure S29. The HSQC spectrum of compound 3 in $\mathrm{CDCl}_{3}$.

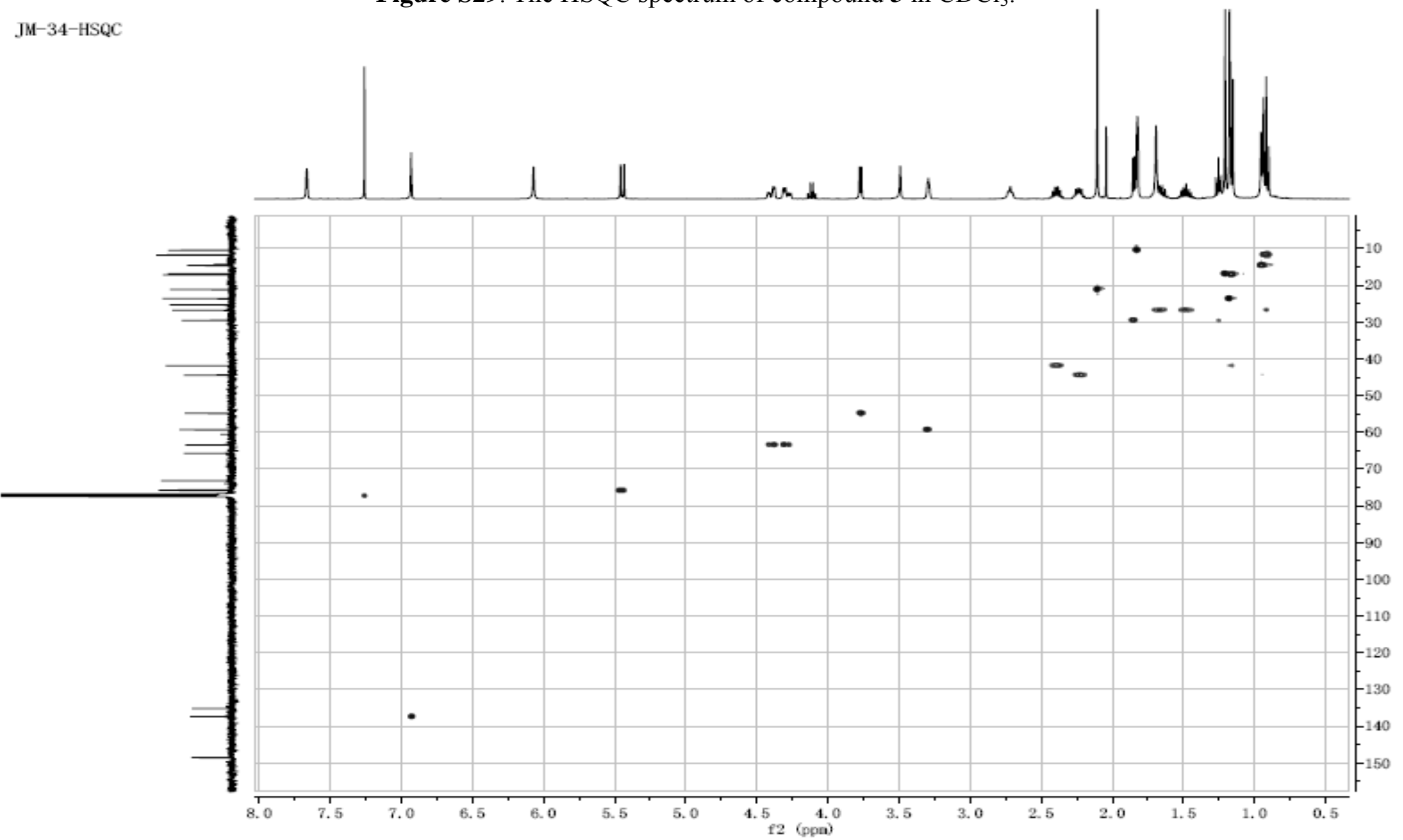


Figure S30. The $\mathrm{HMBC}$ spectrum of compound 3 in $\mathrm{CDCl}_{3}$.

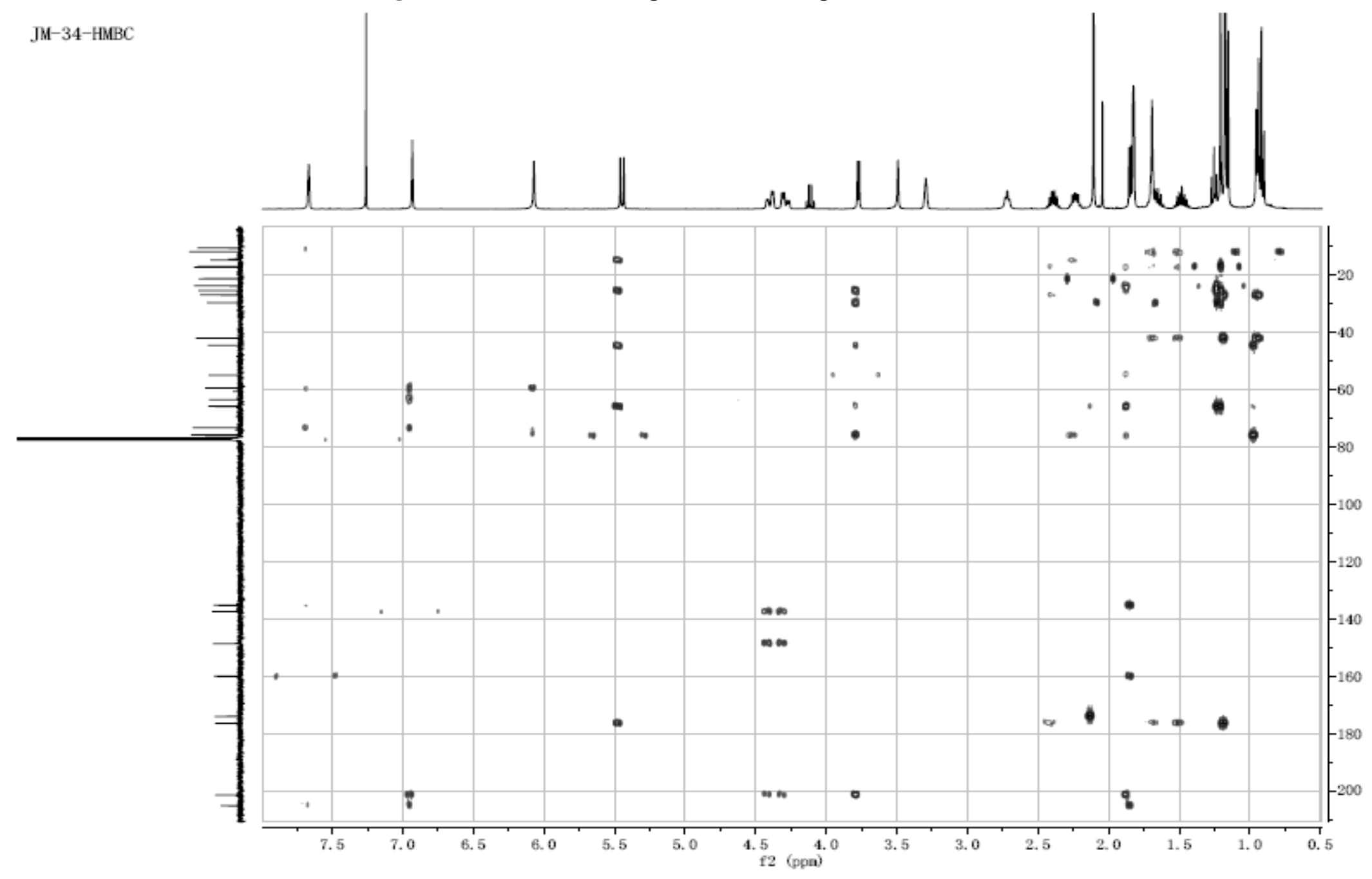


Figure S31. The ${ }^{1} \mathrm{H}-{ }^{1} \mathrm{H}$ COSY spectrum of compound 3 in $\mathrm{CDCl}_{3}$.

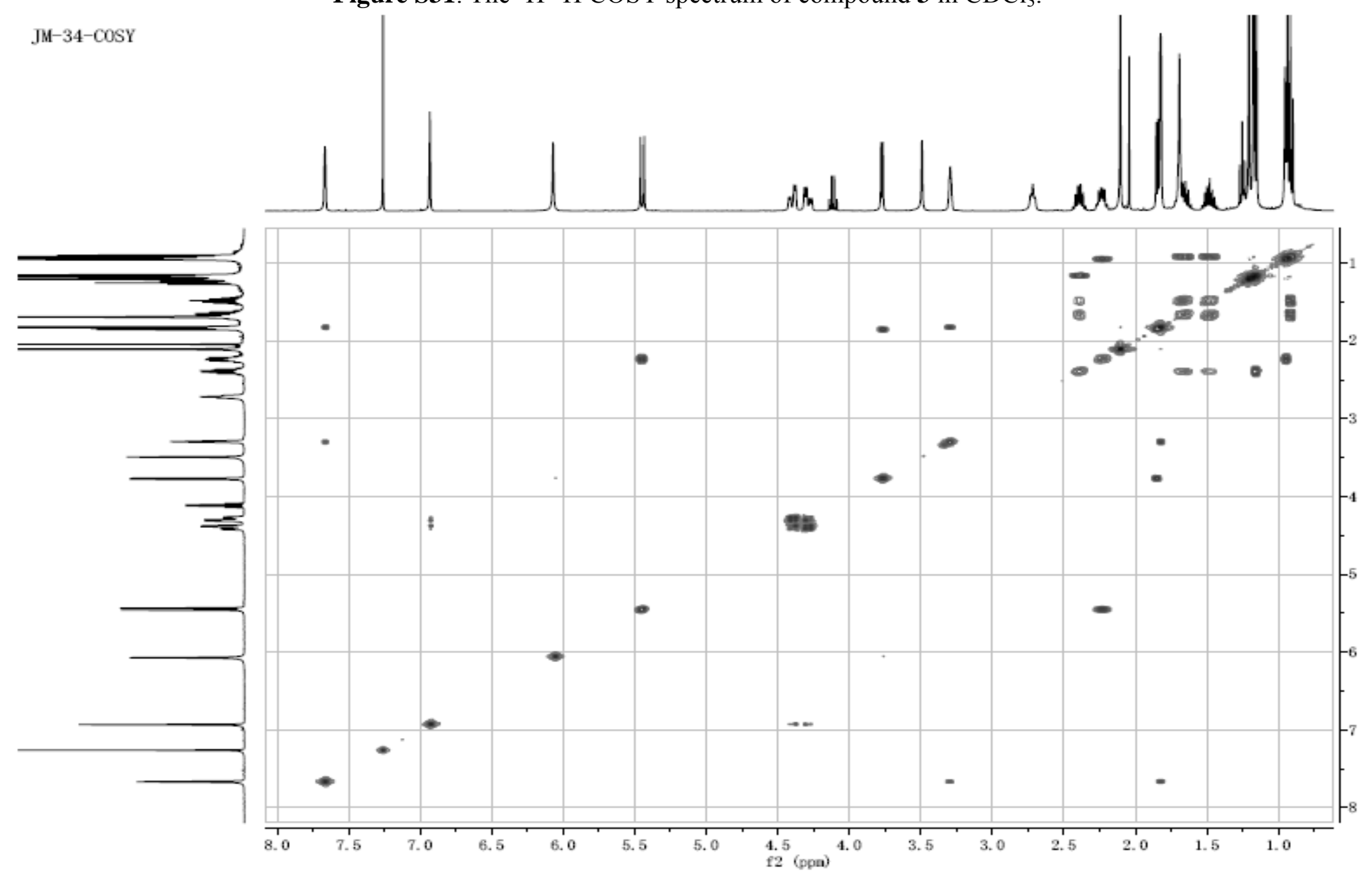


Figure S32. The ROESY spectrum of compound 3 in $\mathrm{CDCl}_{3}$.

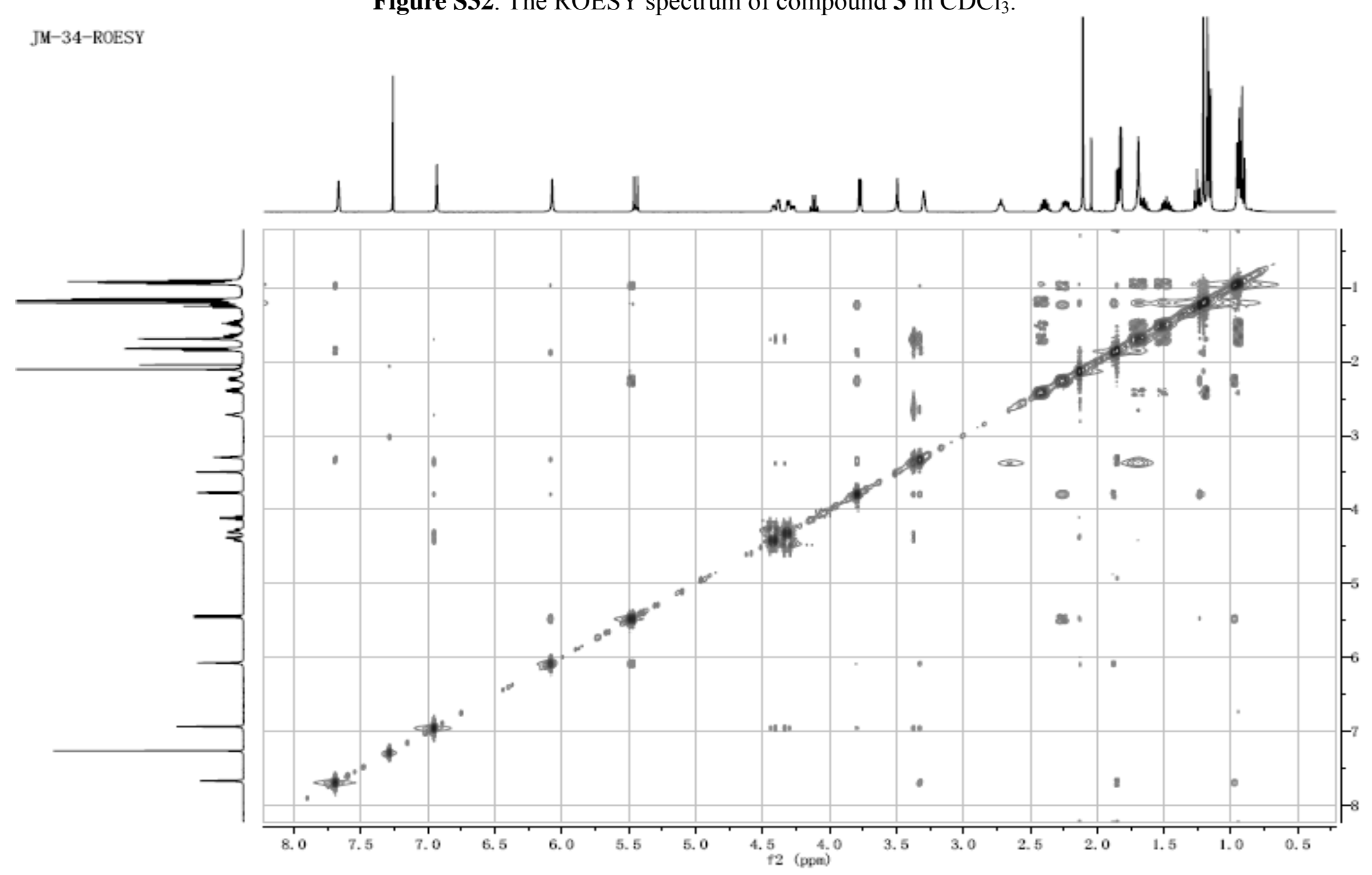




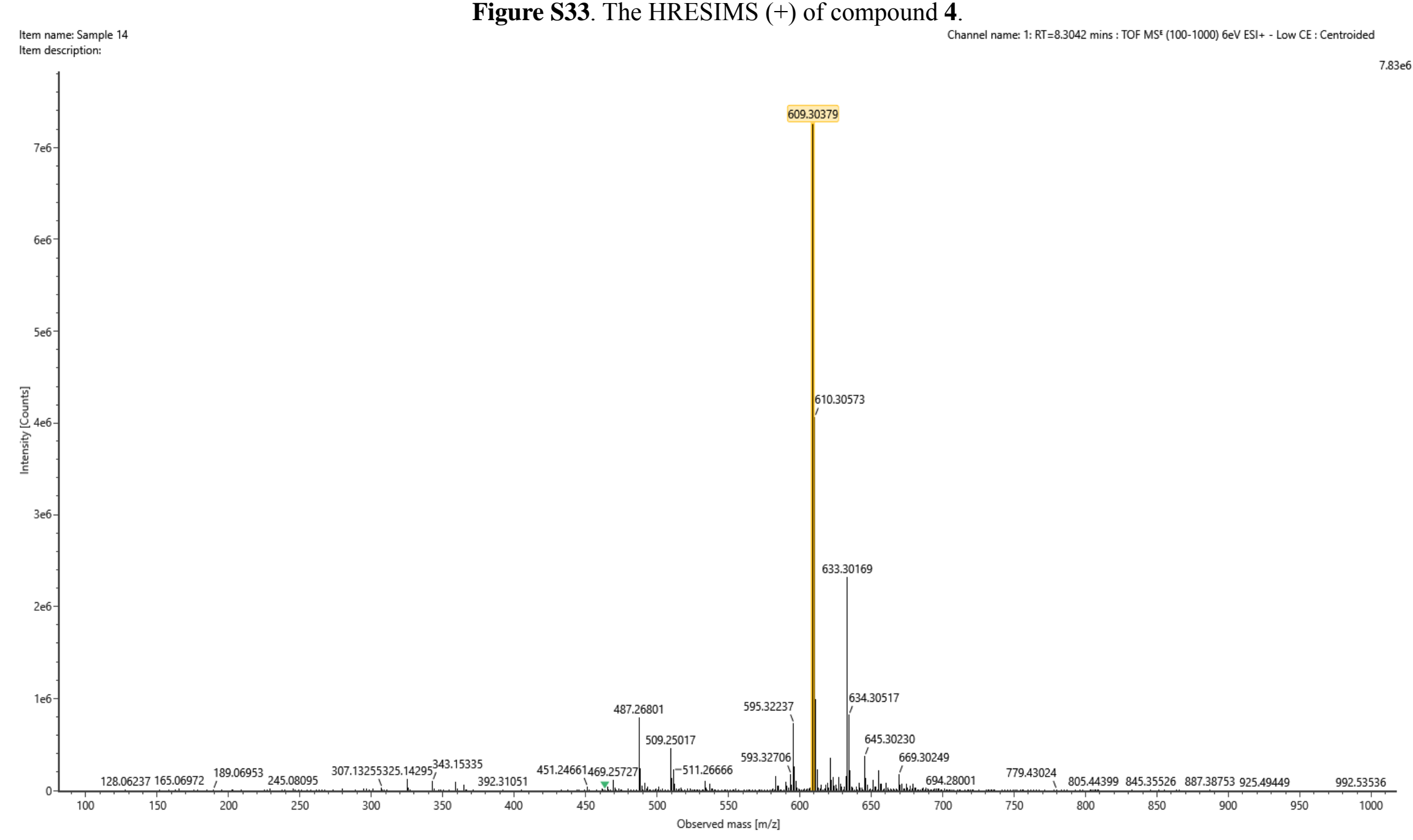




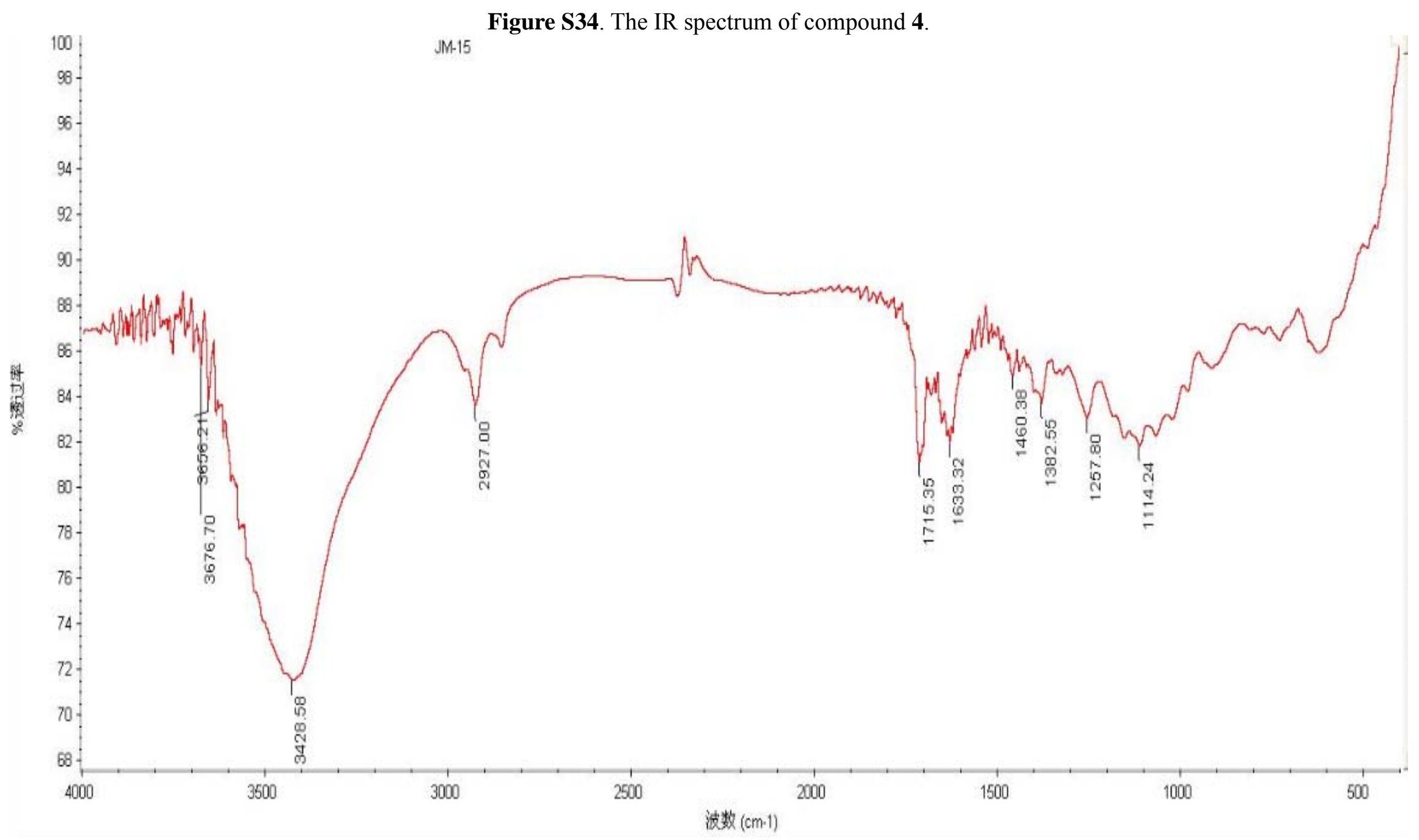




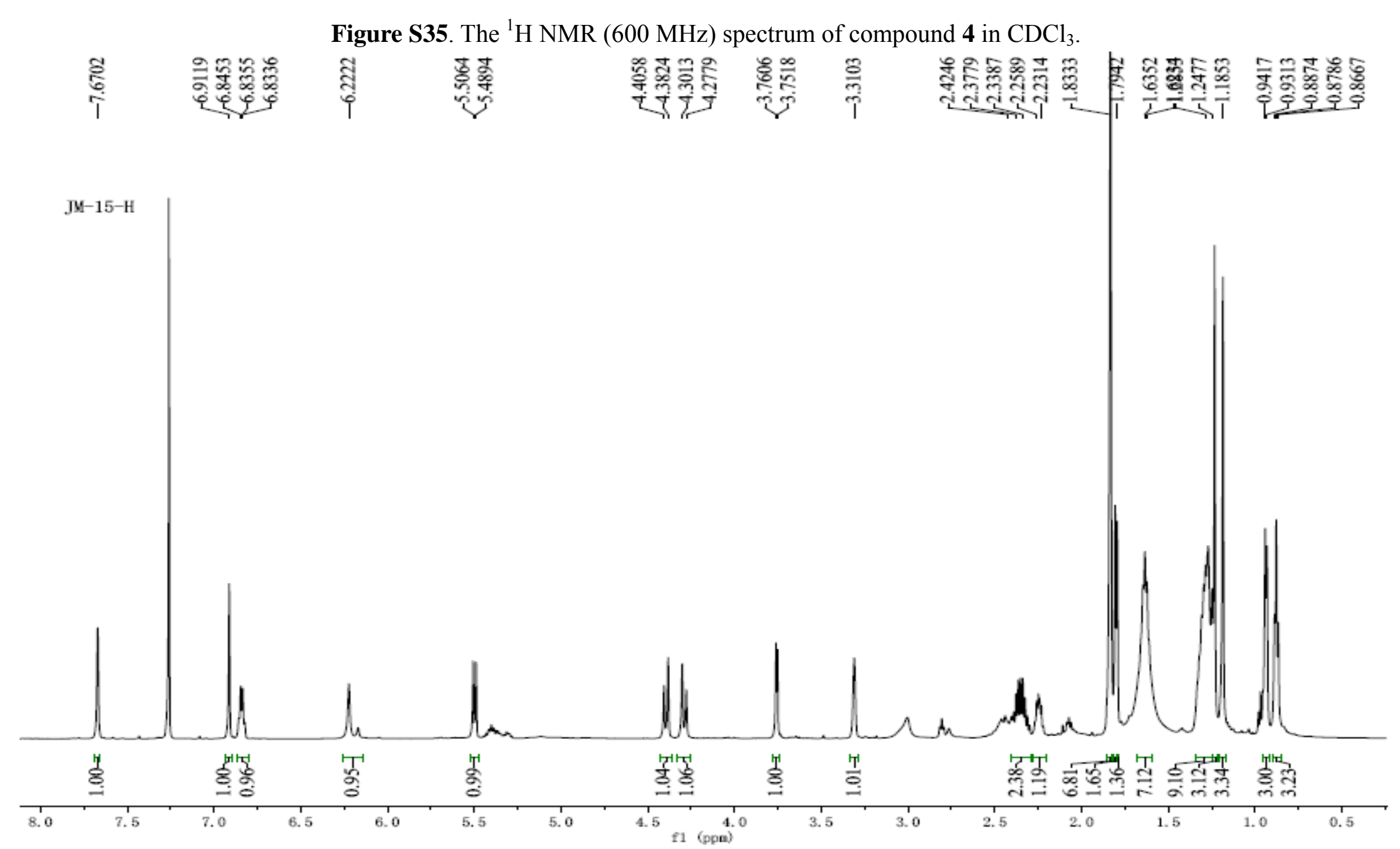


Figure S36. The ${ }^{13} \mathrm{C}$ NMR (150 MHz) spectrum of compound 4 in $\mathrm{CDCl}_{3}$.
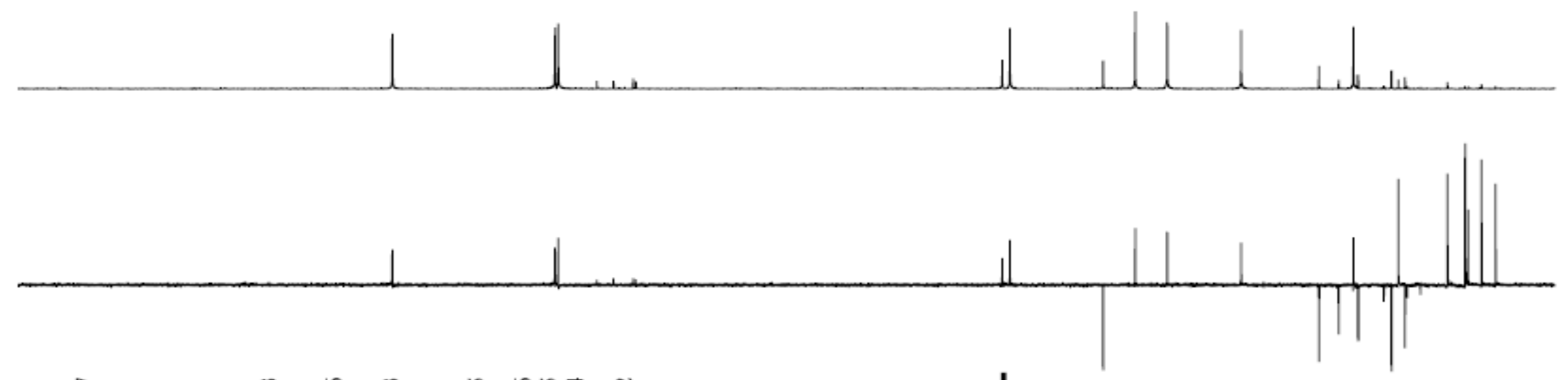

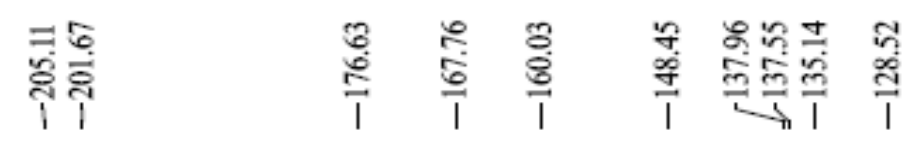

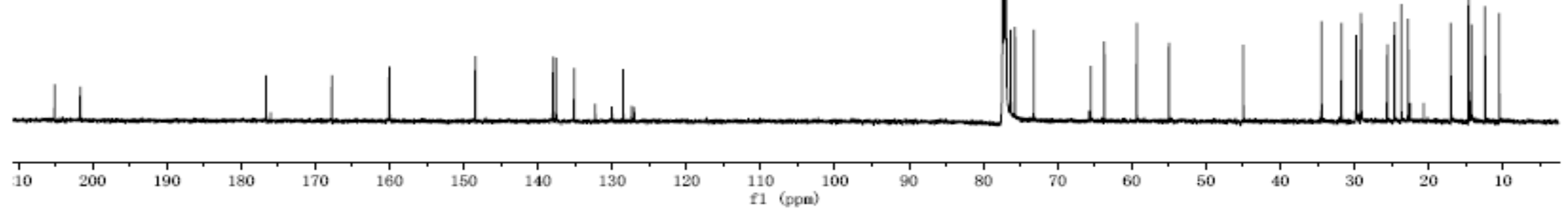


S37. The enlarged ${ }^{13} \mathrm{C}$ NMR $(150 \mathrm{MHz})$ spectrum of compound 4 in $\mathrm{CDCl}_{3}$.

$\mathrm{JM}-15-\mathrm{C}$
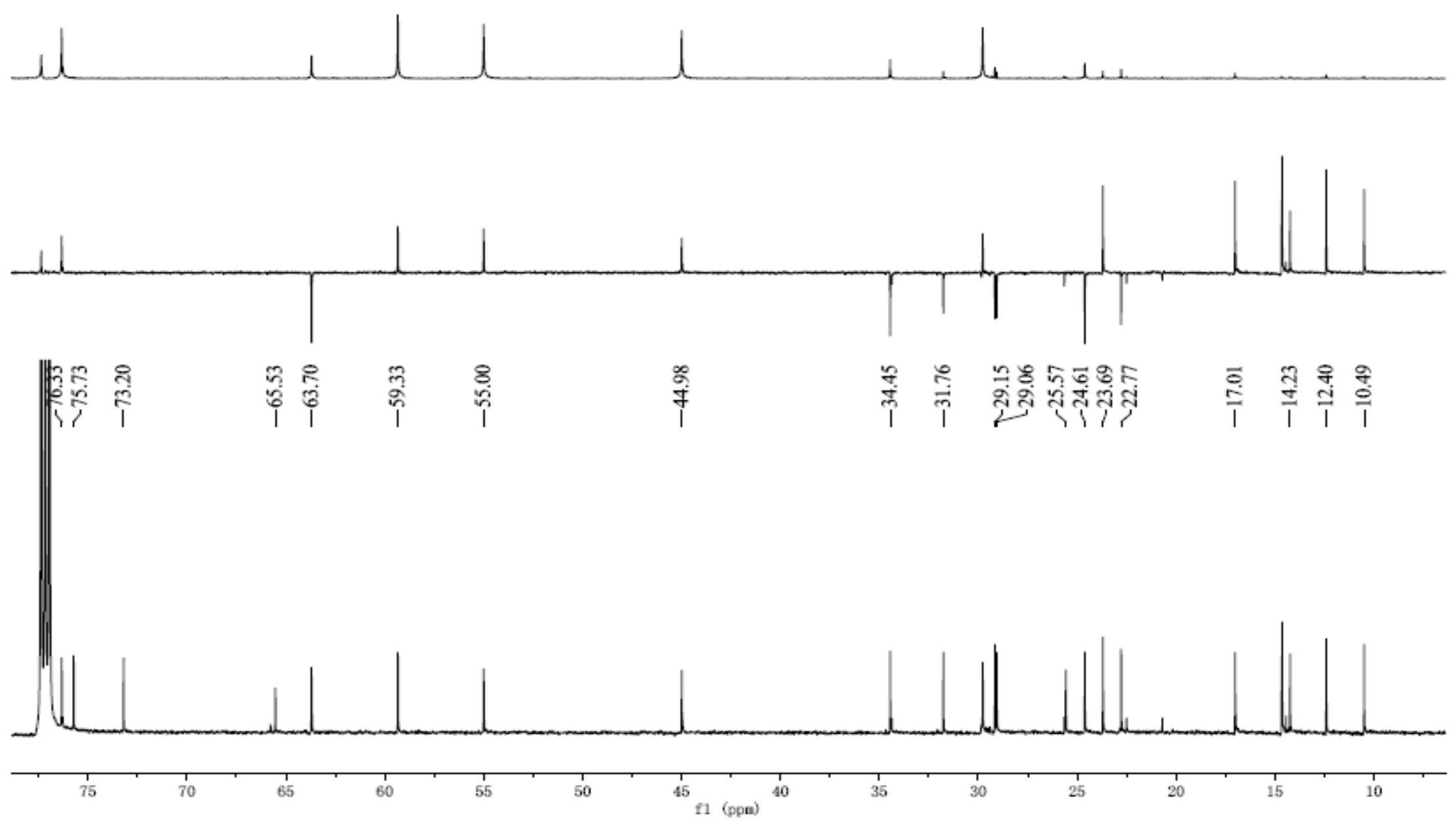
Figure S38. The HSQC spectrum of compound 4 in $\mathrm{CDCl}_{3}$.

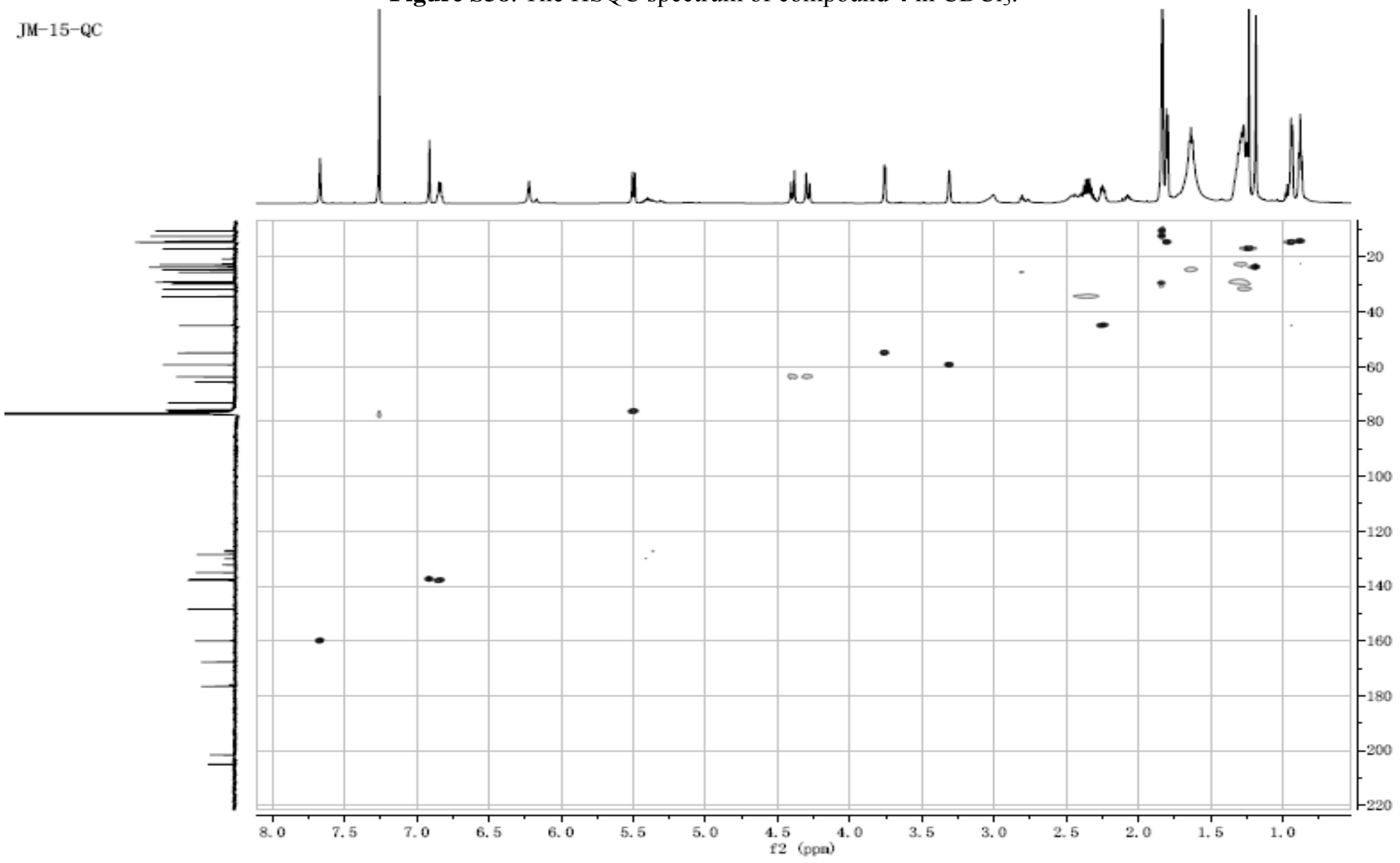


Figure S39. The HMBC spectrum of compound 4 in $\mathrm{CDCl}_{3}$.

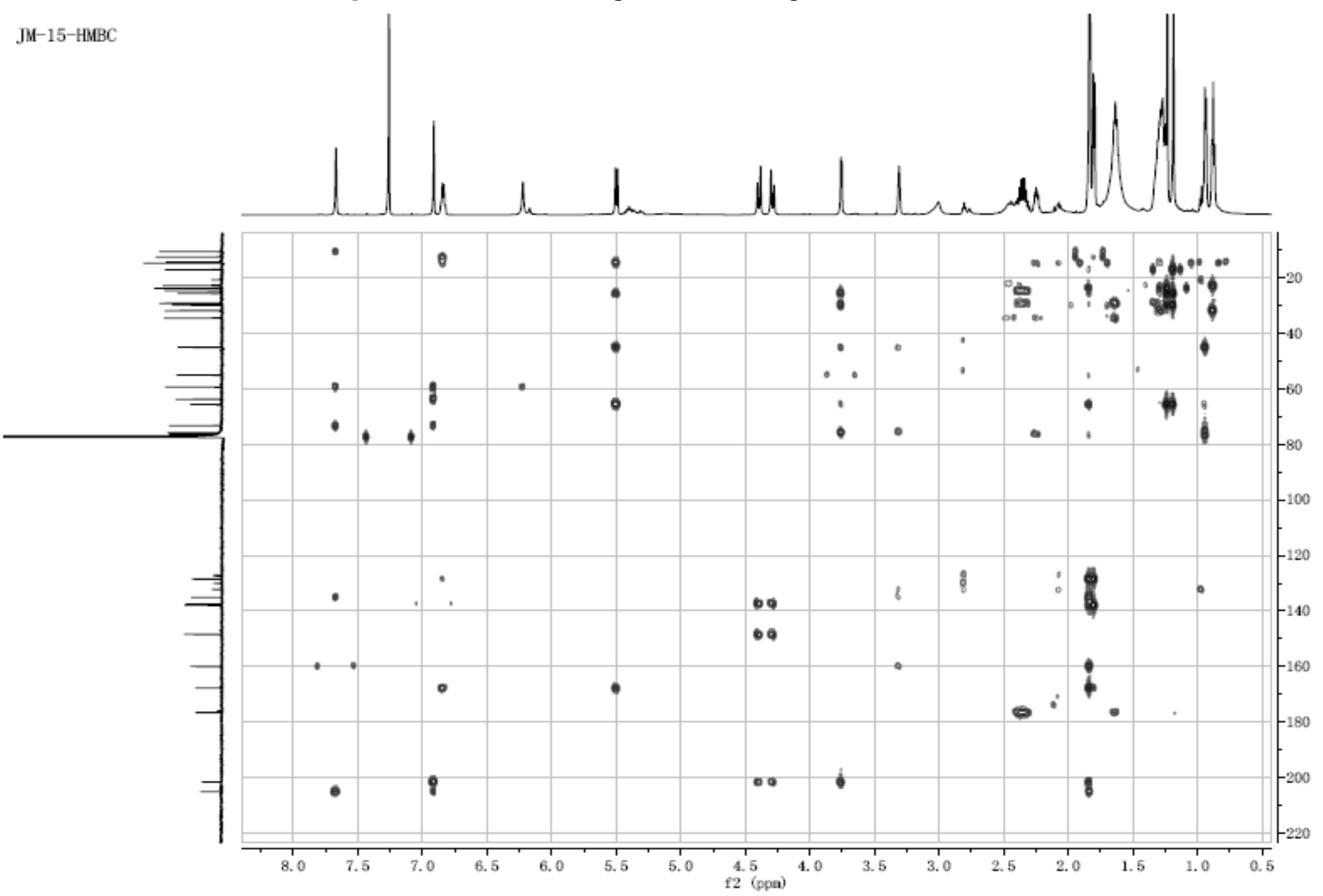


Figure S40. The ${ }^{1} \mathrm{H}-{ }^{1} \mathrm{H}$ COSY spectrum of compound 4 in $\mathrm{CDCl}_{3}$.

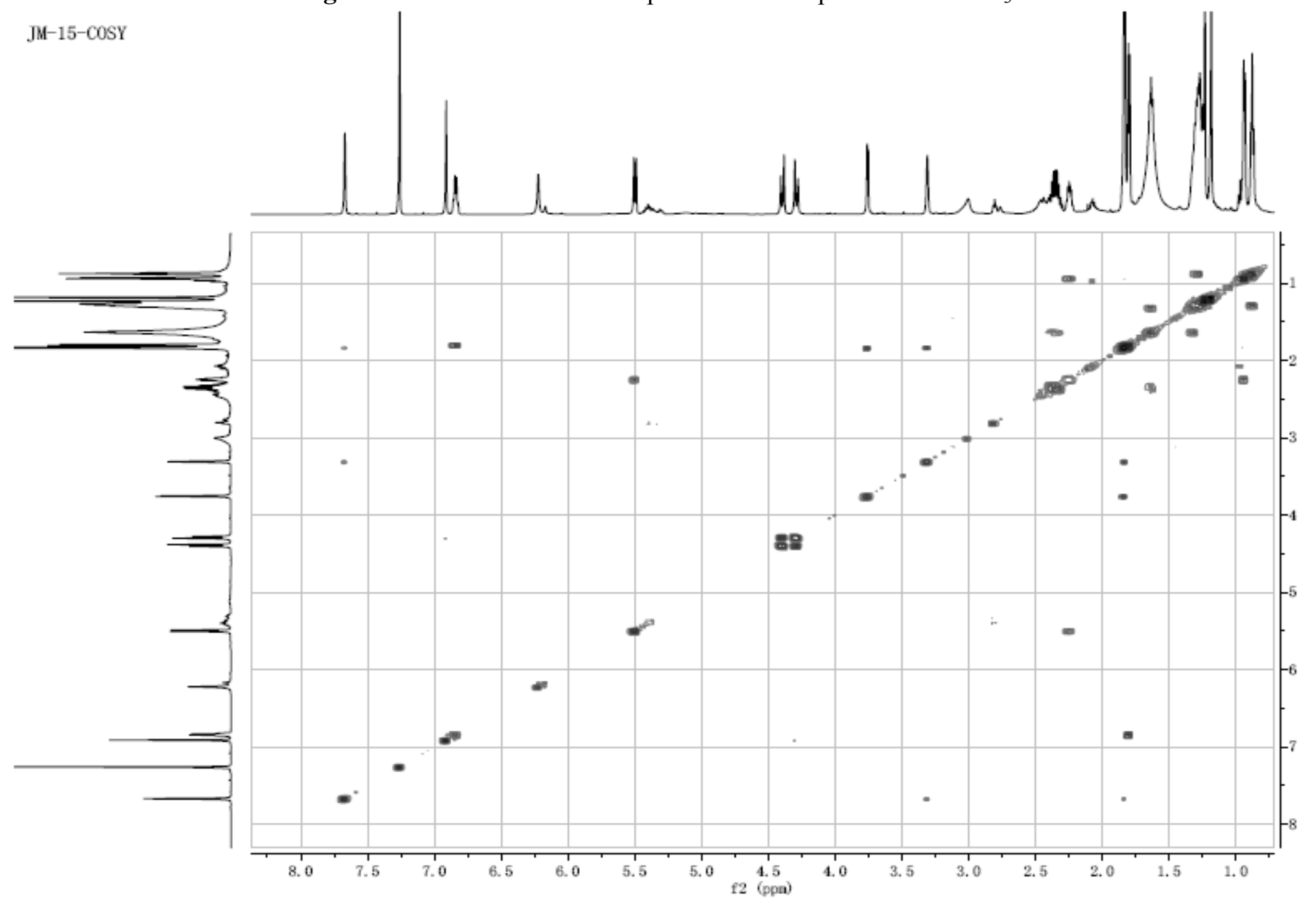


Figure S41. The ROESY spectrum of compound 4 in $\mathrm{CDCl}_{3}$.

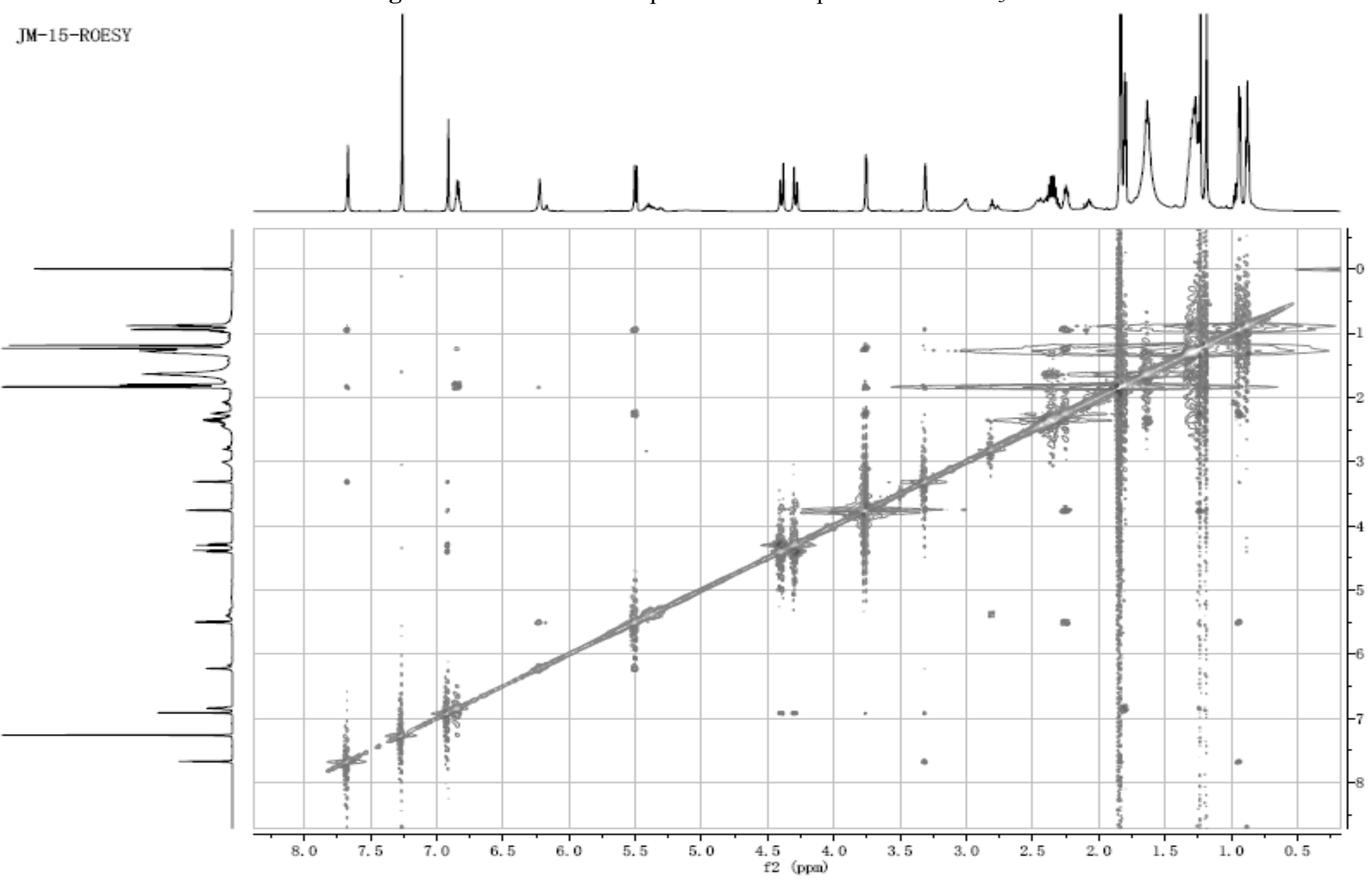




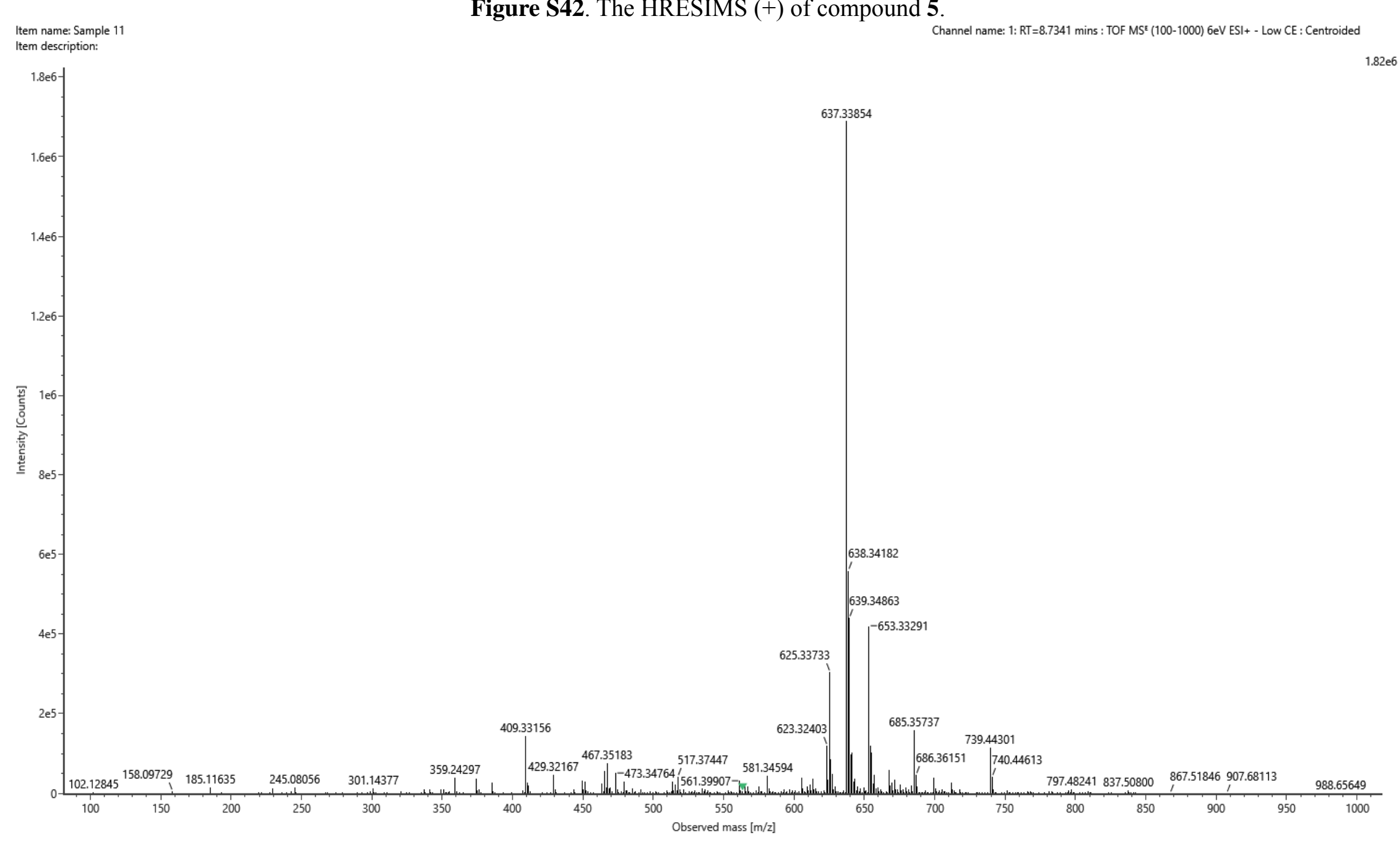


Figure S43. The IR spectrum of compound 5.

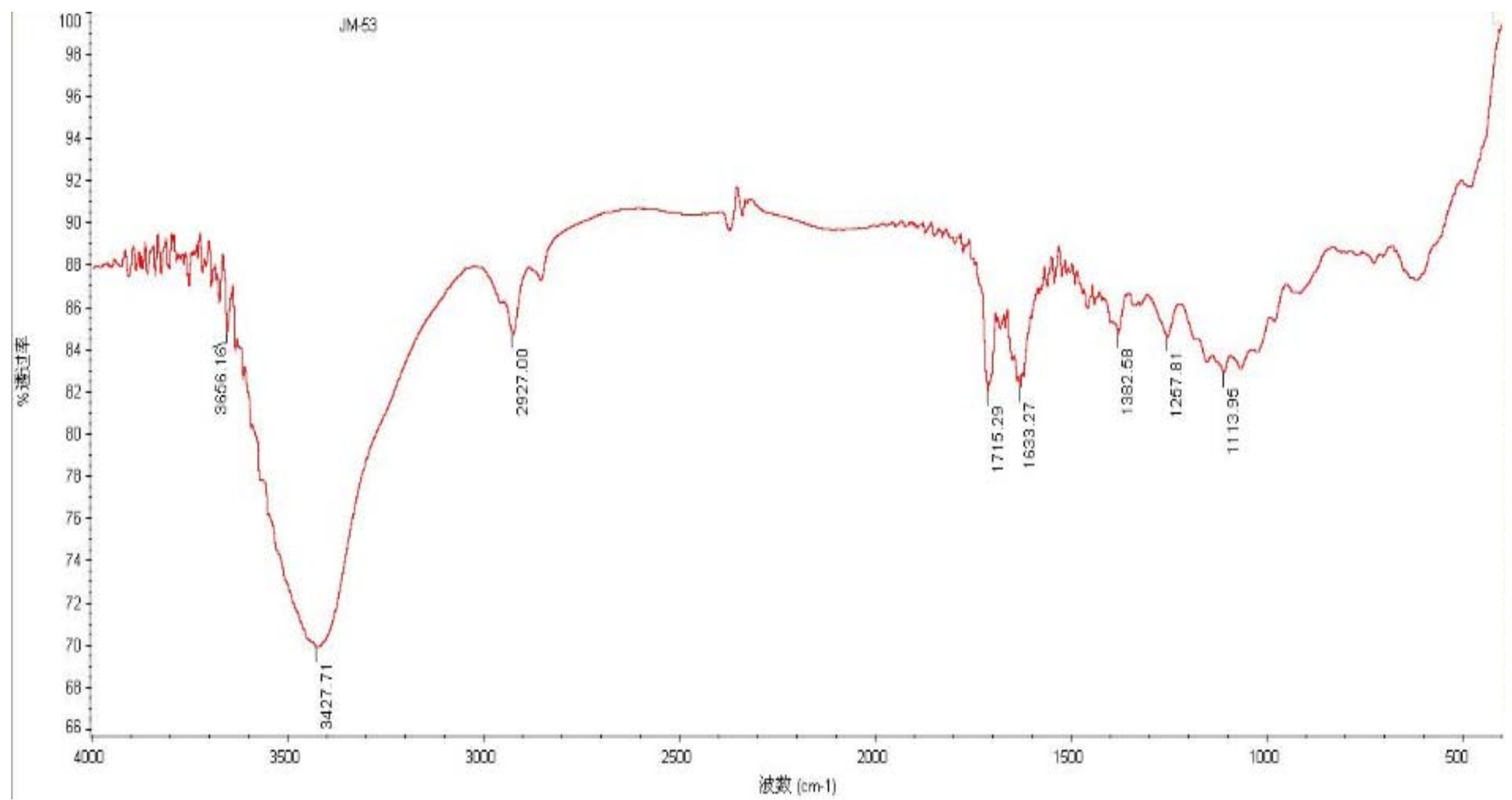


Figure S44. The ${ }^{1} \mathrm{H}$ NMR (600 MHz) spectrum of compound 5 in $\mathrm{CDCl}_{3}$.

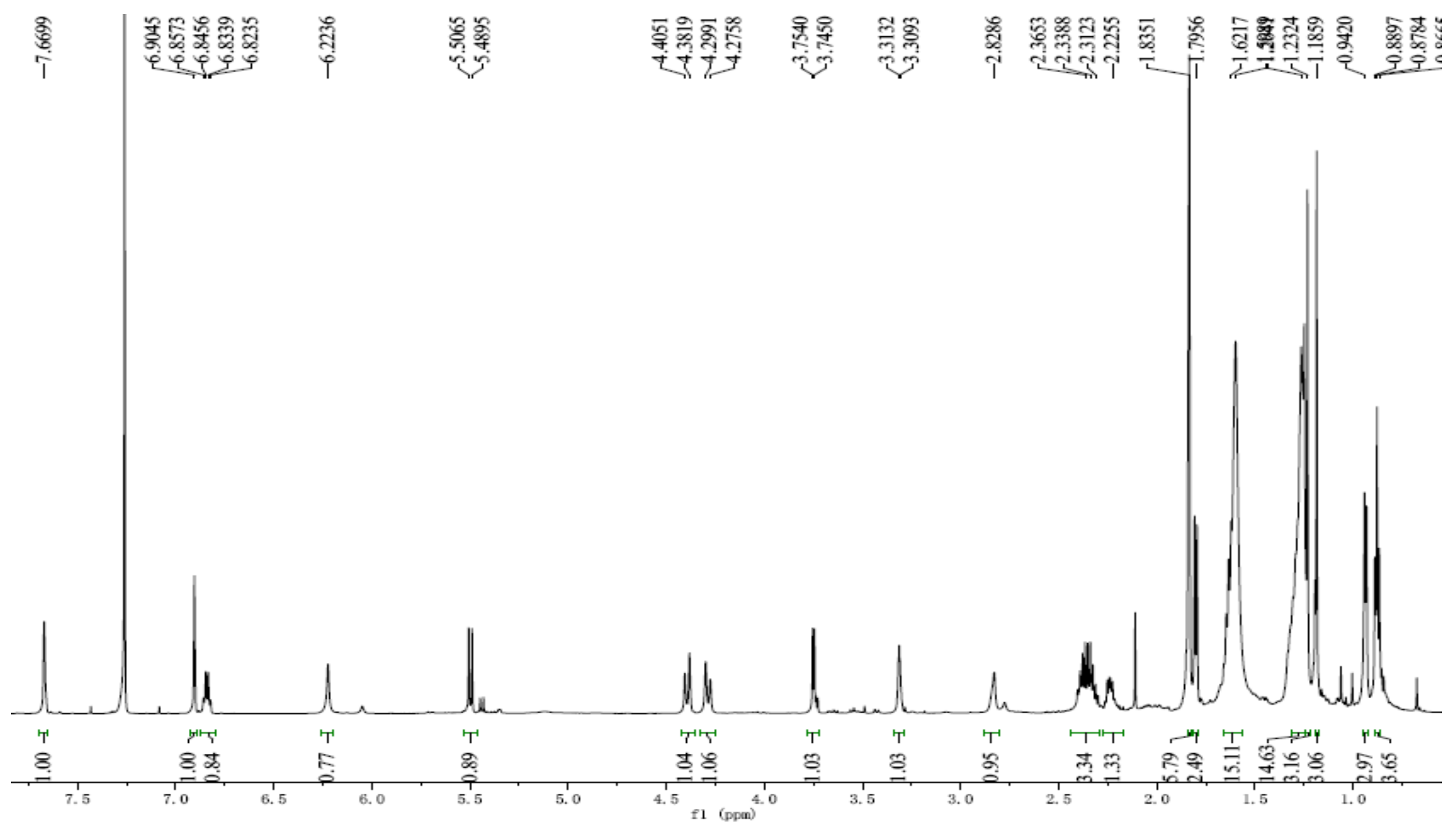


Figure S45. The ${ }^{13} \mathrm{C}$ NMR $(150 \mathrm{MHz})$ spectrum of compound 5 in $\mathrm{CDCl}_{3}$.
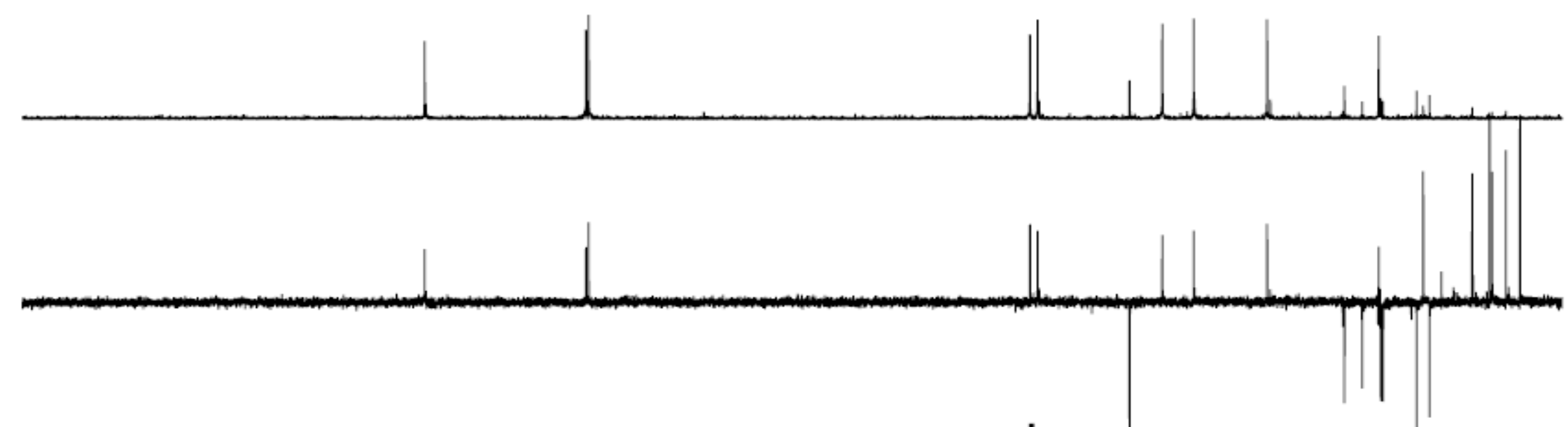

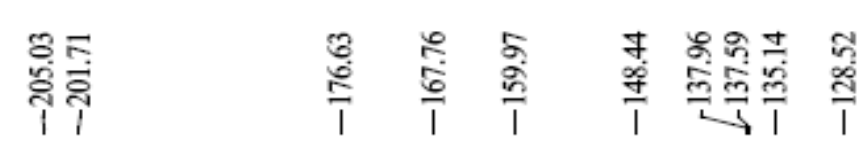
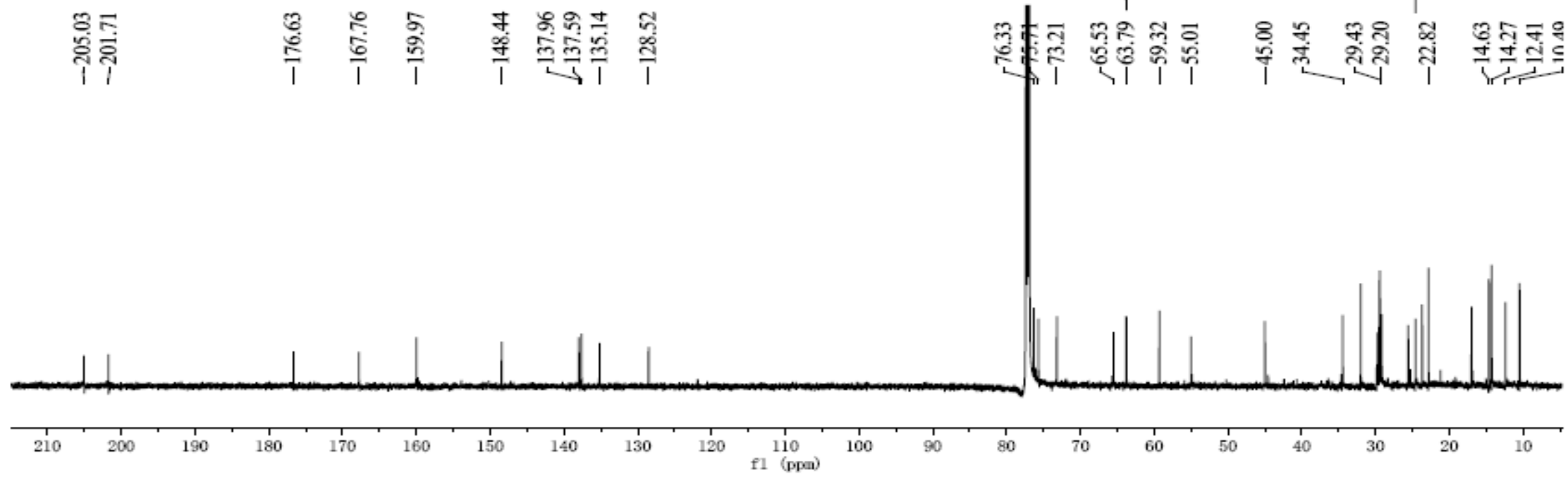
Figure S46. The enlarged ${ }^{13} \mathrm{C}$ NMR (150 MHz) spectrum of compound 5 in $\mathrm{CDCl}_{3}$.
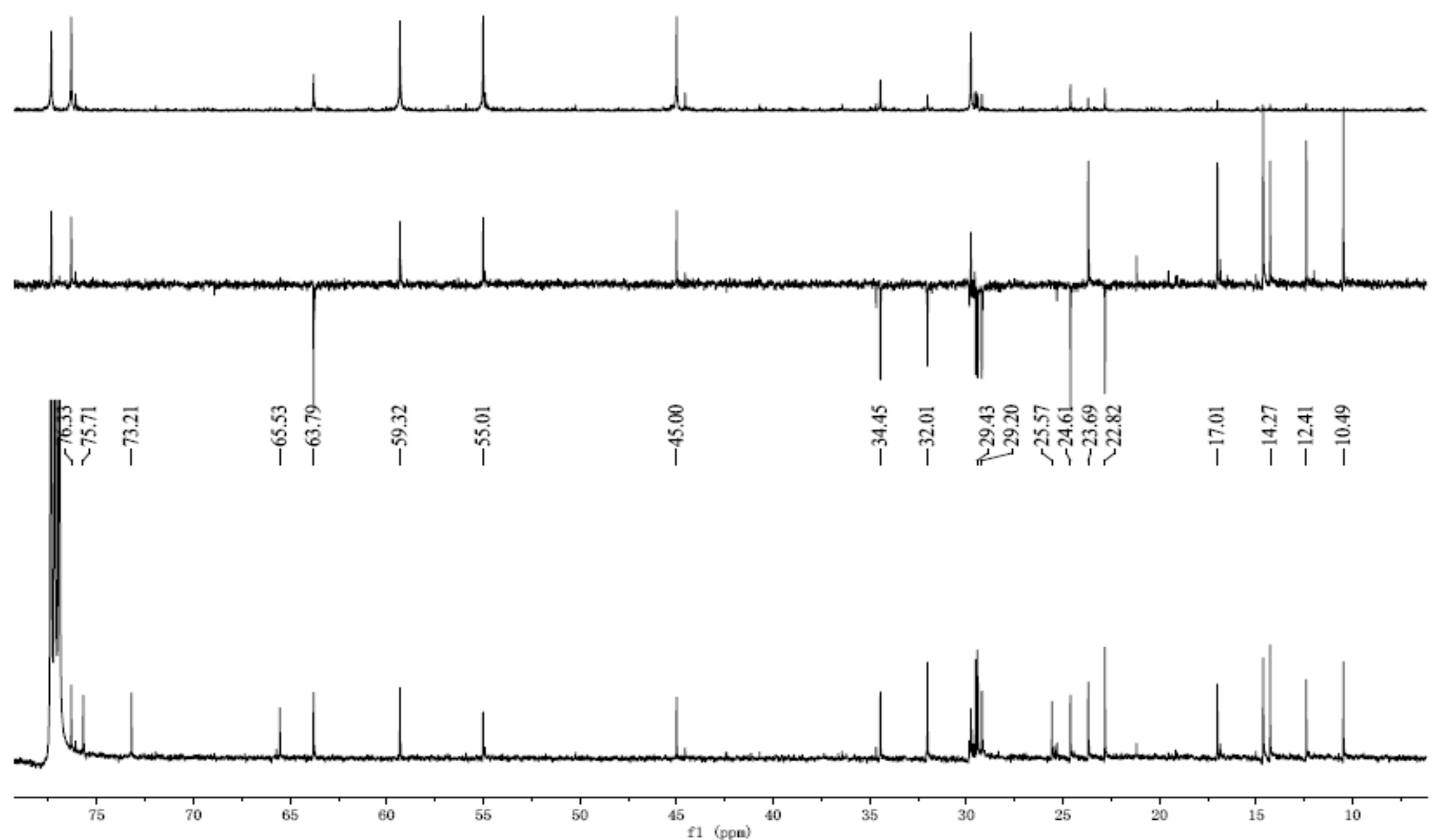
Figure S47. The HSQC spectrum of compound 5 in $\mathrm{CDCl}_{3}$.

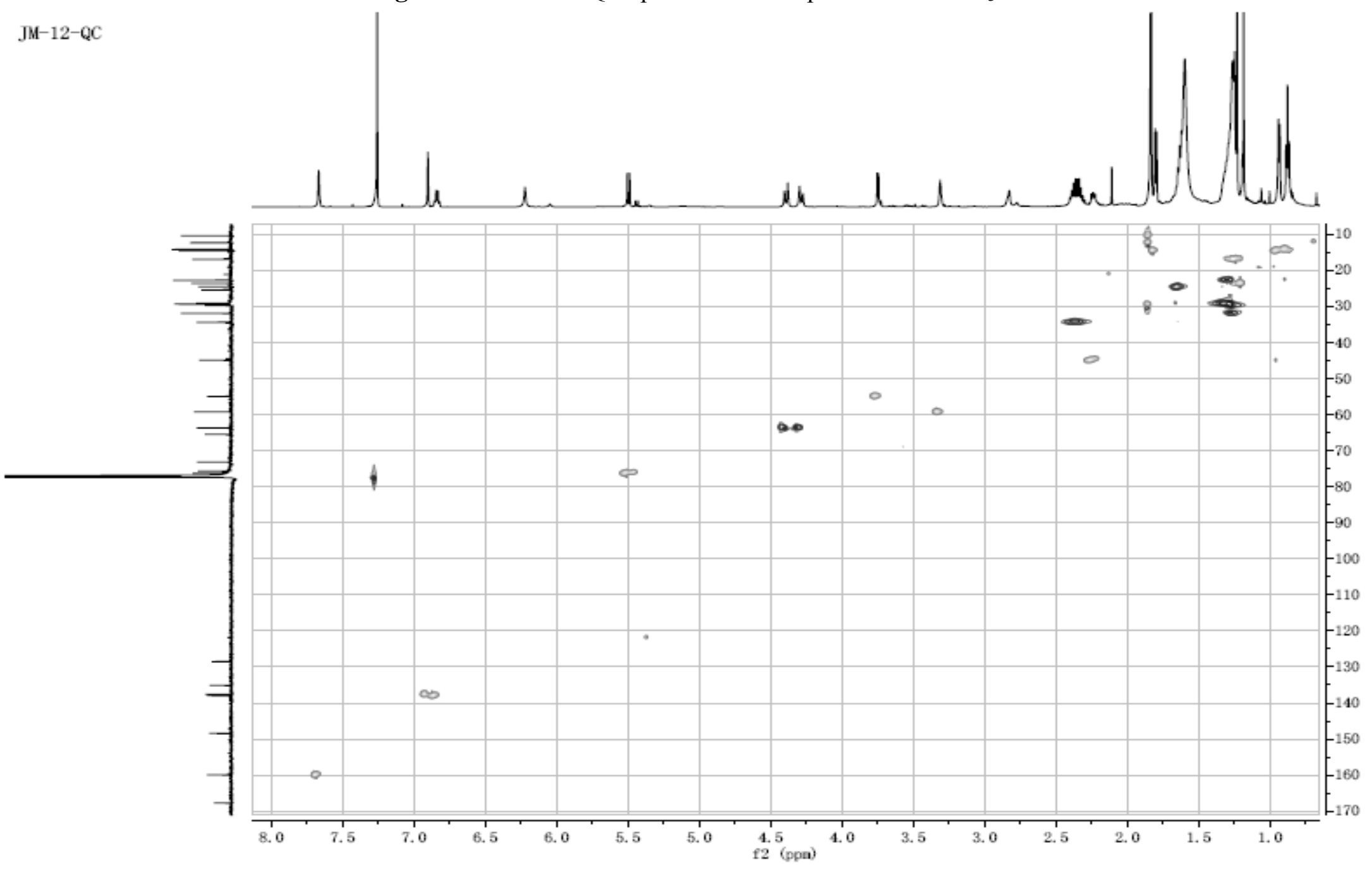


Figure S48. The $\mathrm{HMBC}$ spectrum of compound 5 in $\mathrm{CDCl}_{3}$.

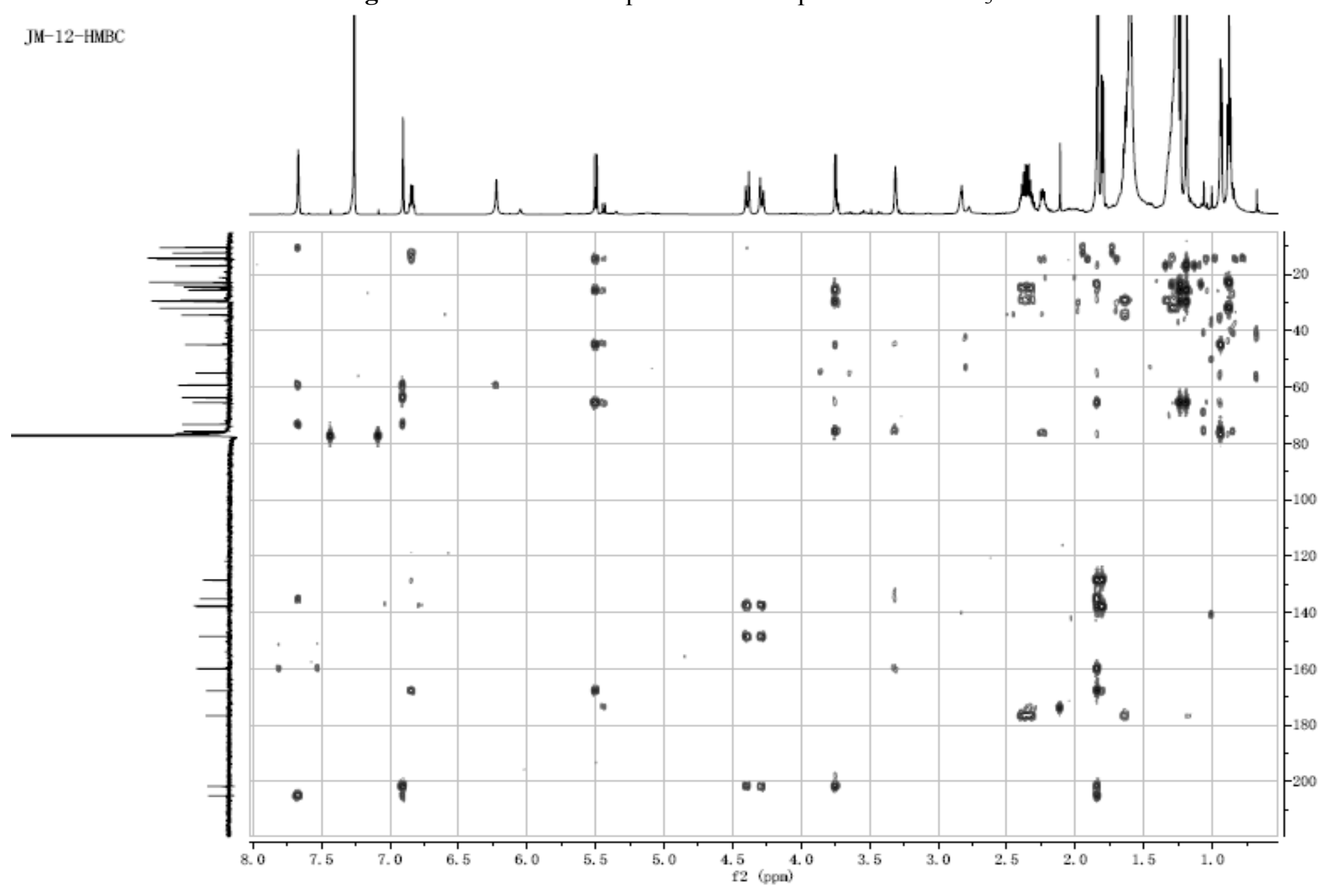


Figure S49. The ${ }^{1} \mathrm{H}-{ }^{1} \mathrm{H}$ COSY spectrum of compound 5 in $\mathrm{CDCl}_{3}$.

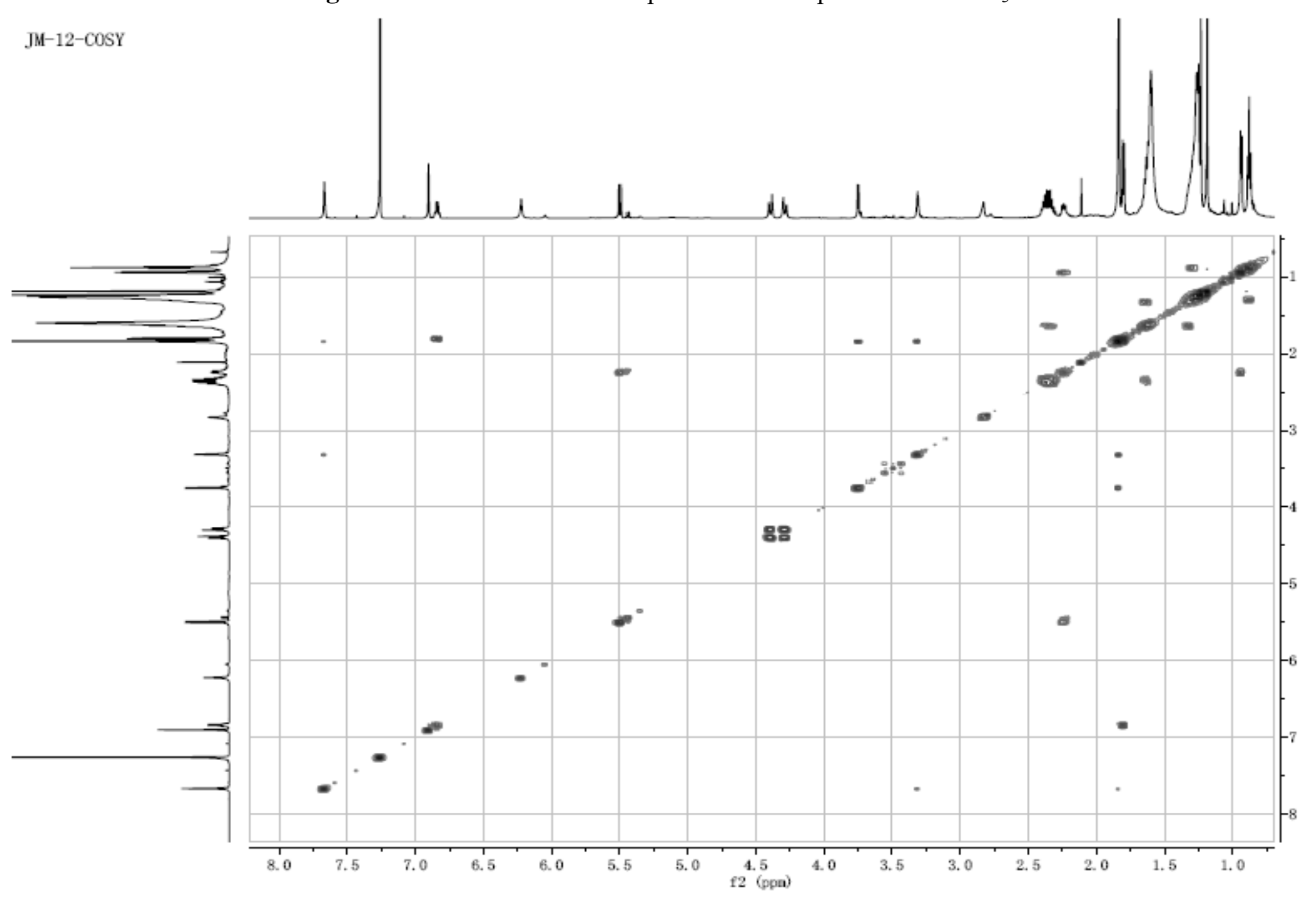


Figure S50. The ROESY spectrum of compound 5 in $\mathrm{CDCl}_{3}$.

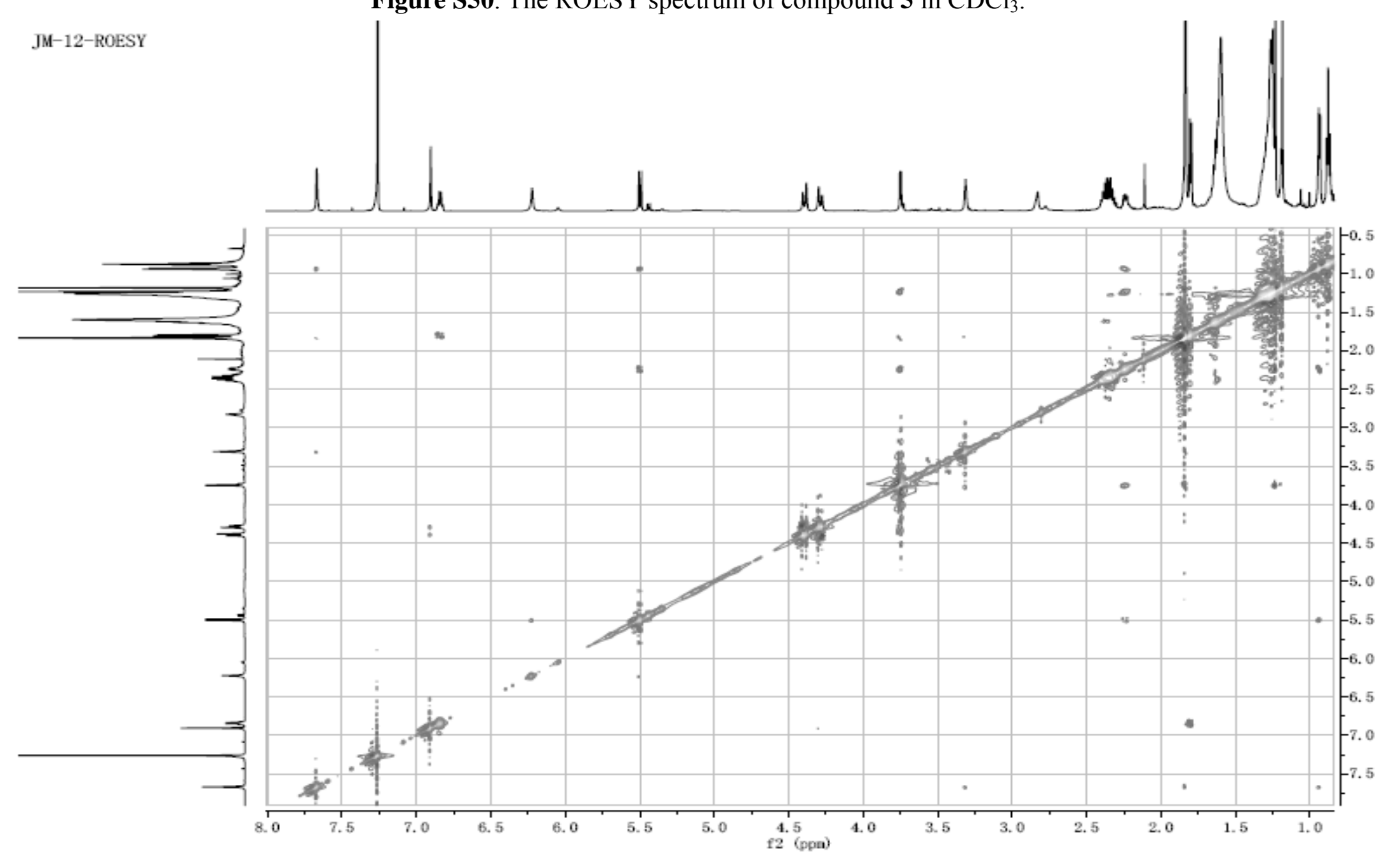




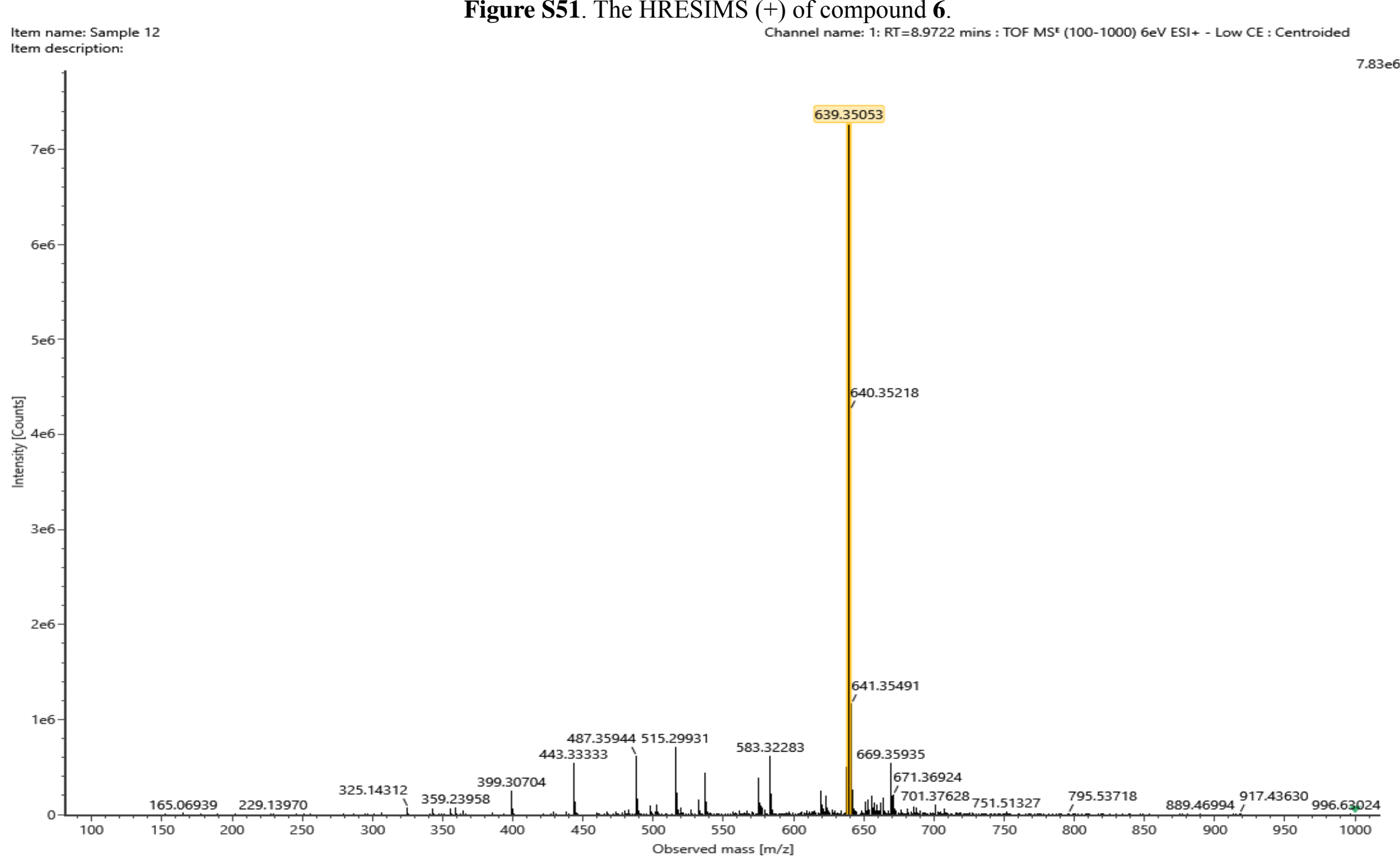




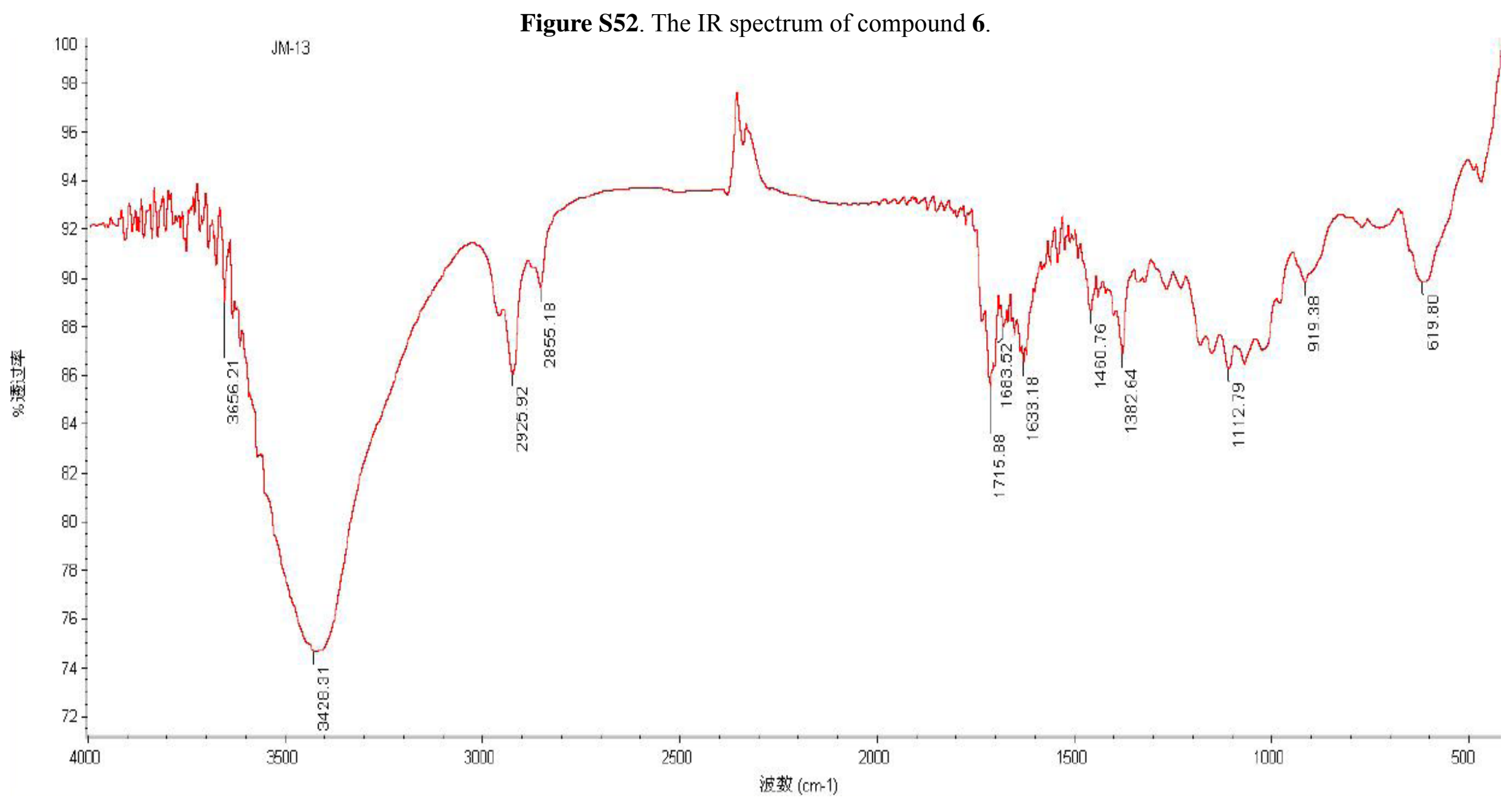


Figure S53. The ${ }^{1} \mathrm{H}$ NMR (600 MHz) spectrum of compound 6 in $\mathrm{CDCl}_{3}$.

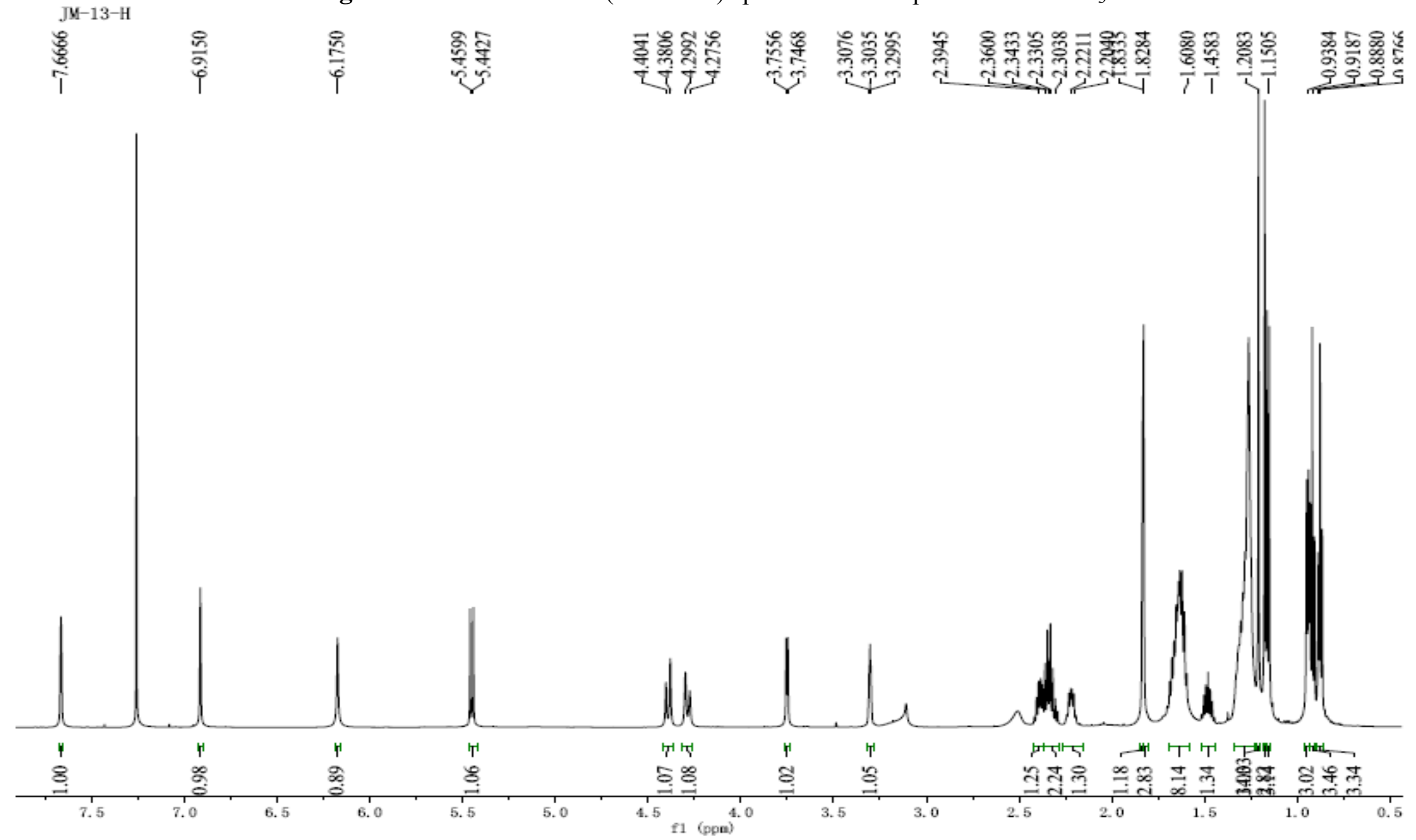


Figure S54. The ${ }^{13} \mathrm{C}$ NMR (150 MHz) spectrum of compound 6 in $\mathrm{CDCl}_{3}$.

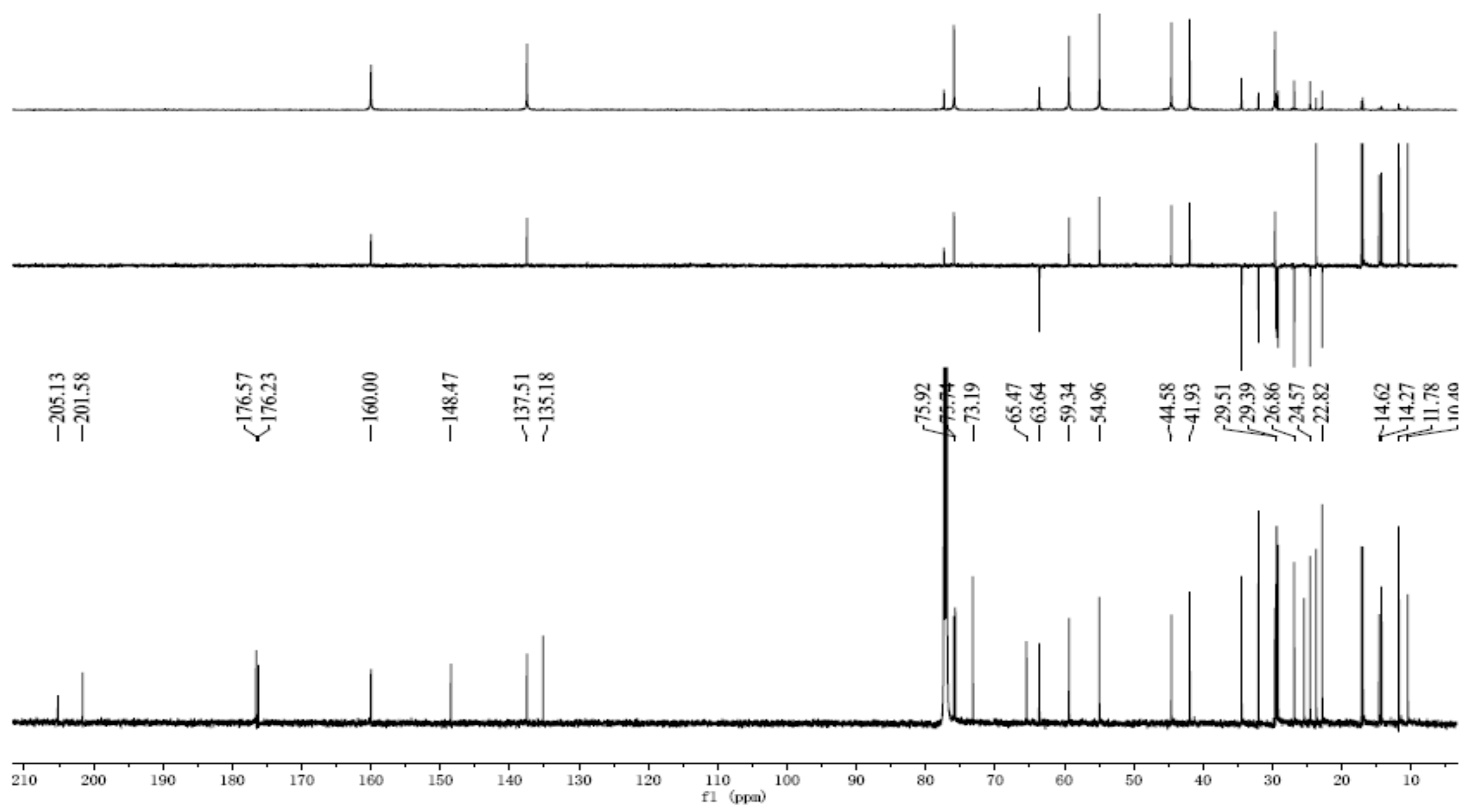



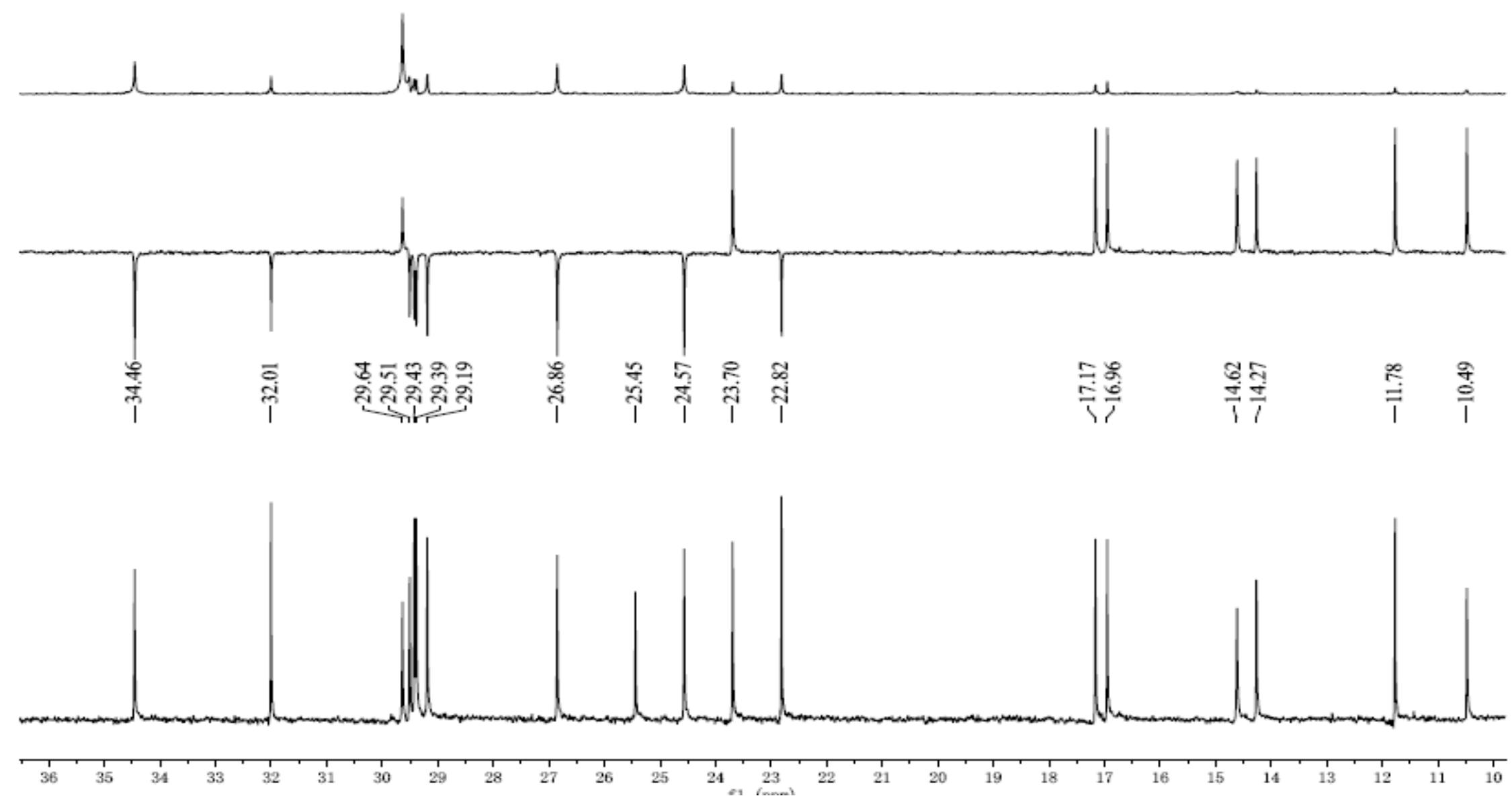
Figure S56. The HSQC spectrum of compound 6 in $\mathrm{CDCl}_{3}$.

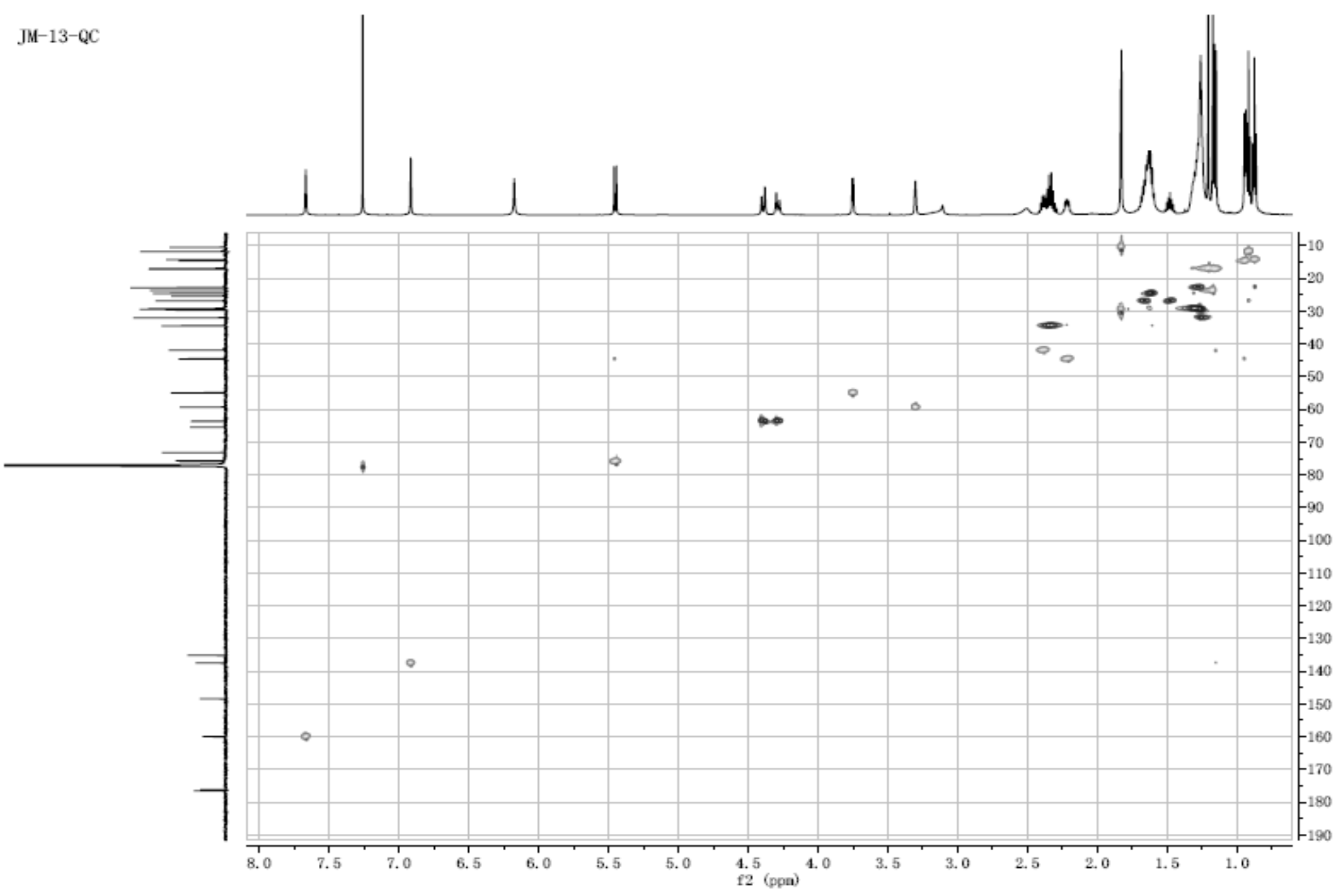


Figure S57. The HMBC spectrum of compound 6 in $\mathrm{CDCl}_{3}$.

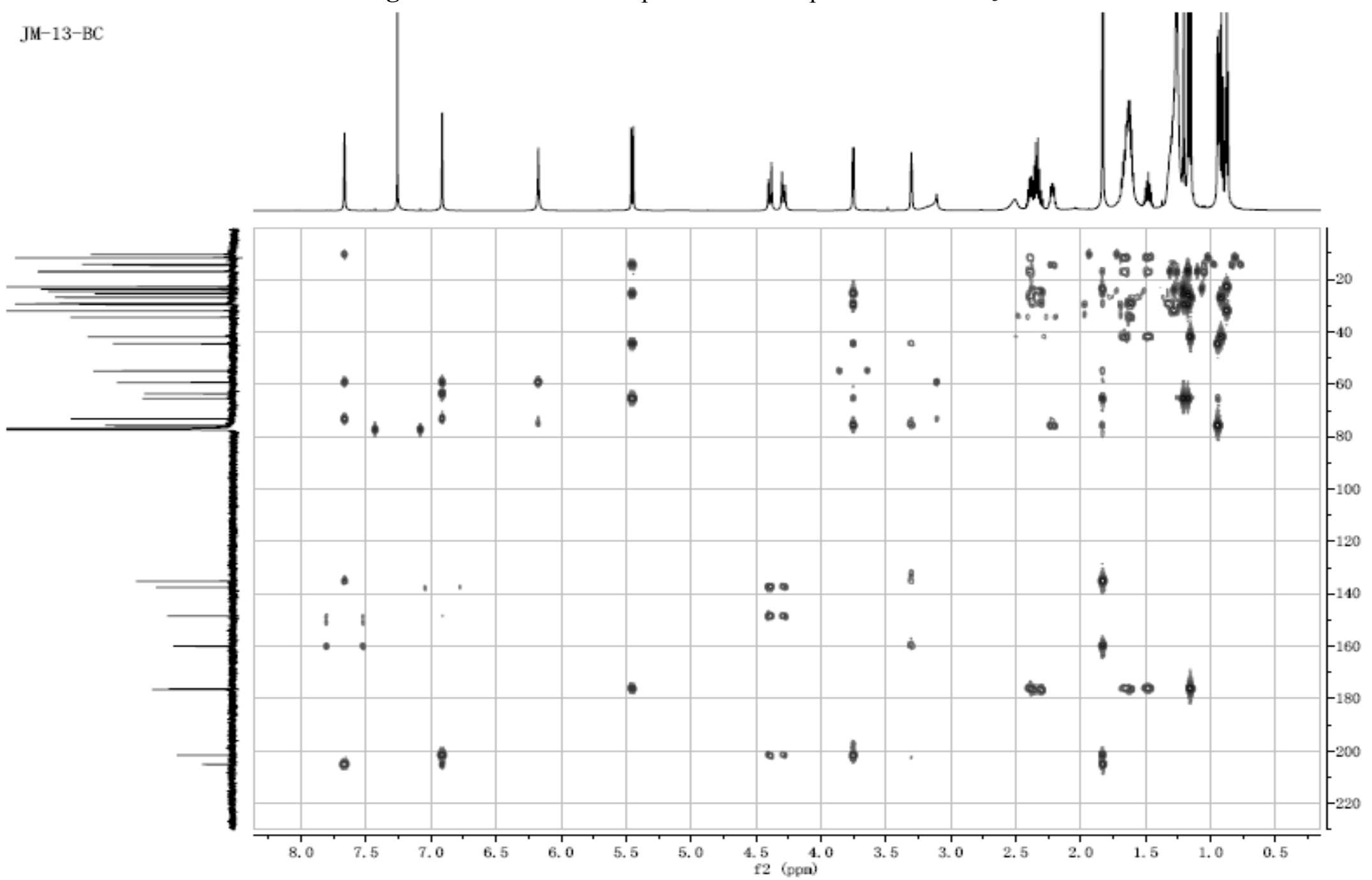


Figure S58. The ${ }^{1} \mathrm{H}-{ }^{1} \mathrm{H}$ COSY spectrum of compound 6 in $\mathrm{CDCl}_{3}$.

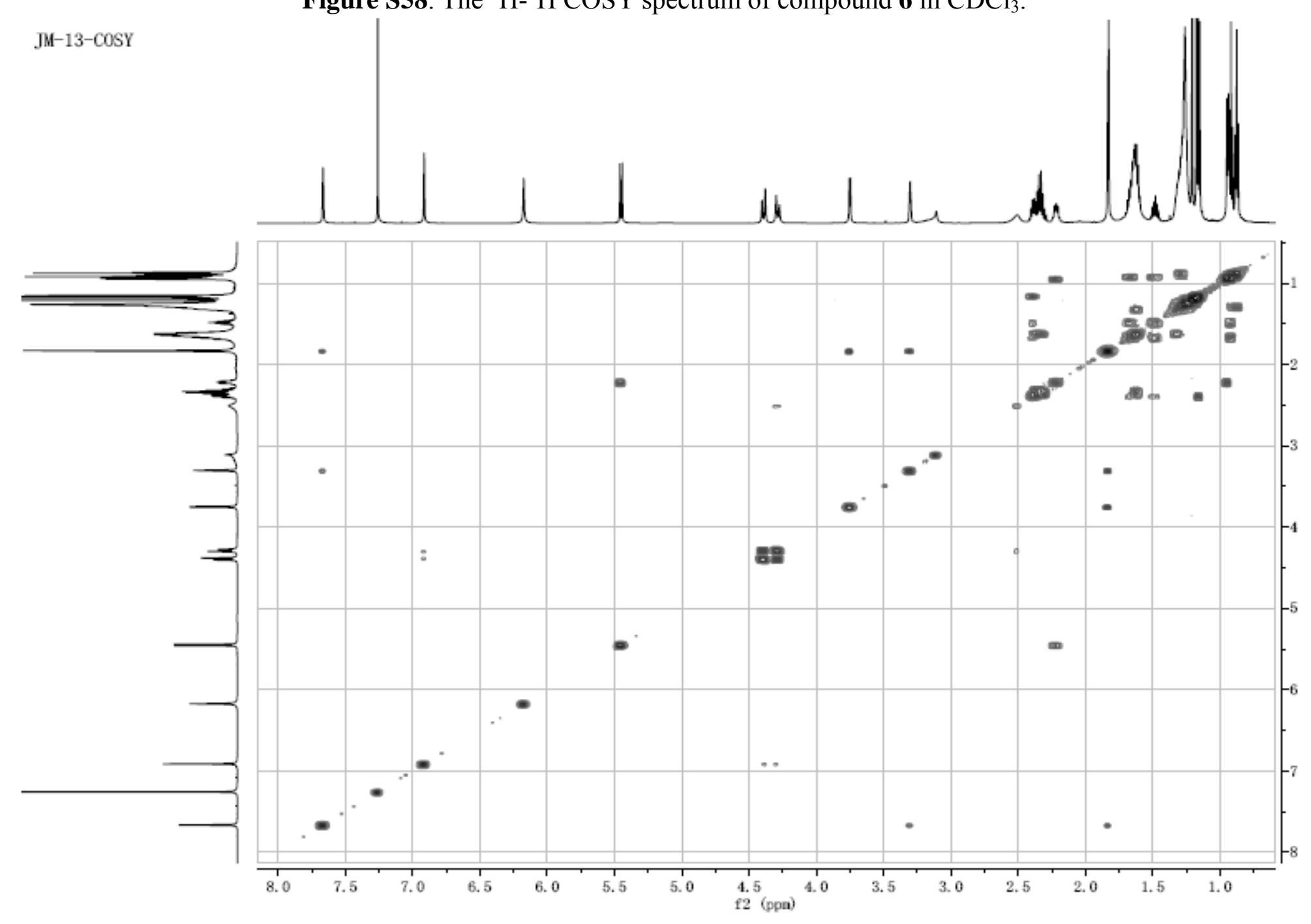


Figure S59. The ROESY spectrum of compound 6 in $\mathrm{CDCl}_{3}$.

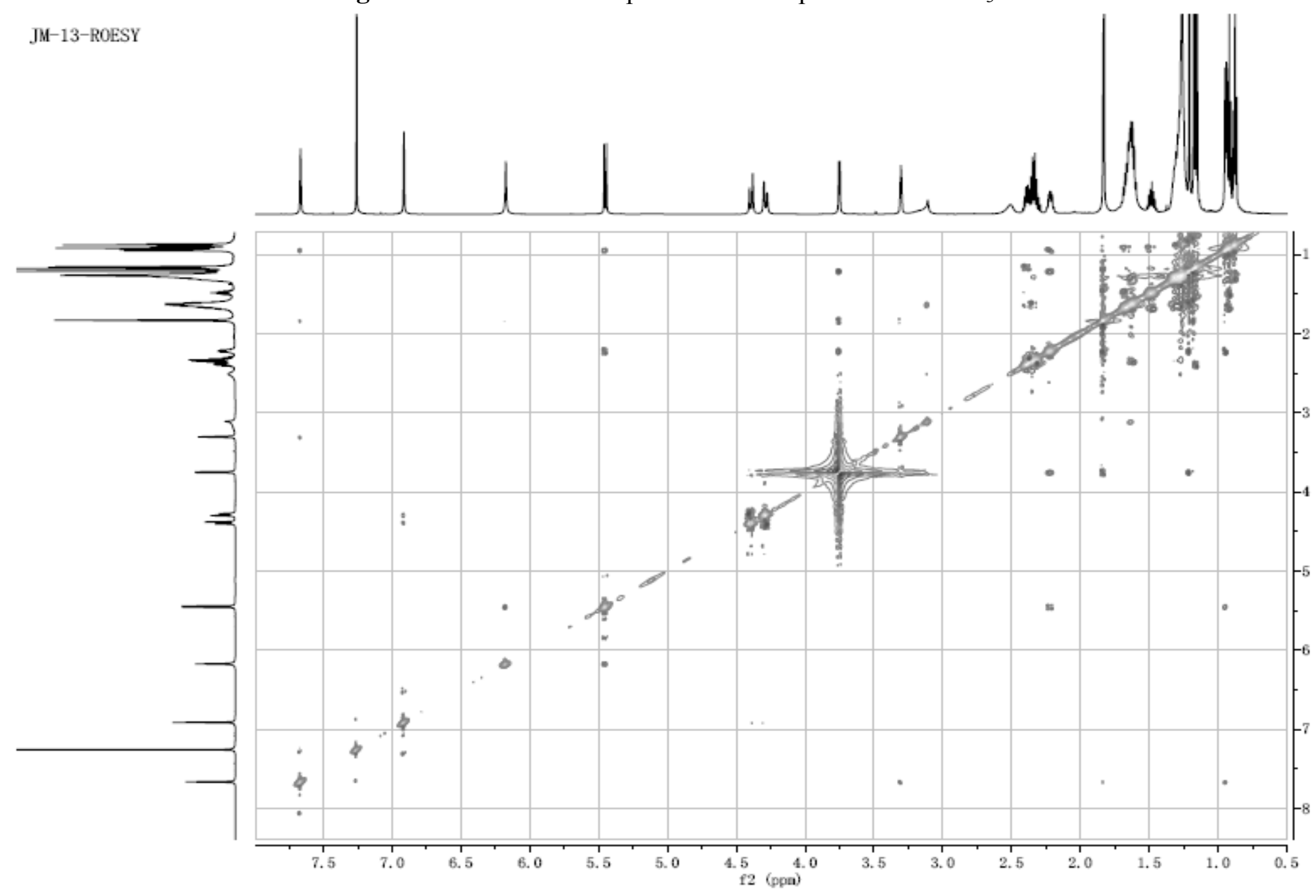




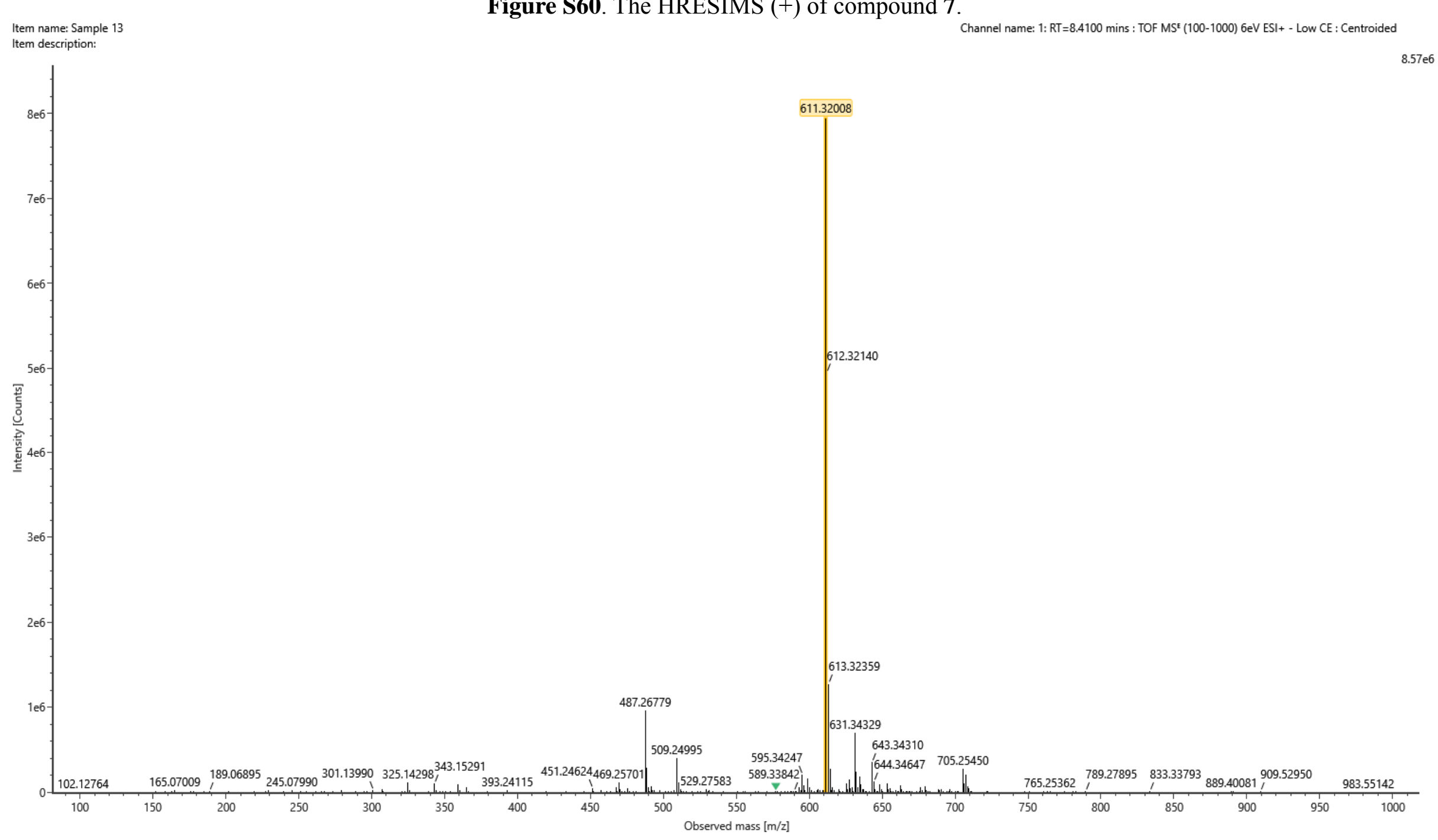


Figure S61. The IR spectrum of compound 7.

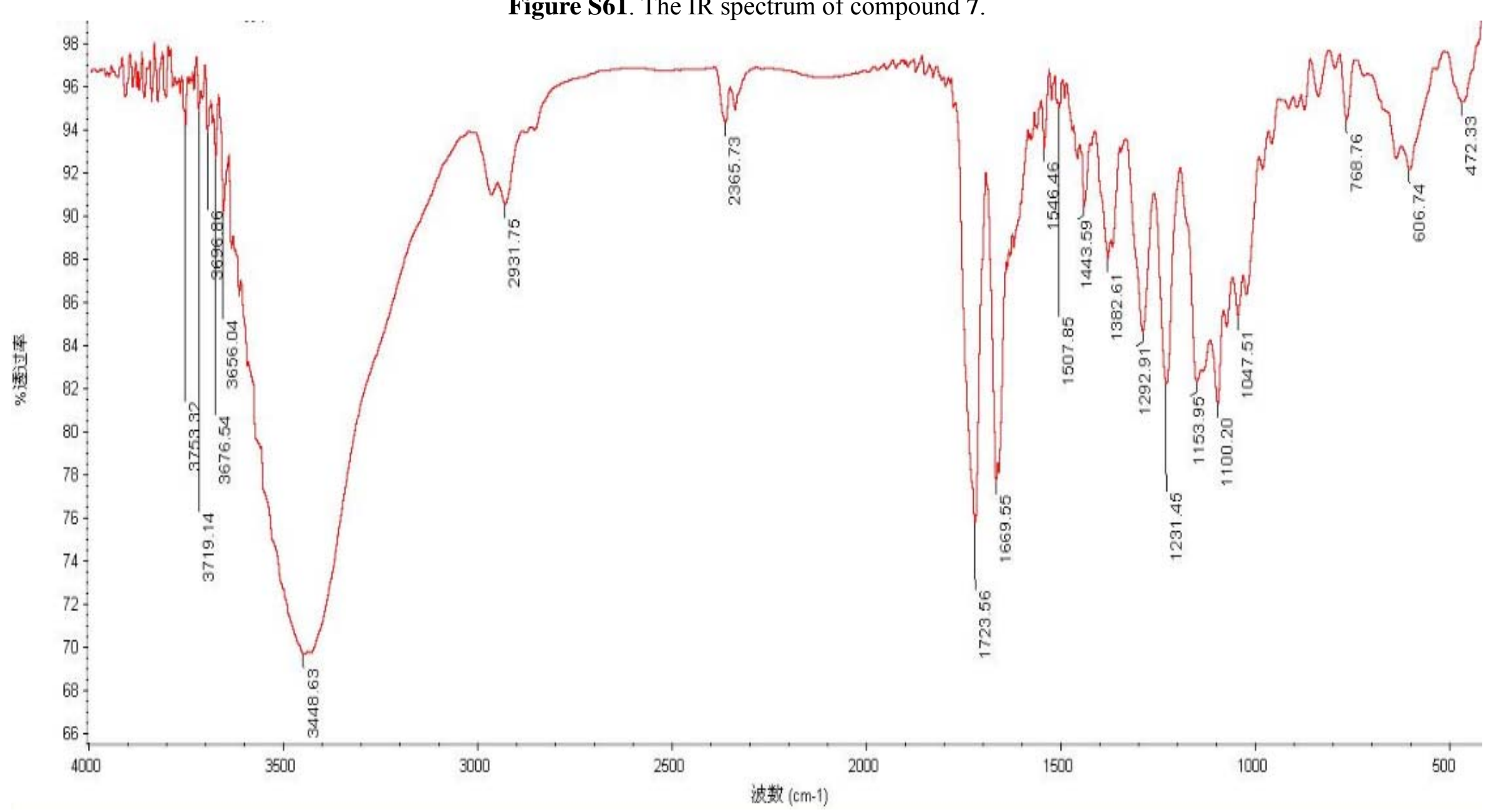


Figure S62. The CD spectrum of compound 7.

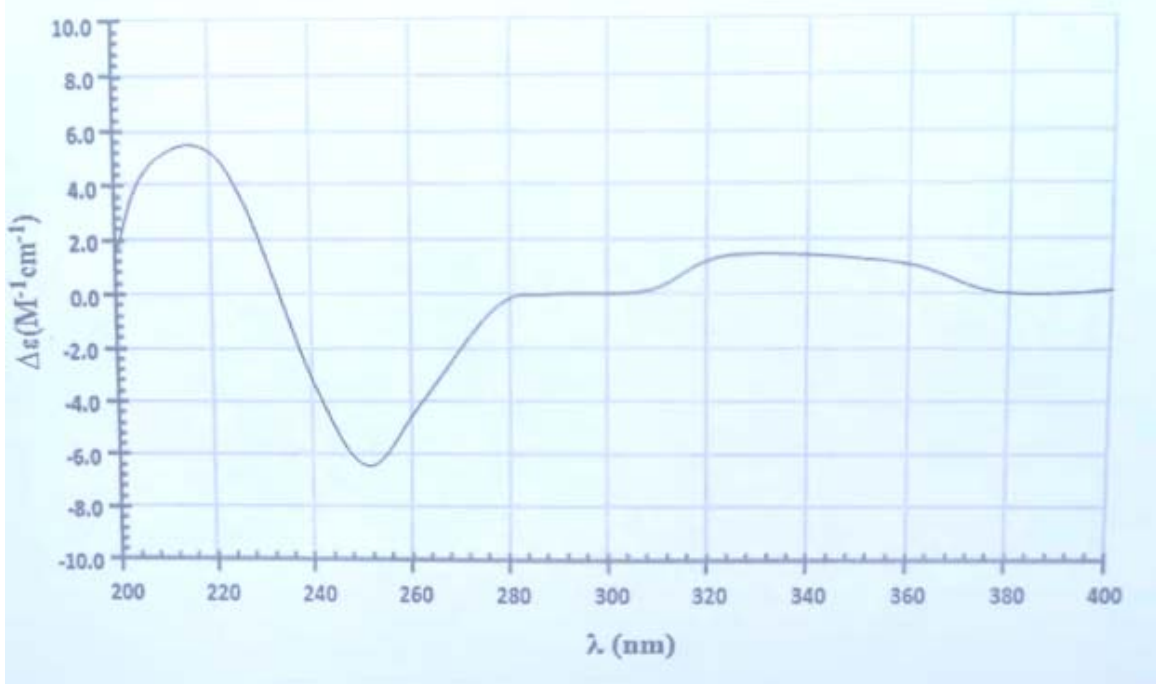


Figure S63. The ${ }^{1} \mathrm{H}$ NMR (600 MHz) spectrum of compound 7 in $\mathrm{CDCl}_{3}$.

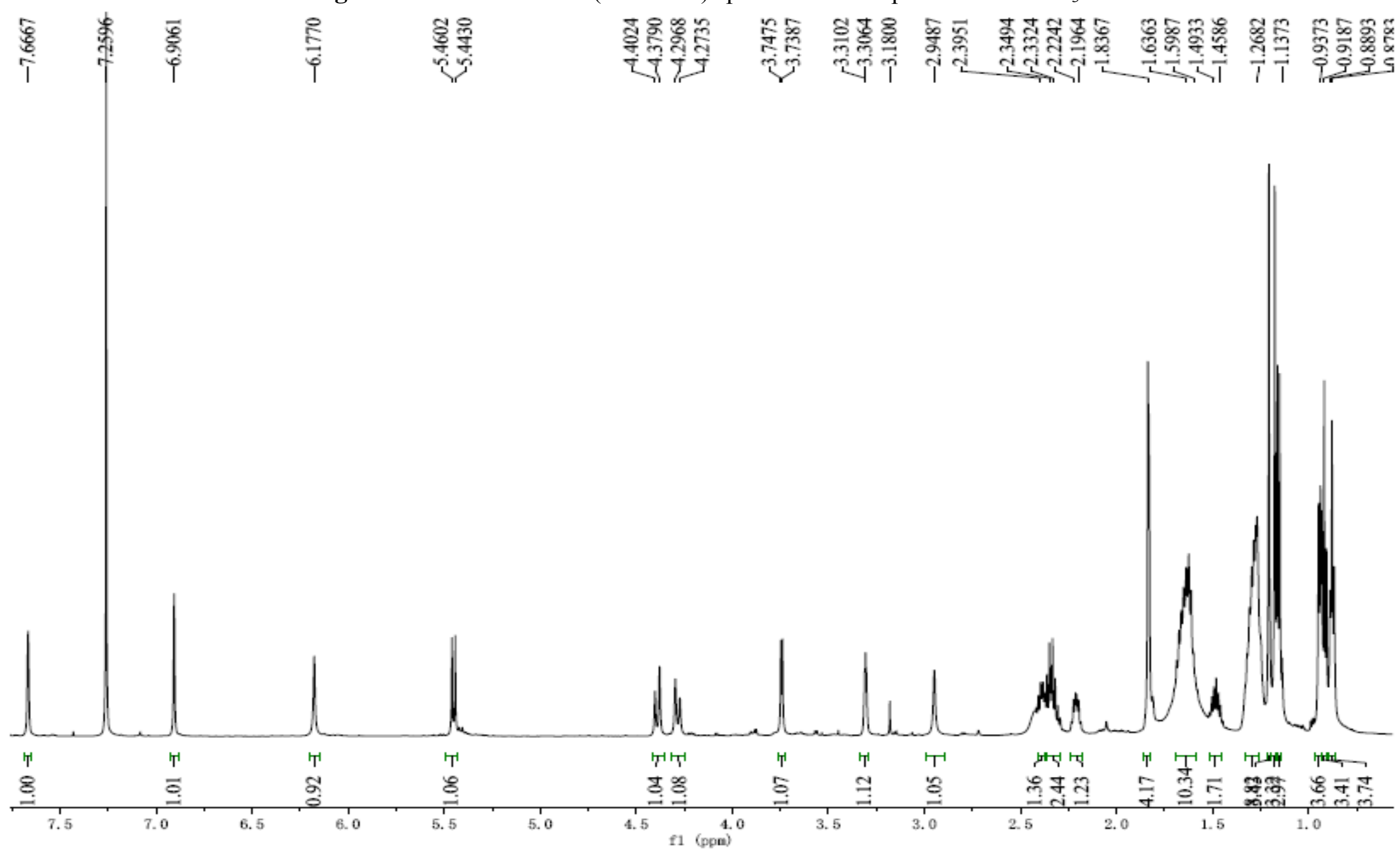


Figure S64. The ${ }^{13} \mathrm{C}$ NMR (150 MHz) spectrum of compound 7 in $\mathrm{CDCl}_{3}$.
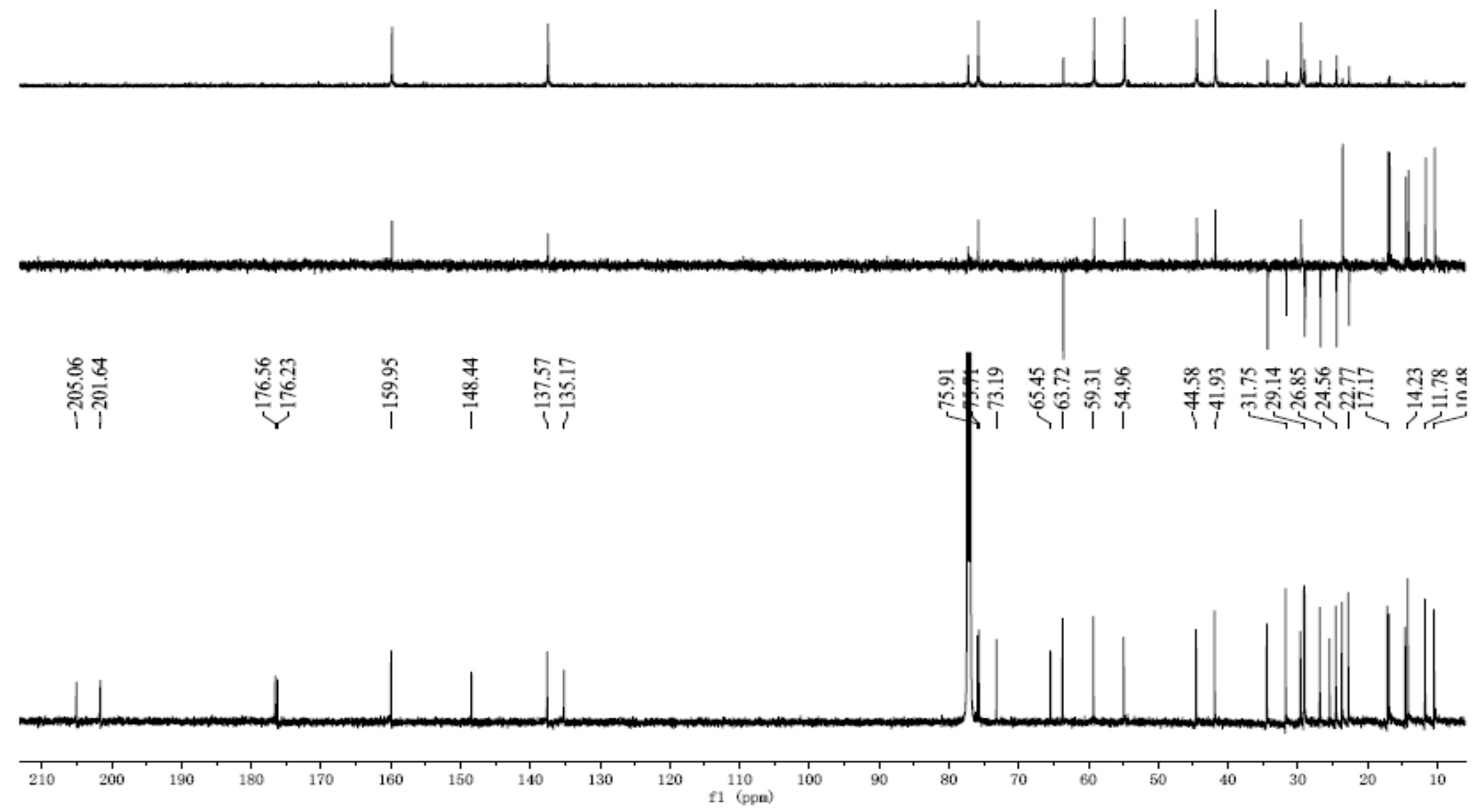
Figure S65. The enlarged ${ }^{13} \mathrm{C}$ NMR (150 MHz) spectrum of compound 7 in $\mathrm{CDCl}_{3}$.

JM-60-1-C
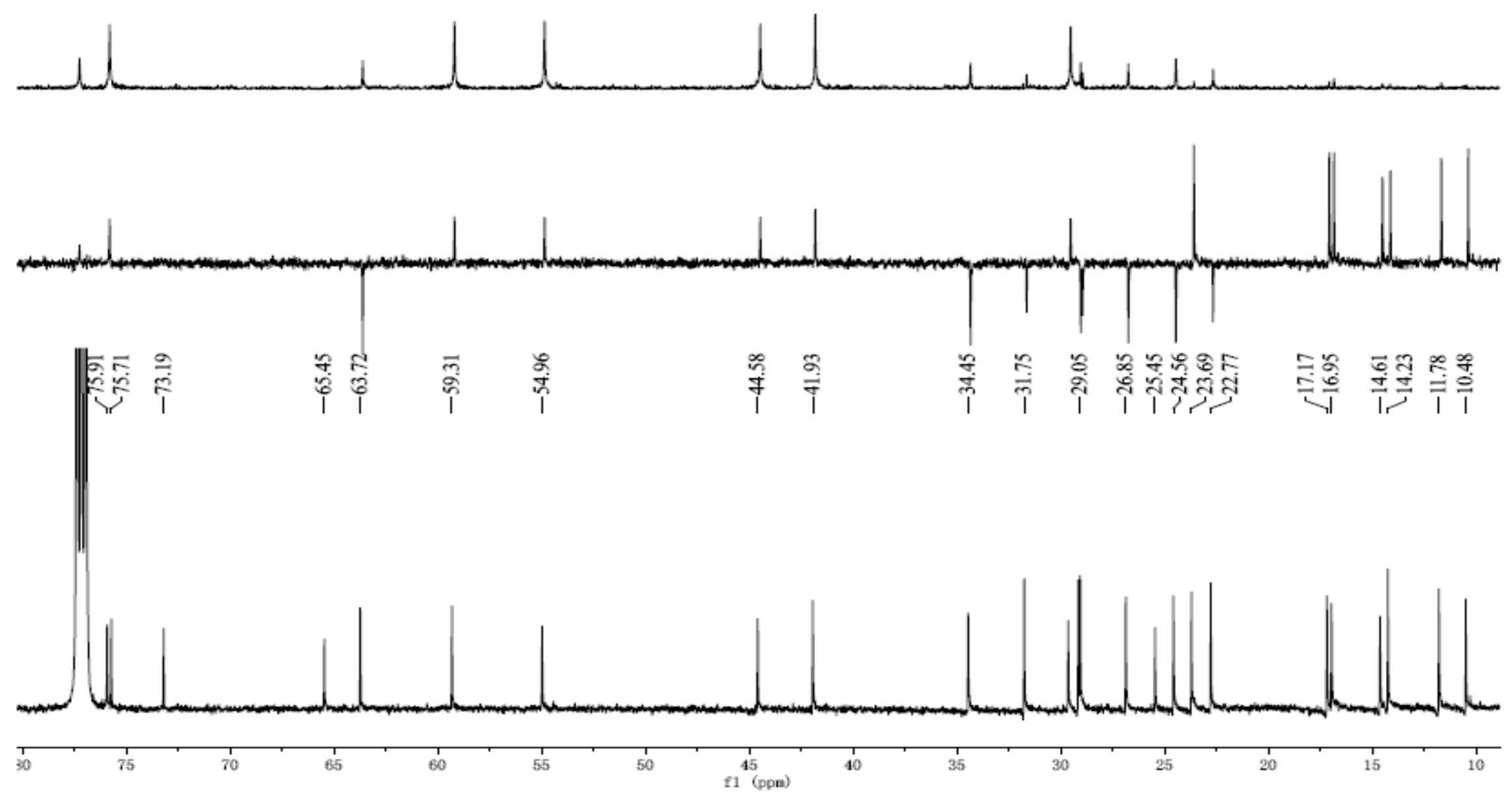
Figure S66. The HSQC spectrum of compound 7 in $\mathrm{CDCl}_{3}$.

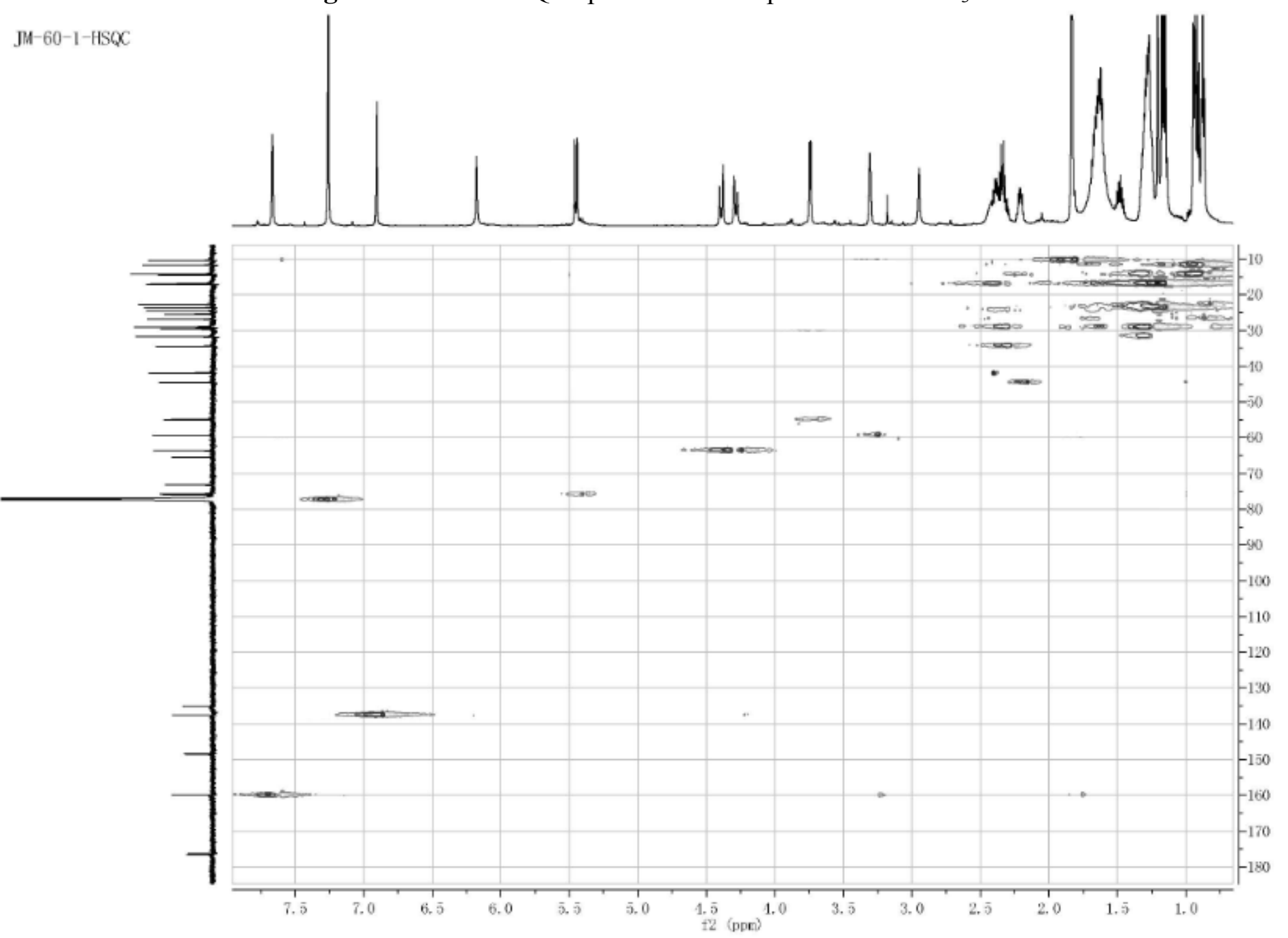


Figure S67. The HMBC spectrum of compound 7 in $\mathrm{CDCl}_{3}$.

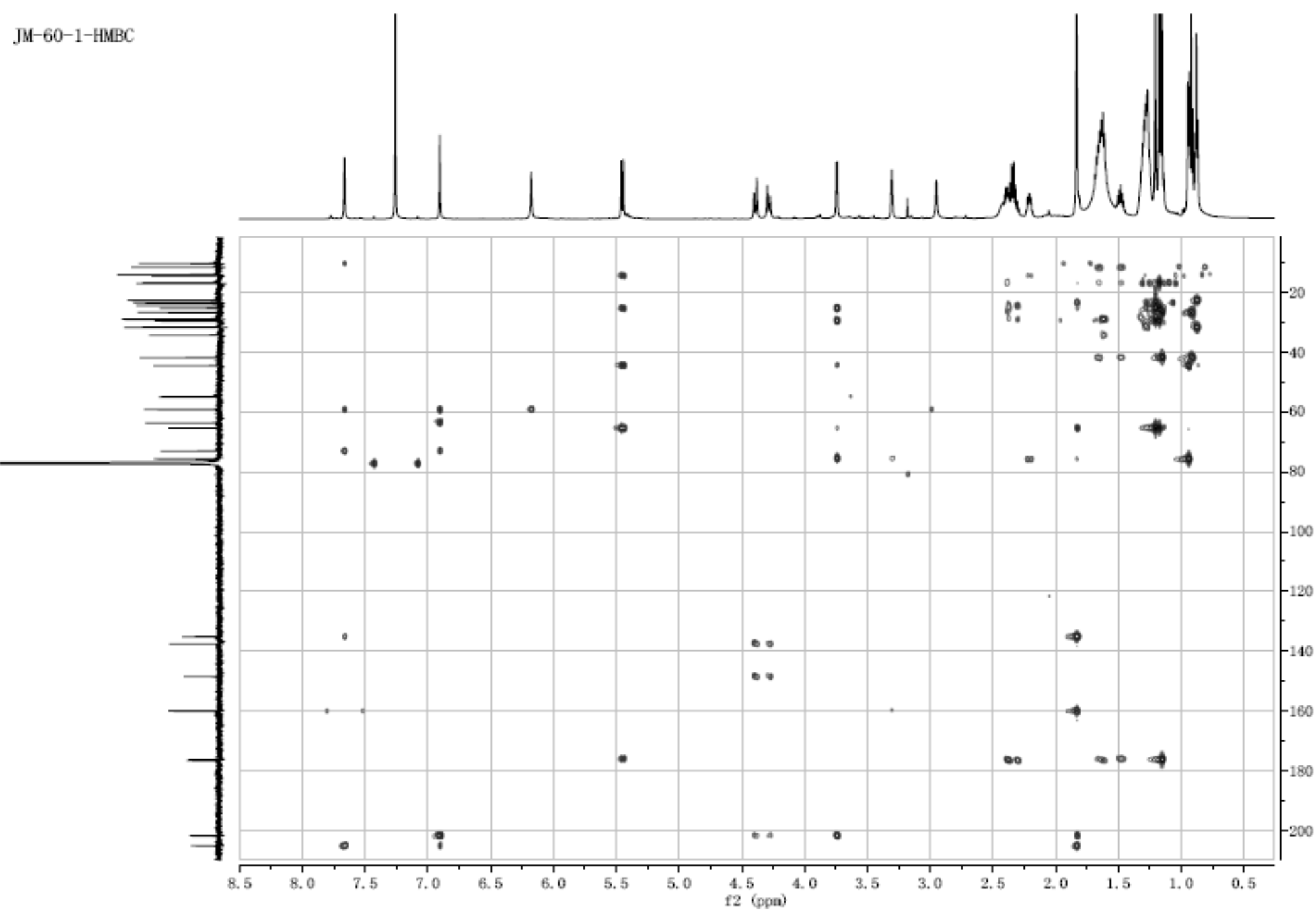


Figure S68. The ${ }^{1} \mathrm{H}-{ }^{1} \mathrm{H}$ COSY spectrum of compound 7 in $\mathrm{CDCl}_{3}$.

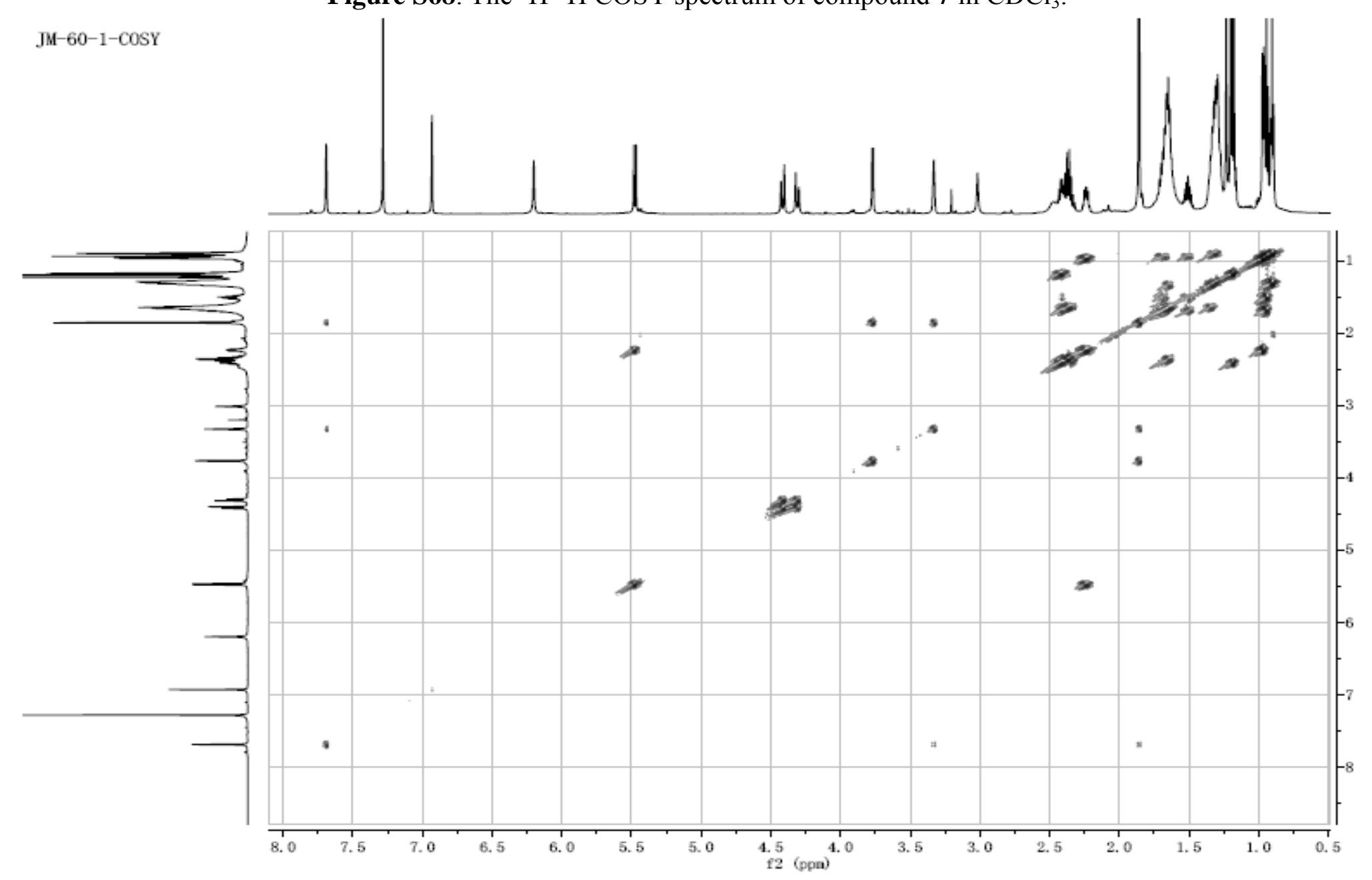


Figure S69. The ROESY spectrum of compound 7 in $\mathrm{CDCl}_{3}$.

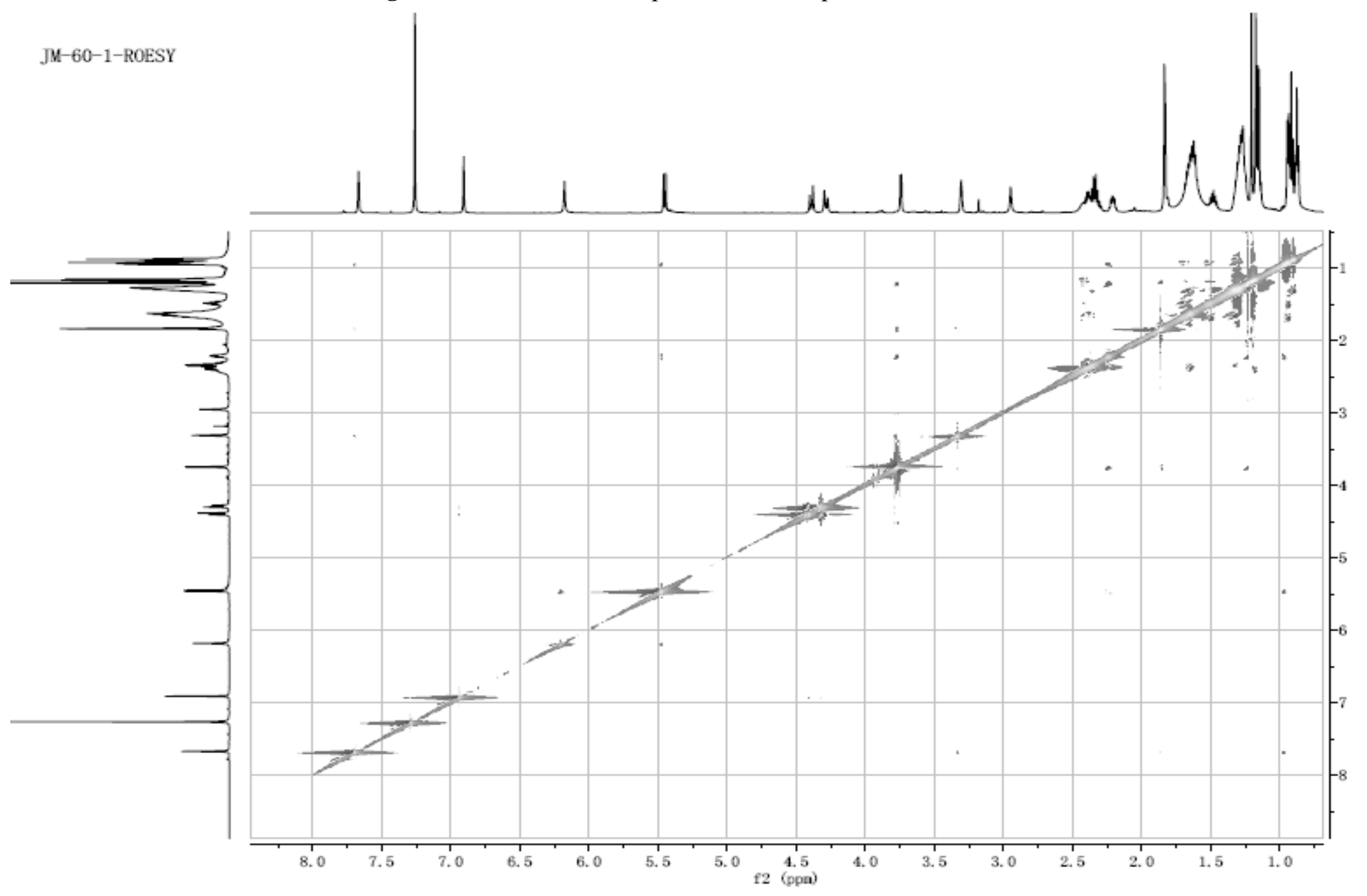


Figure S70. The HRESIMS $(+)$ of compound 8.

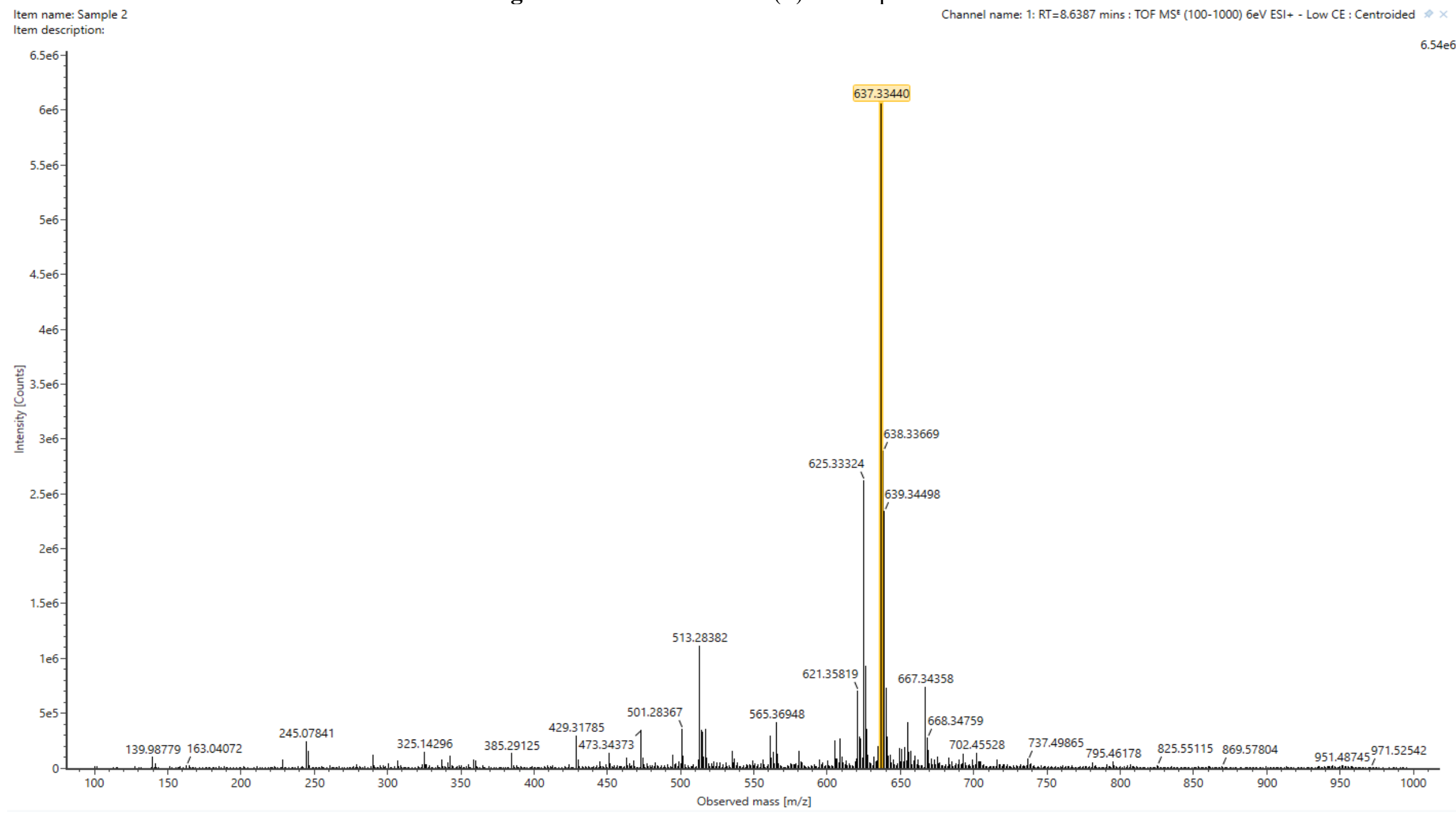




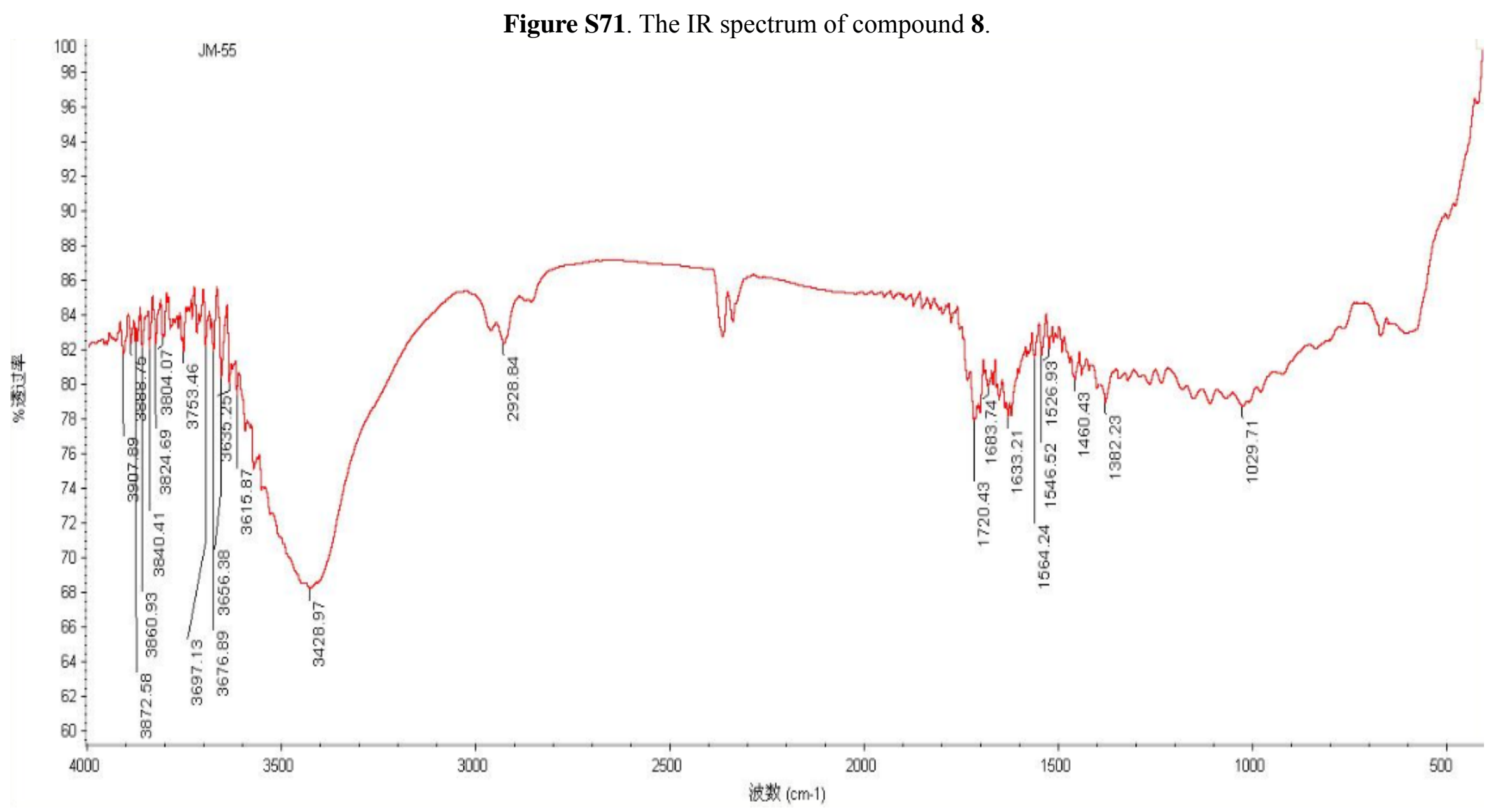


Figure S72. The CD spectrum of compound 8.

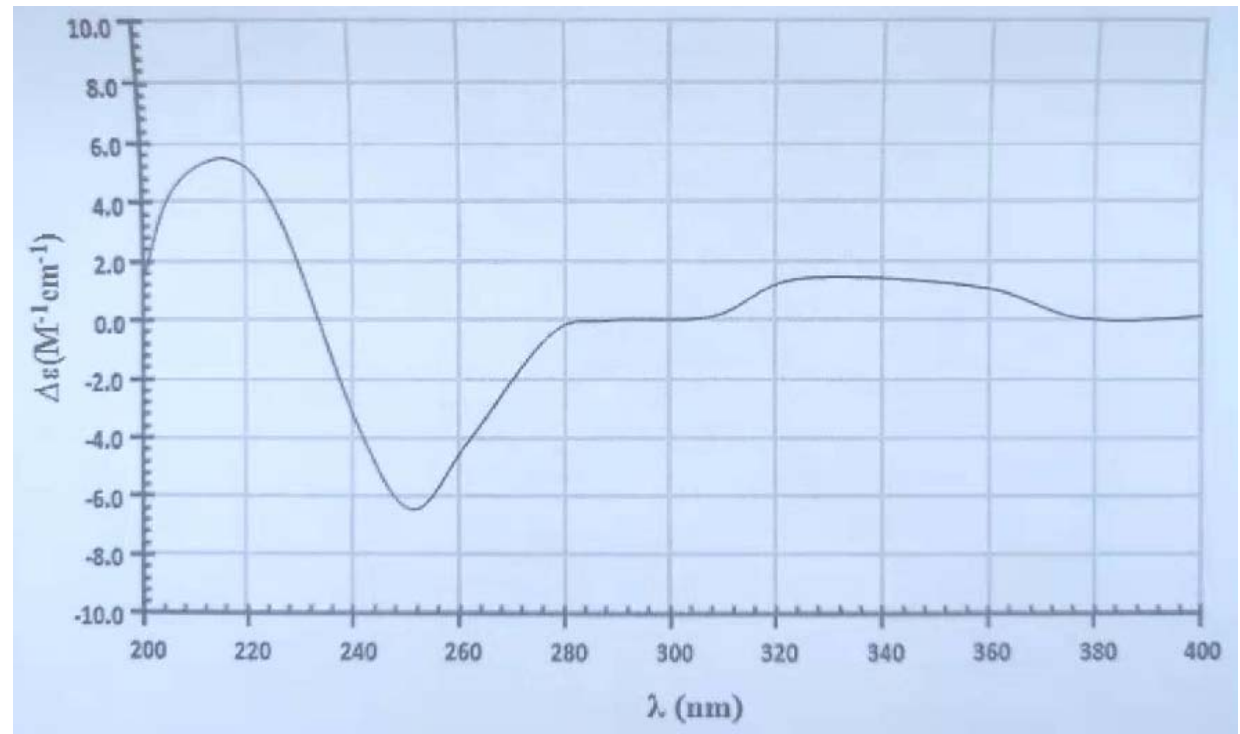




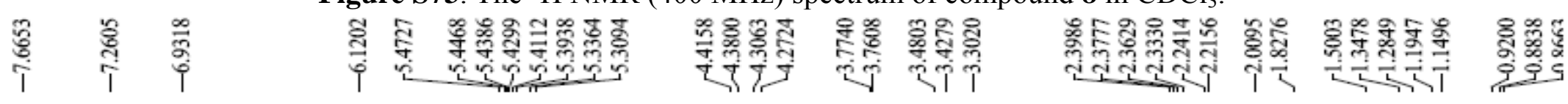

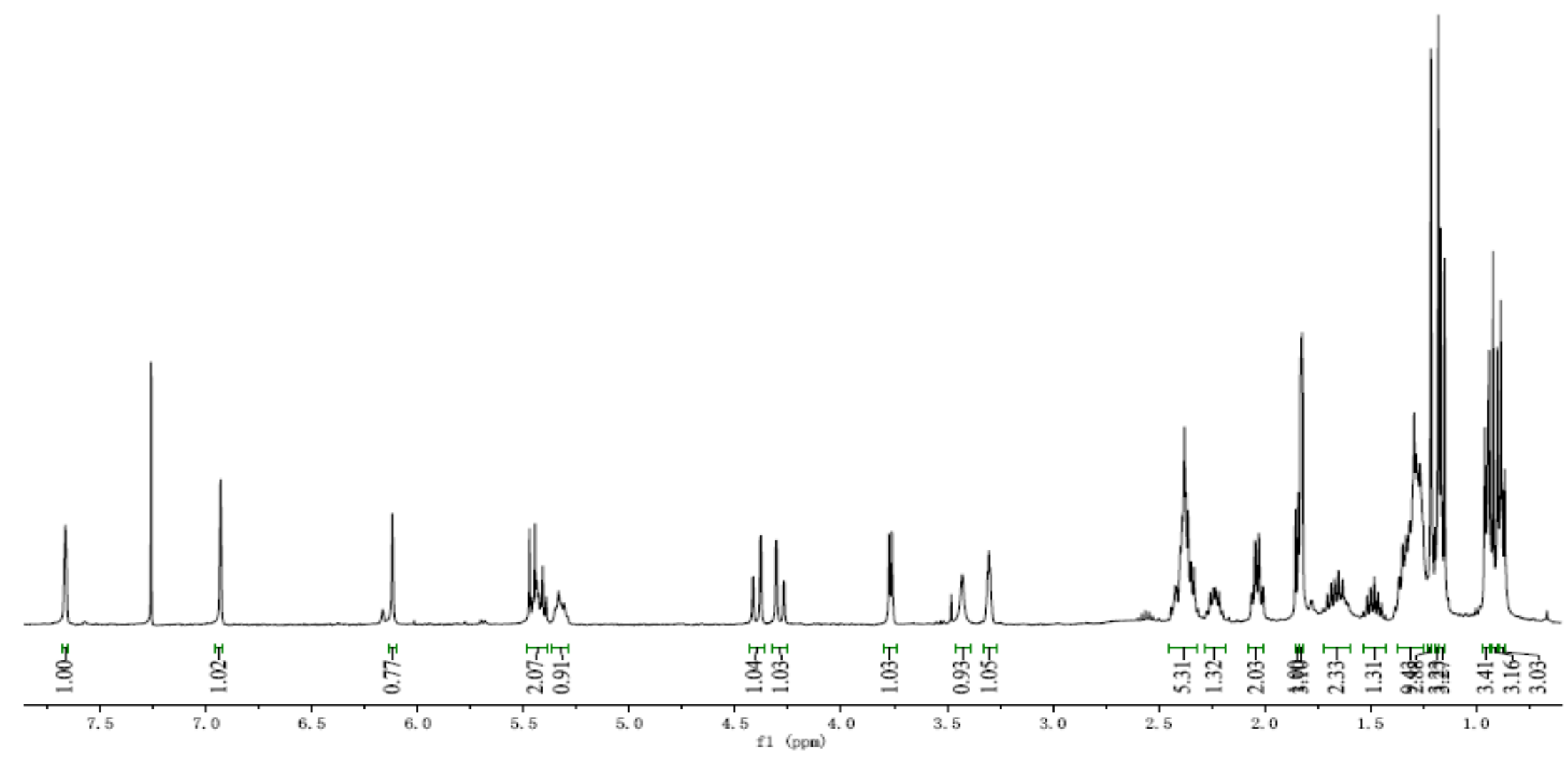


Figure S74. The ${ }^{13} \mathrm{C}$ NMR $(100 \mathrm{MHz})$ spectrum of compound 8 in $\mathrm{CDCl}_{3}$.
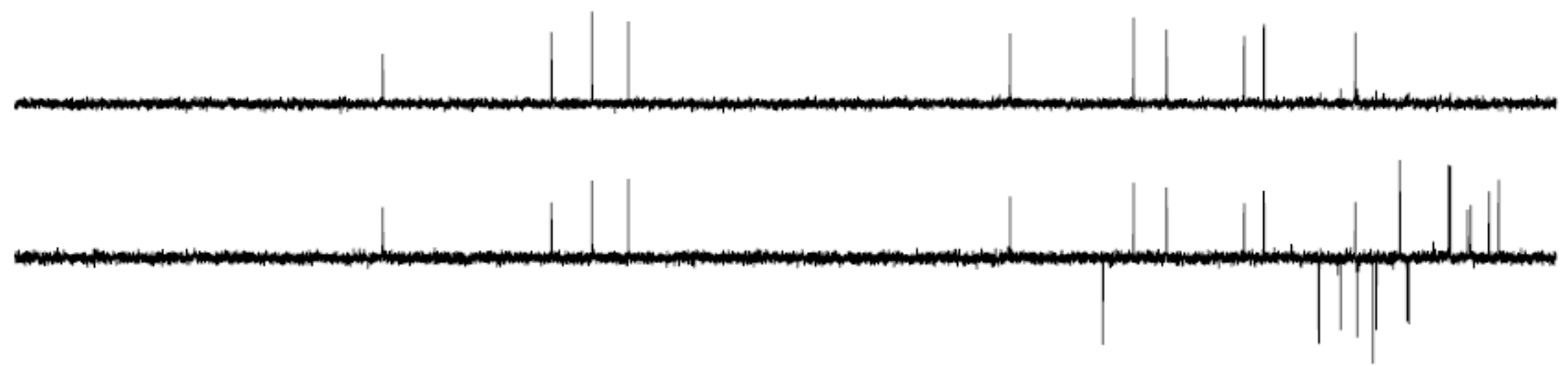

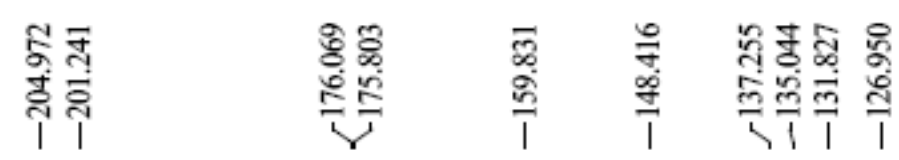
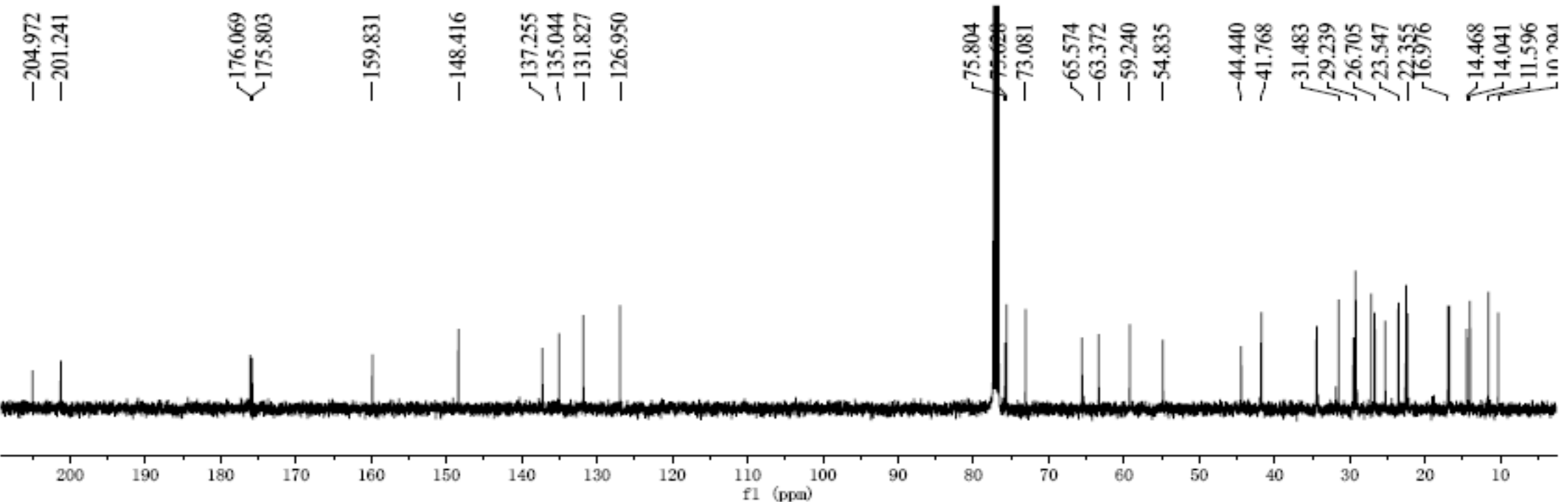
Figure S75. The enlarged ${ }^{13} \mathrm{C}$ NMR (100 MHz) spectrum of compound 8 in $\mathrm{CDCl}_{3}$.
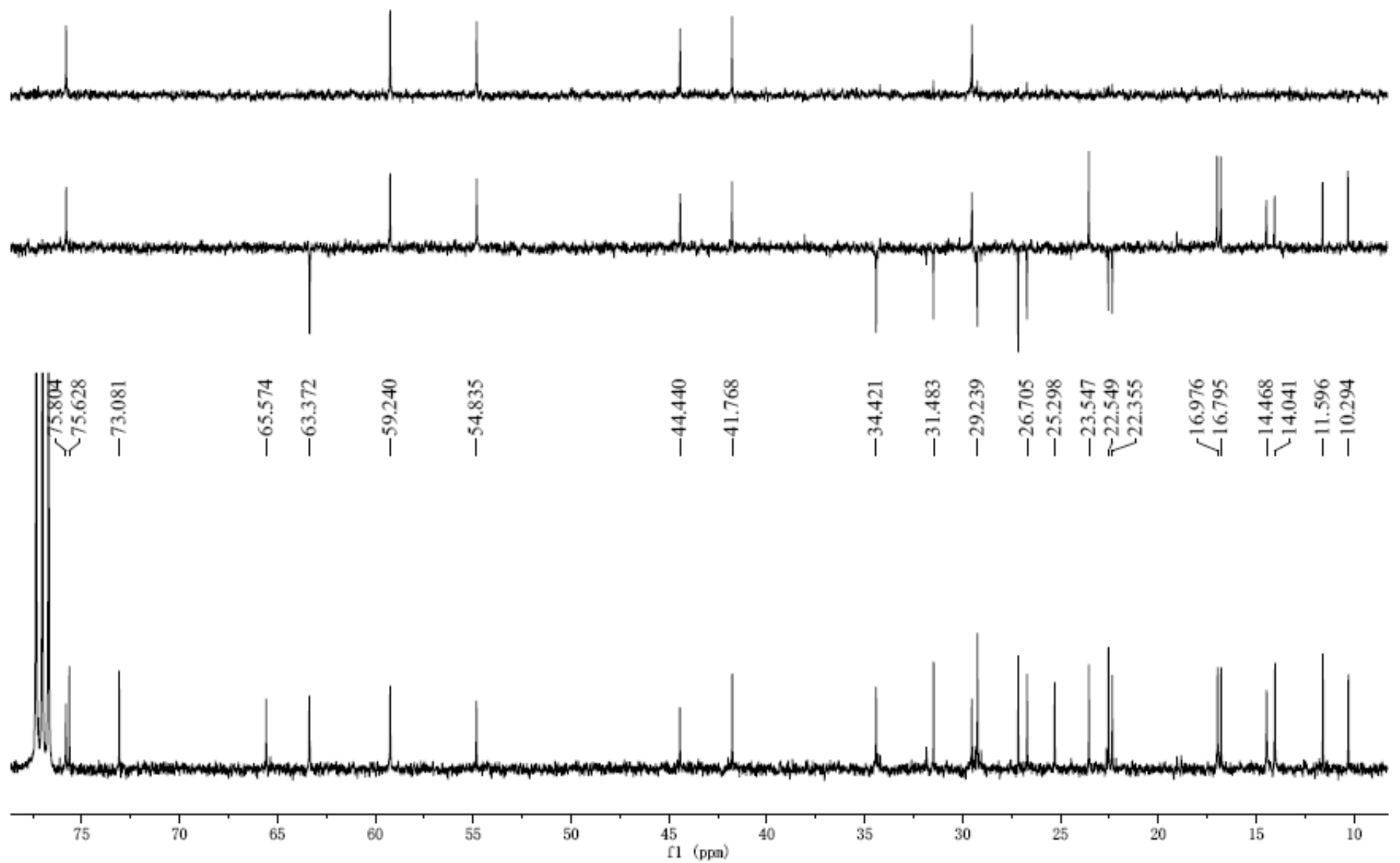
Figure S76. The HSQC spectrum of compound 8 in $\mathrm{CDCl}_{3}$.

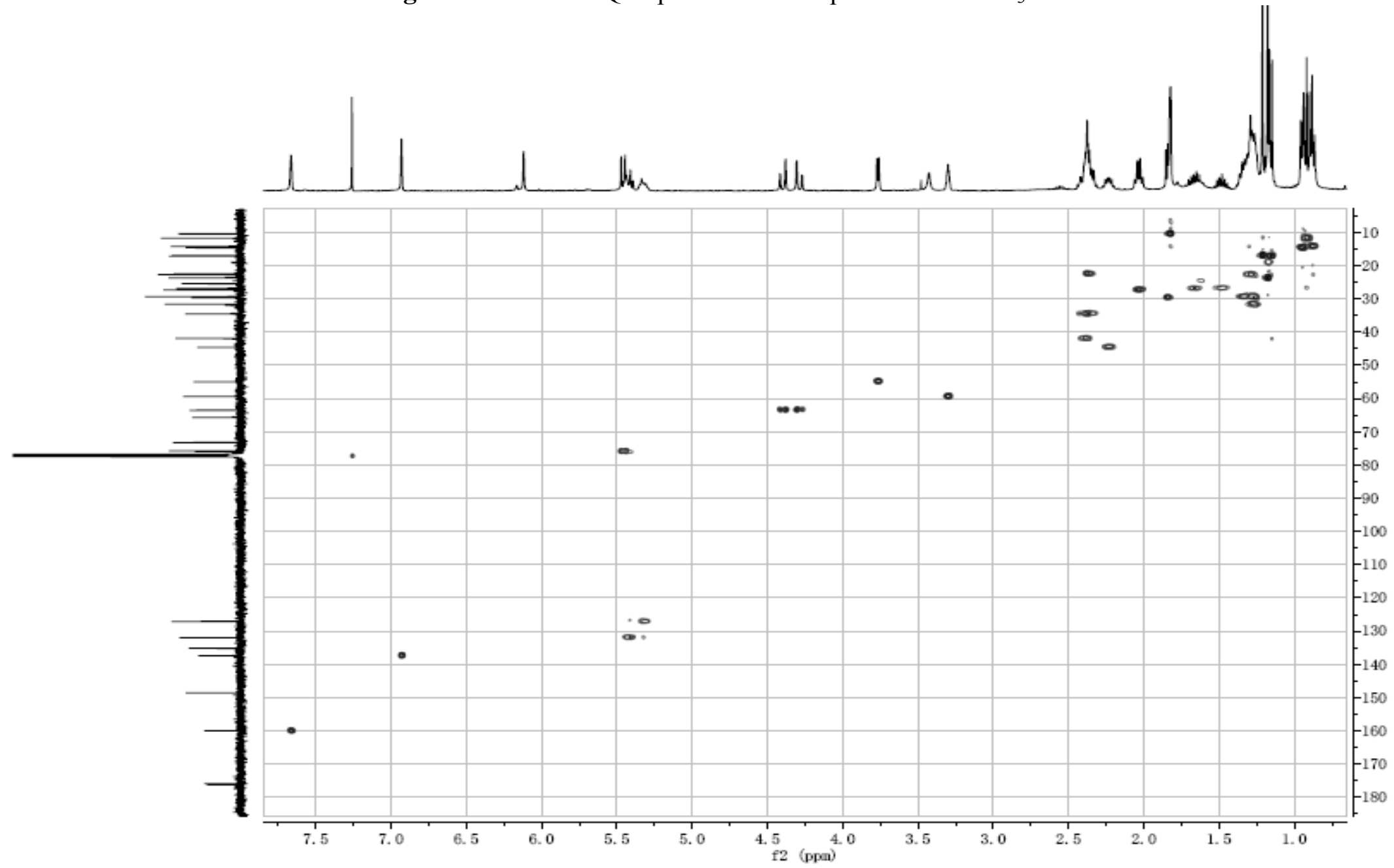


Figure S77. The HMBC spectrum of compound 8 in $\mathrm{CDCl}_{3}$.

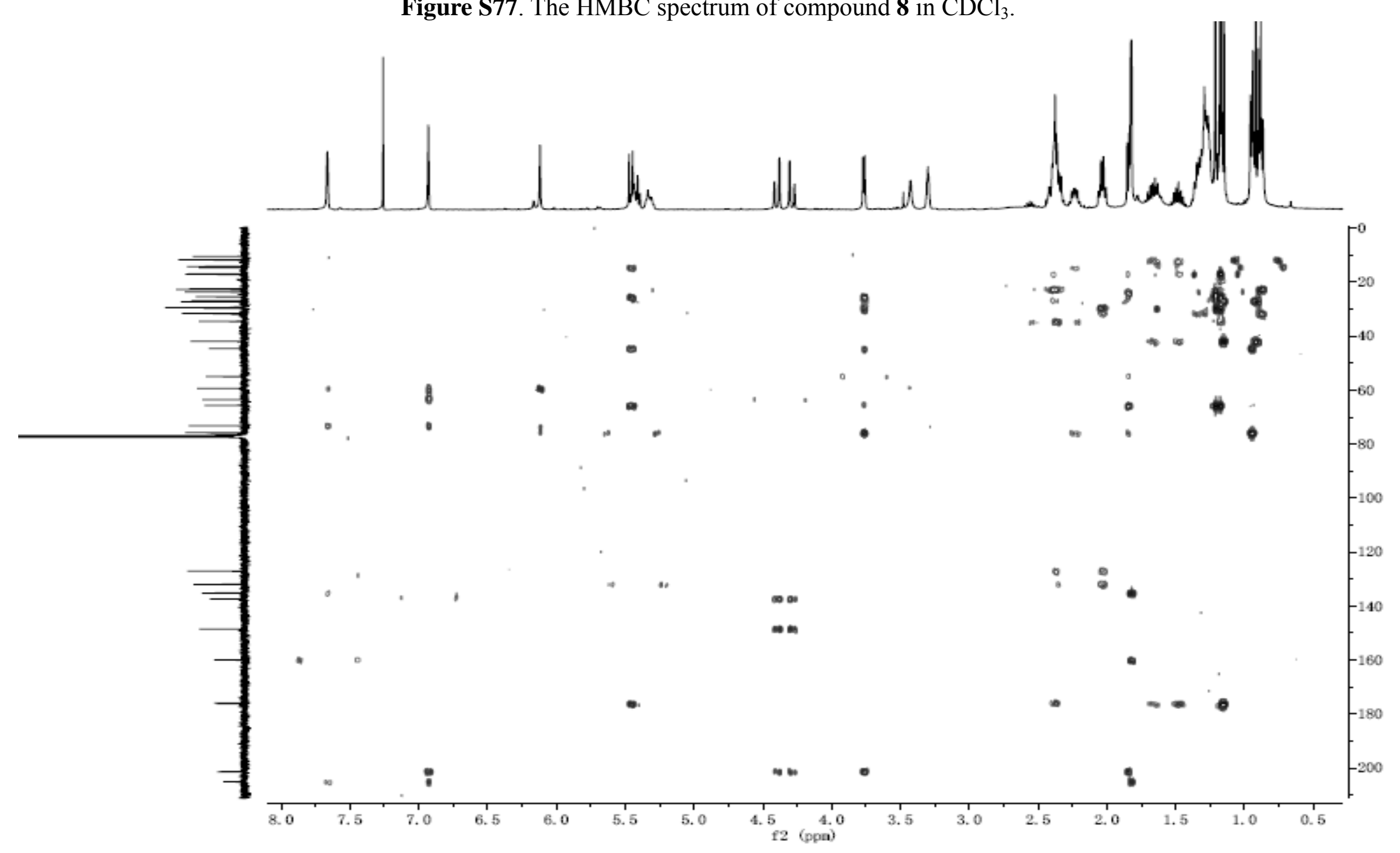


Figure S78. The ${ }^{1} \mathrm{H}-{ }^{1} \mathrm{H}$ COSY spectrum of compound 8 in $\mathrm{CDCl}_{3}$.

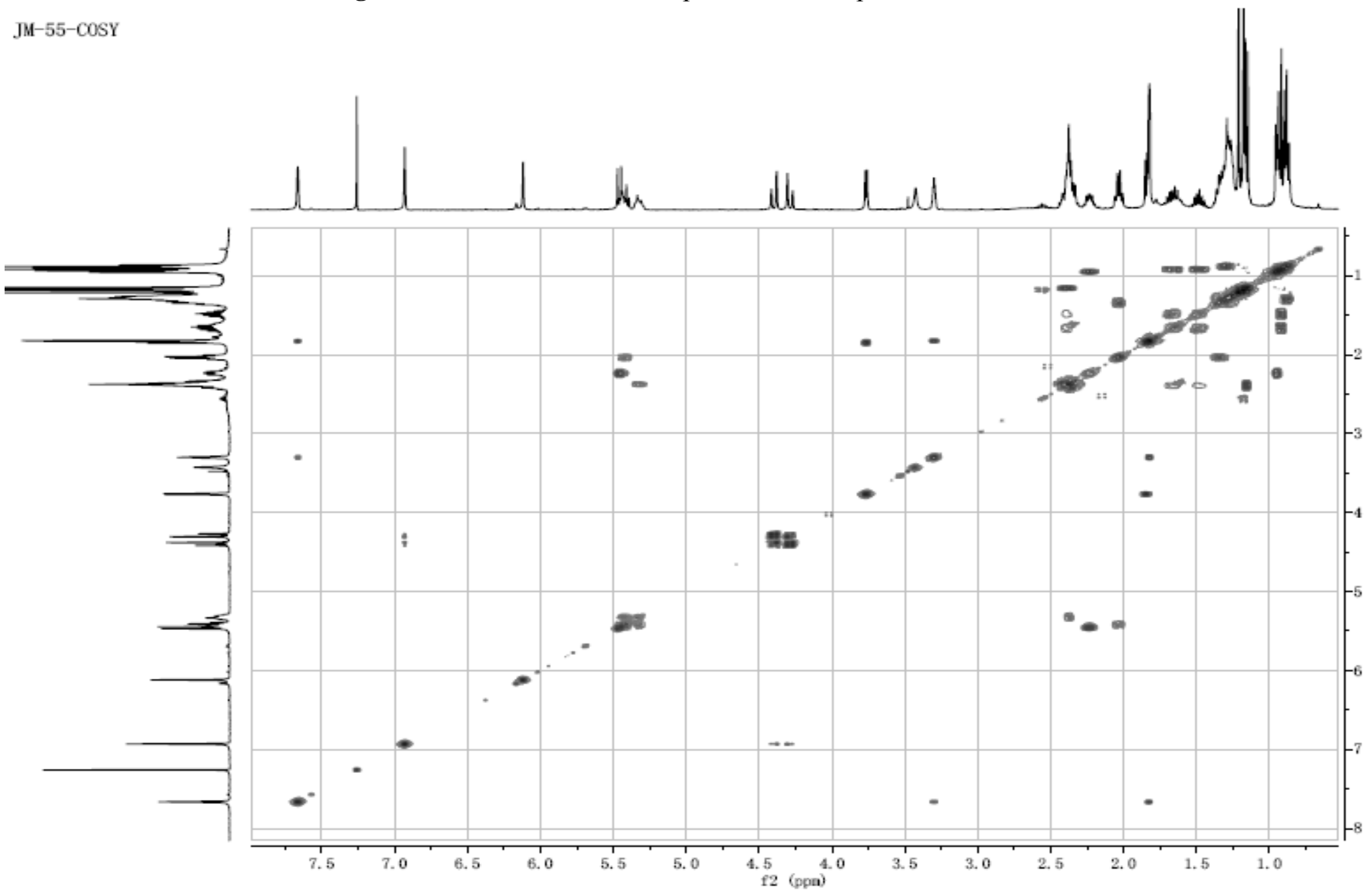


Figure S79. The ROESY spectrum of compound 8 in $\mathrm{CDCl}_{3}$.

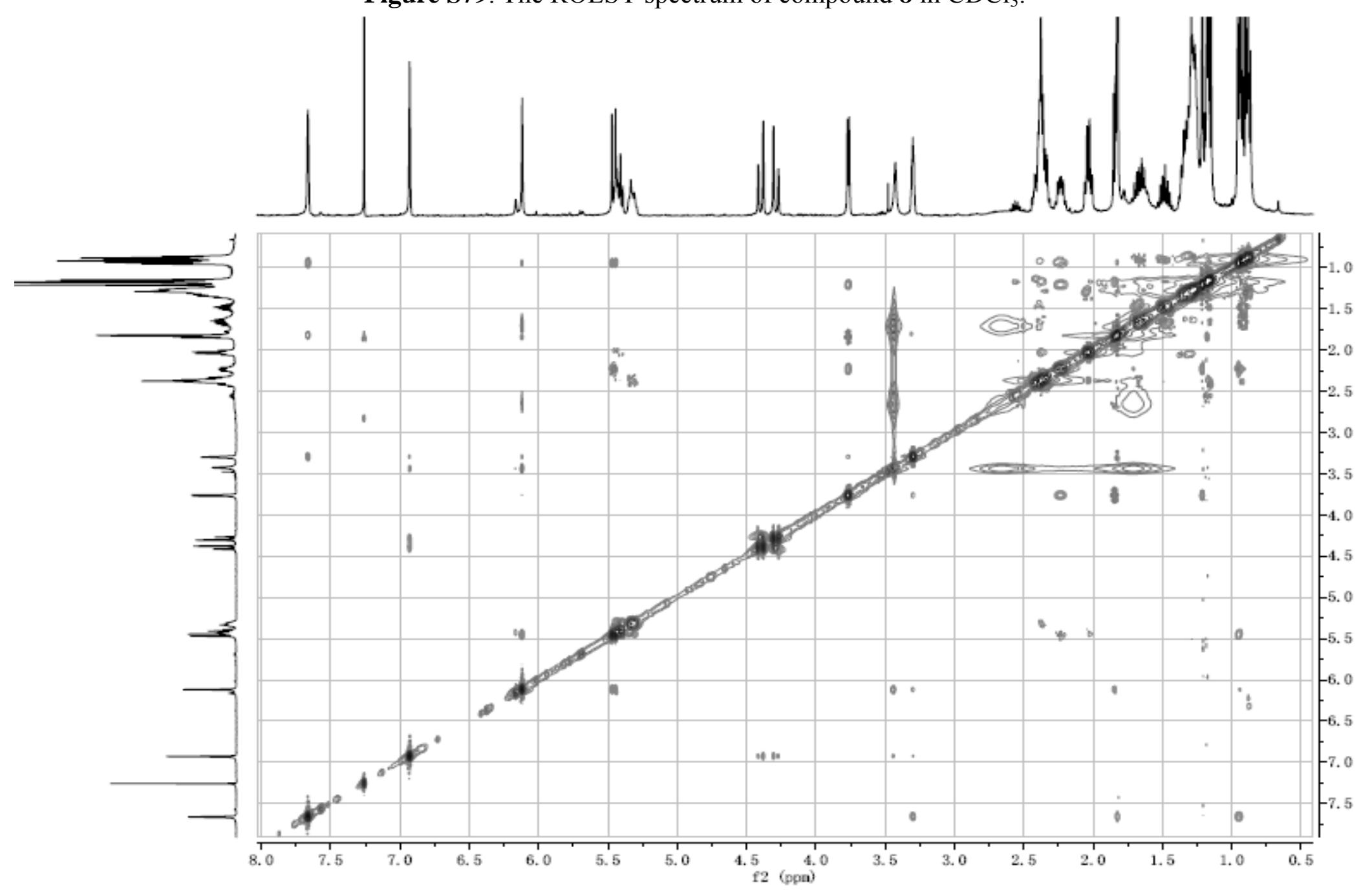


Figure S80. The HRESIMS $(+)$ of compound $\mathbf{9}$.

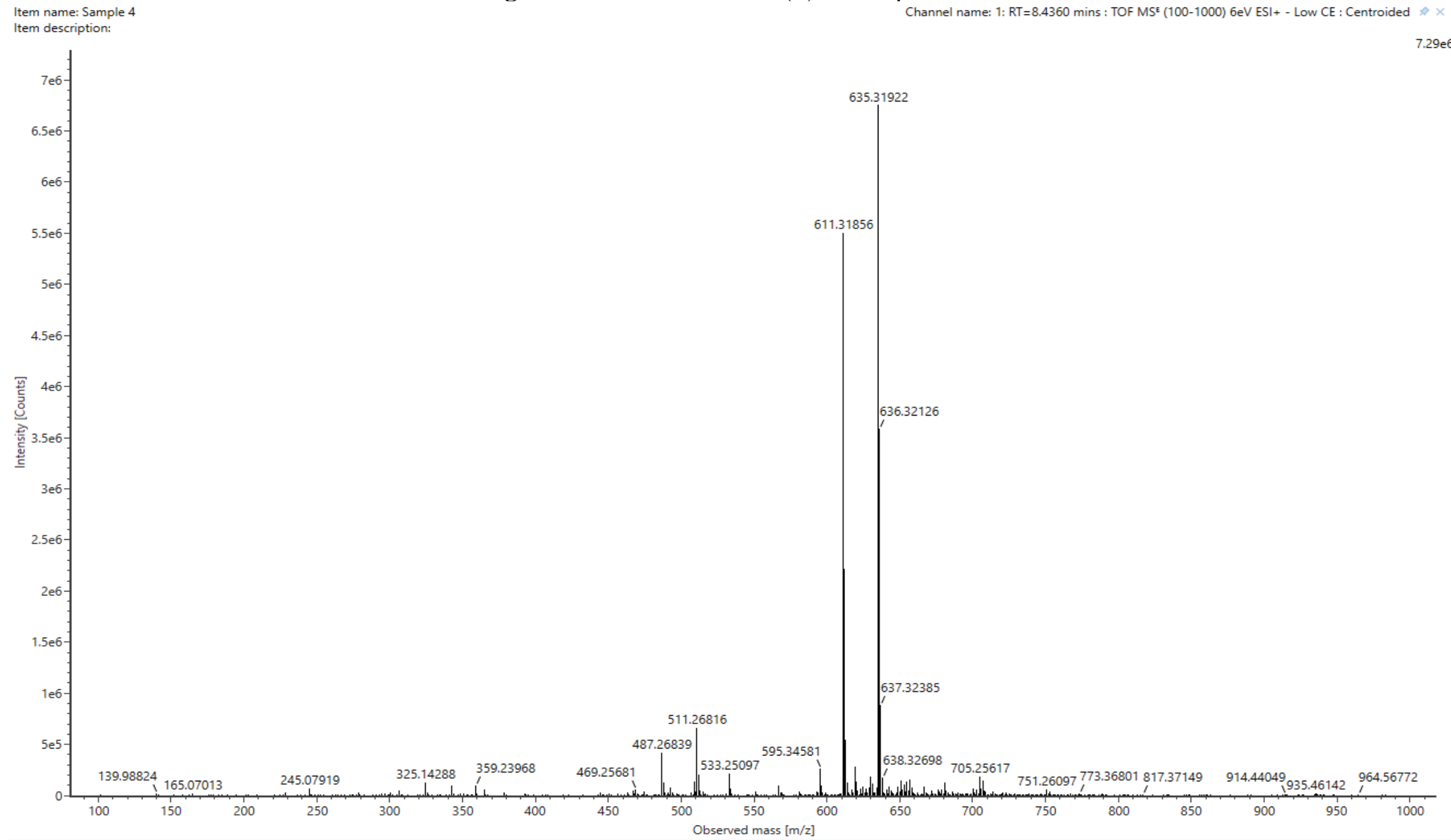


Figure S81. The IR spectrum of compound 9.

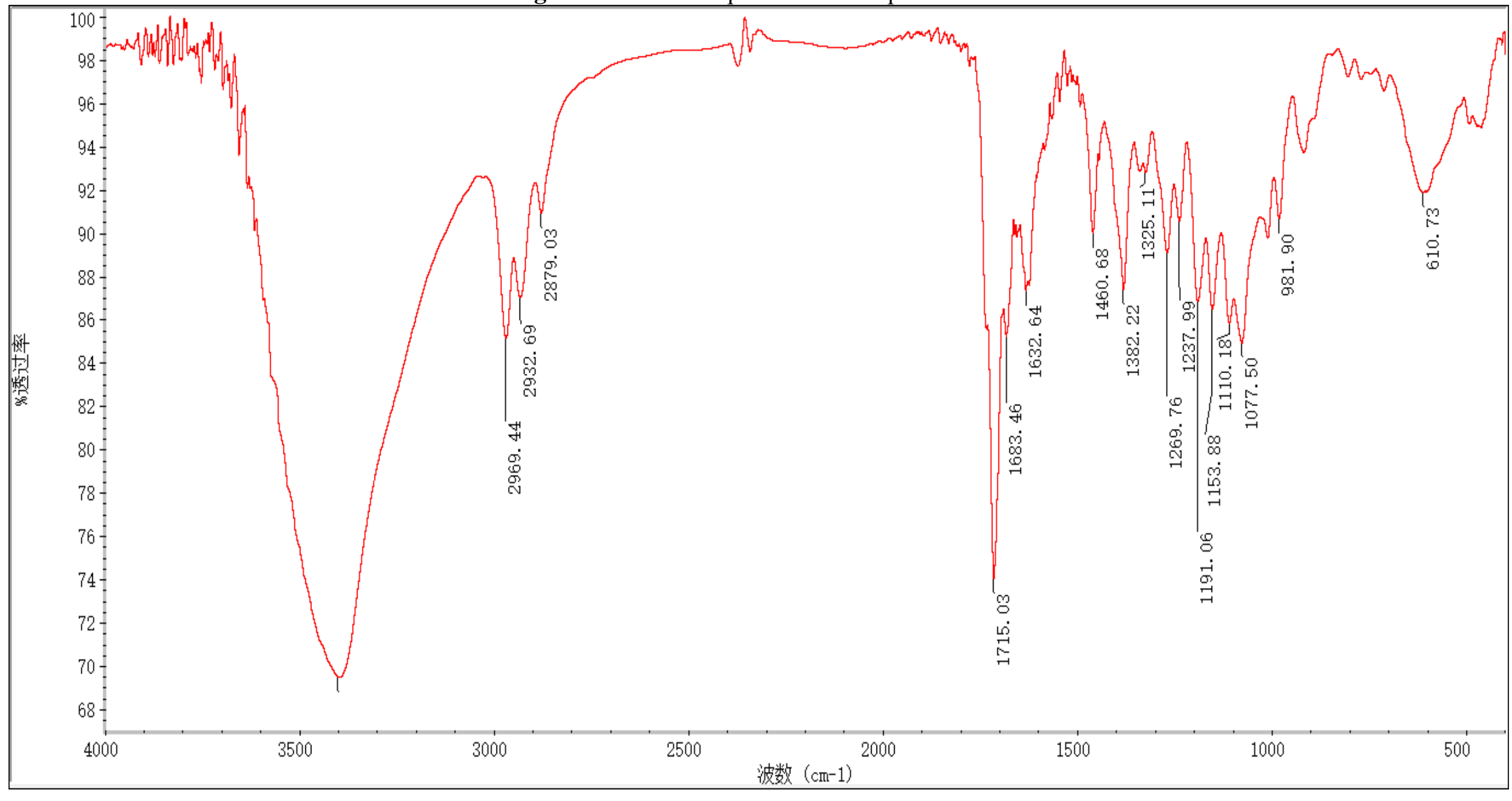


Figure S82. The CD spectrum of compound $\mathbf{9}$.

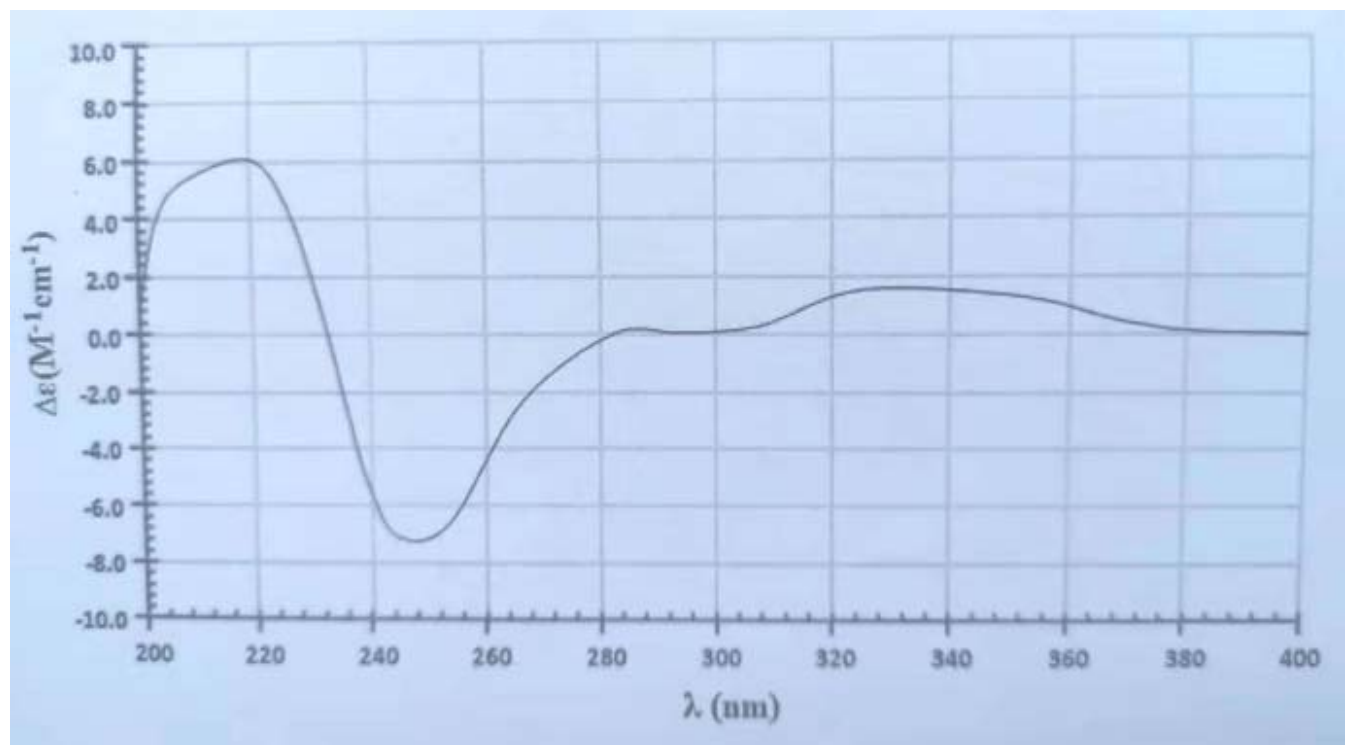


Figure S83. The ${ }^{1} \mathrm{H}$ NMR (600 MHz) spectrum of compound 9 in $\mathrm{CDCl}_{3}$.

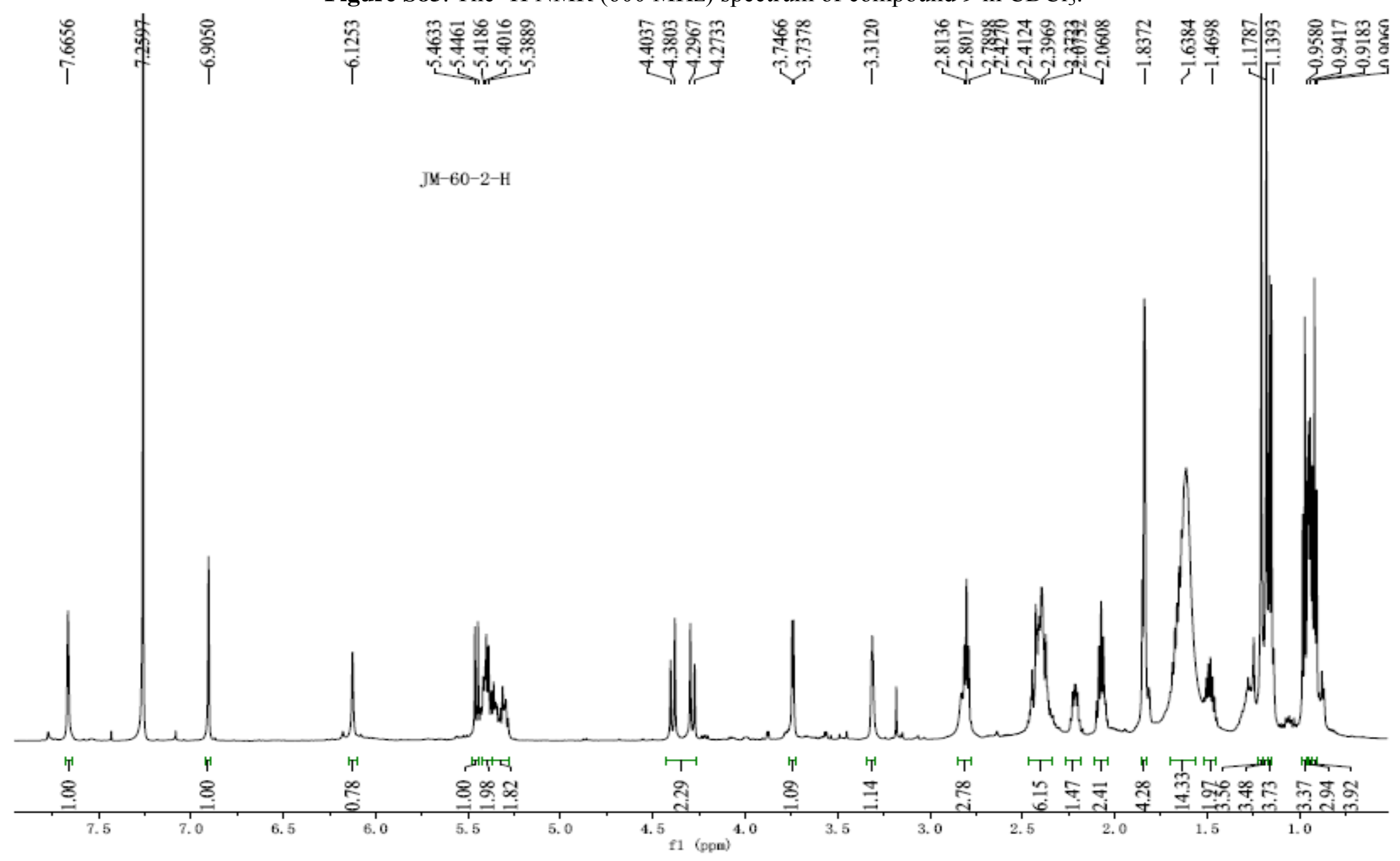


$J M-60-2-C$

Figure S84. The ${ }^{13} \mathrm{C}$ NMR (150 MHz) spectrum of compound 9 in $\mathrm{CDCl}_{3}$.

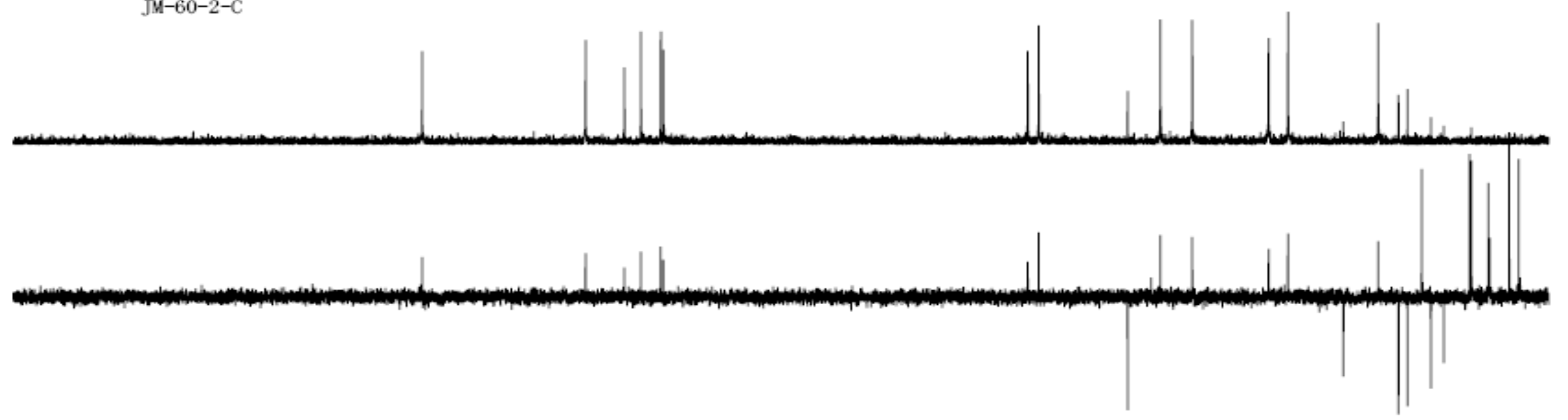

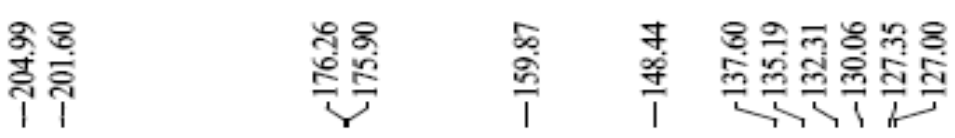

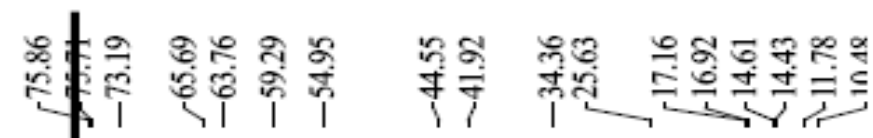
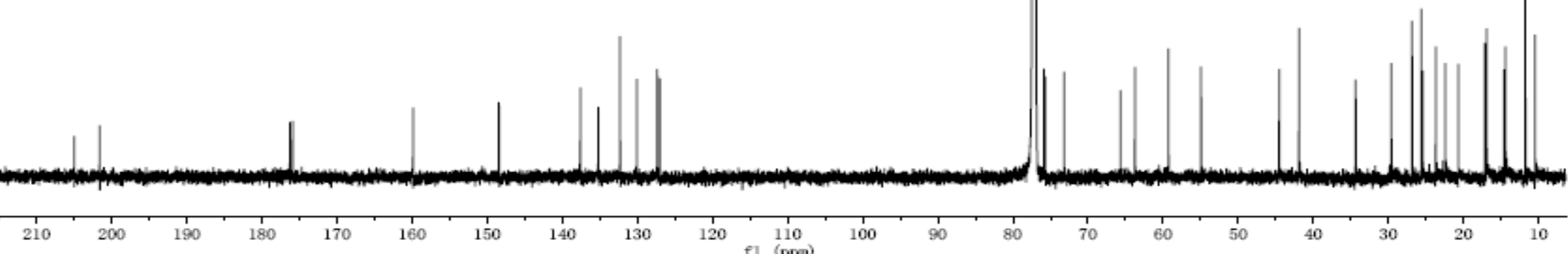
Figure S85. The enlarged ${ }^{13} \mathrm{C}$ NMR (150 MHz) spectrum of compound 9 in $\mathrm{CDCl}_{3}$.
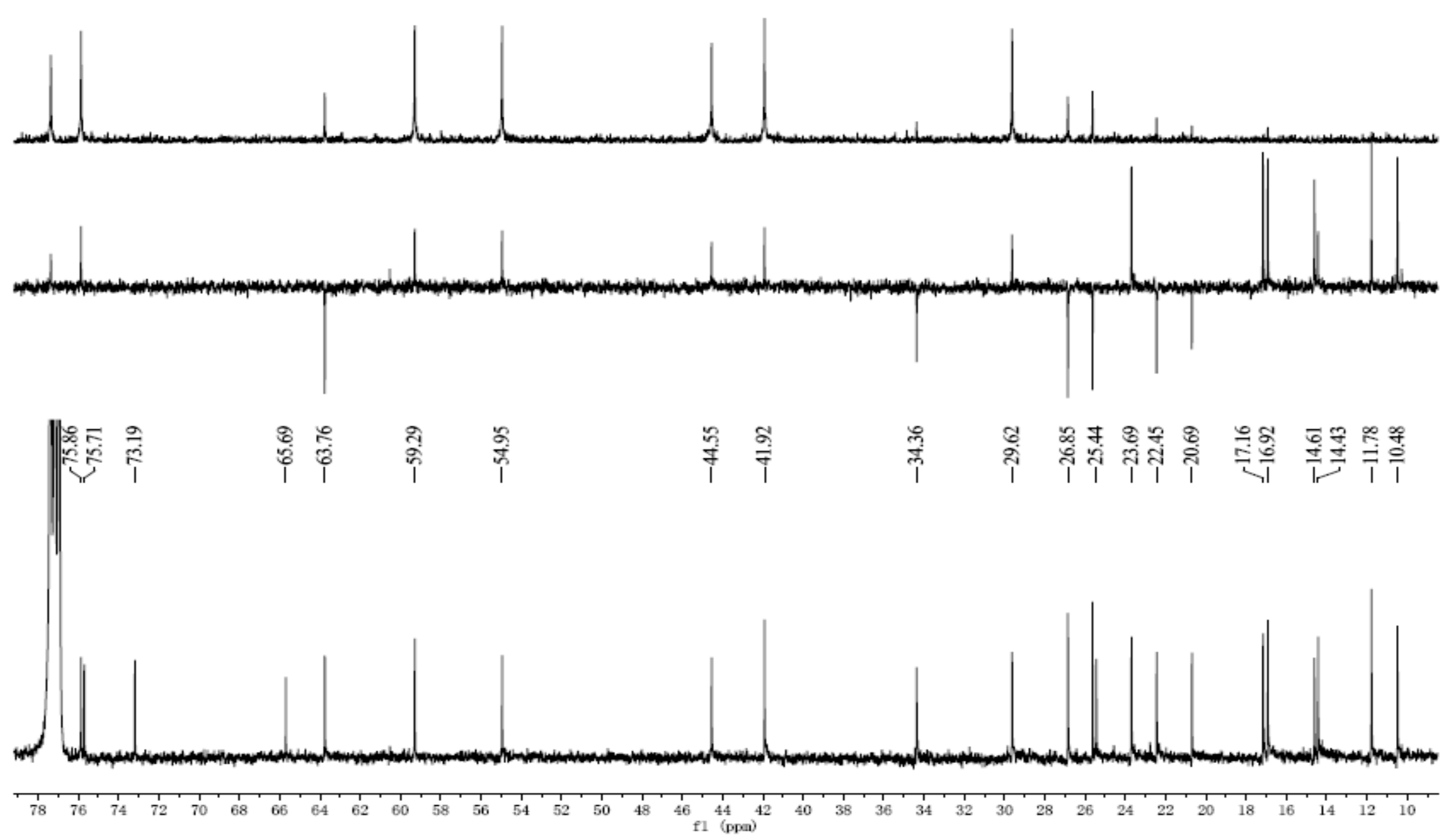
Figure S86. The HSQC spectrum of compound 9 in $\mathrm{CDCl}_{3}$.

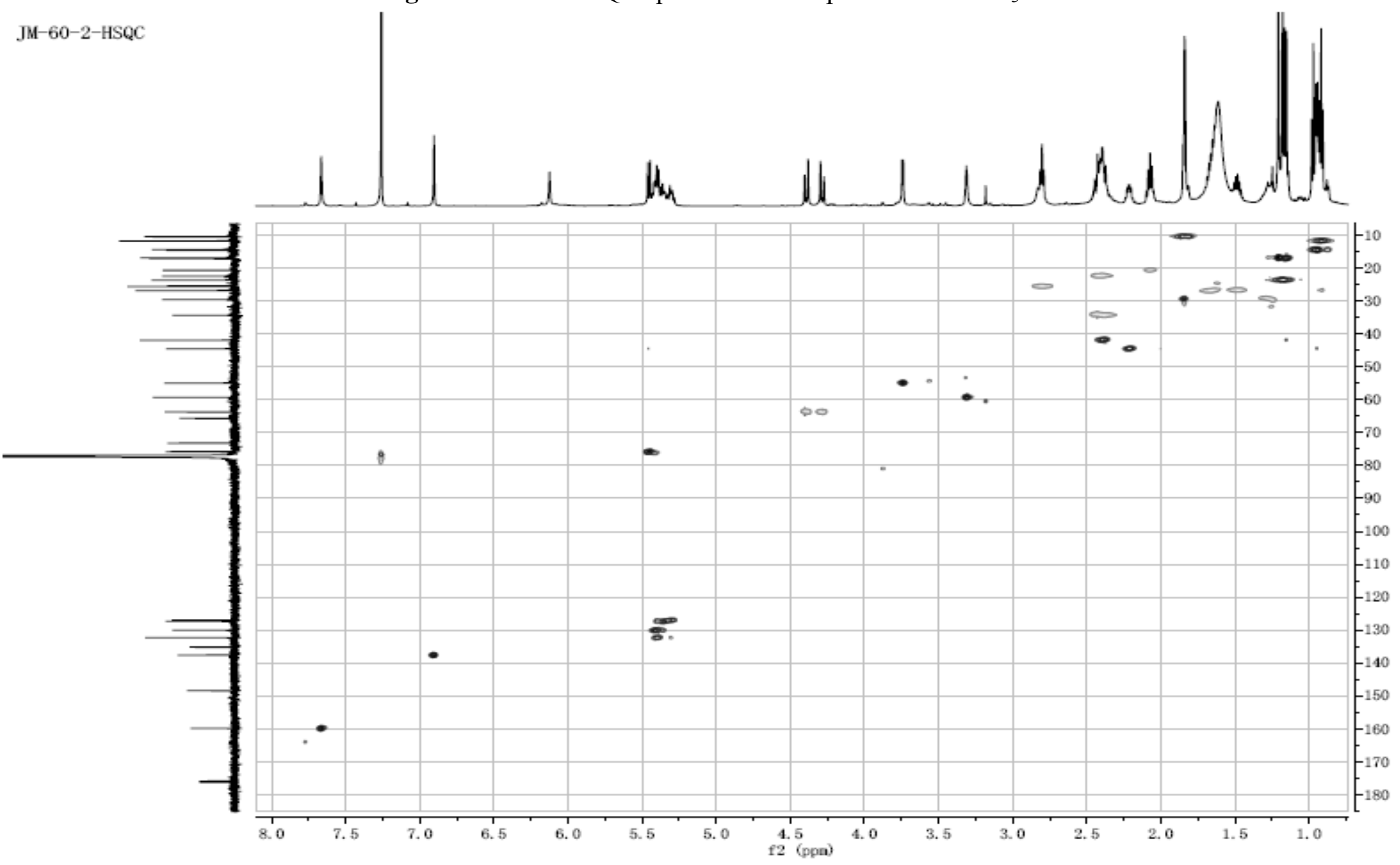


Figure S87. The $\mathrm{HMBC}$ spectrum of compound $\mathbf{9}$ in $\mathrm{CDCl}_{3}$.

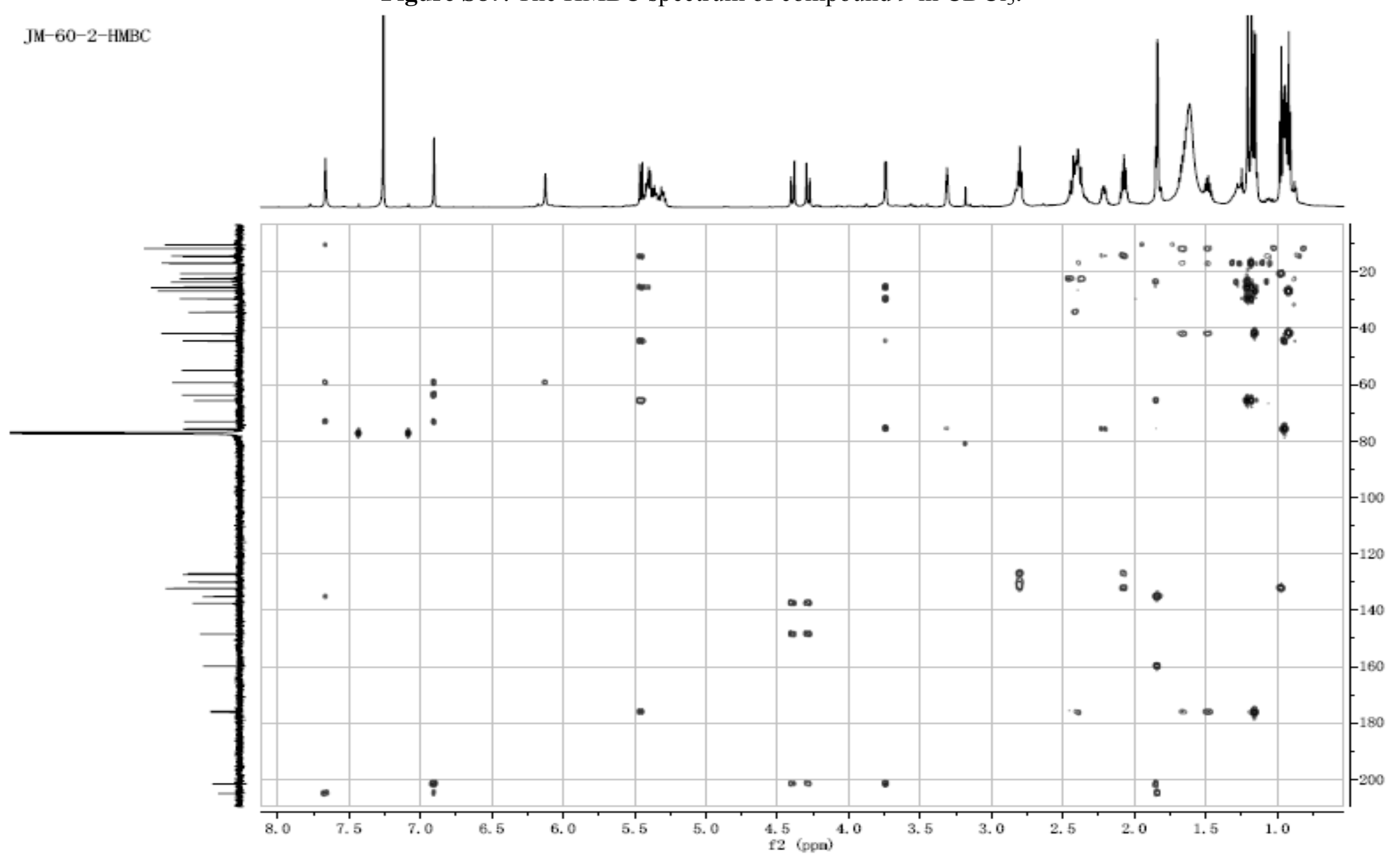


Figure S88. The ${ }^{1} \mathrm{H}-{ }^{1} \mathrm{H}$ COSY spectrum of compound 9 in $\mathrm{CDCl}_{3}$.

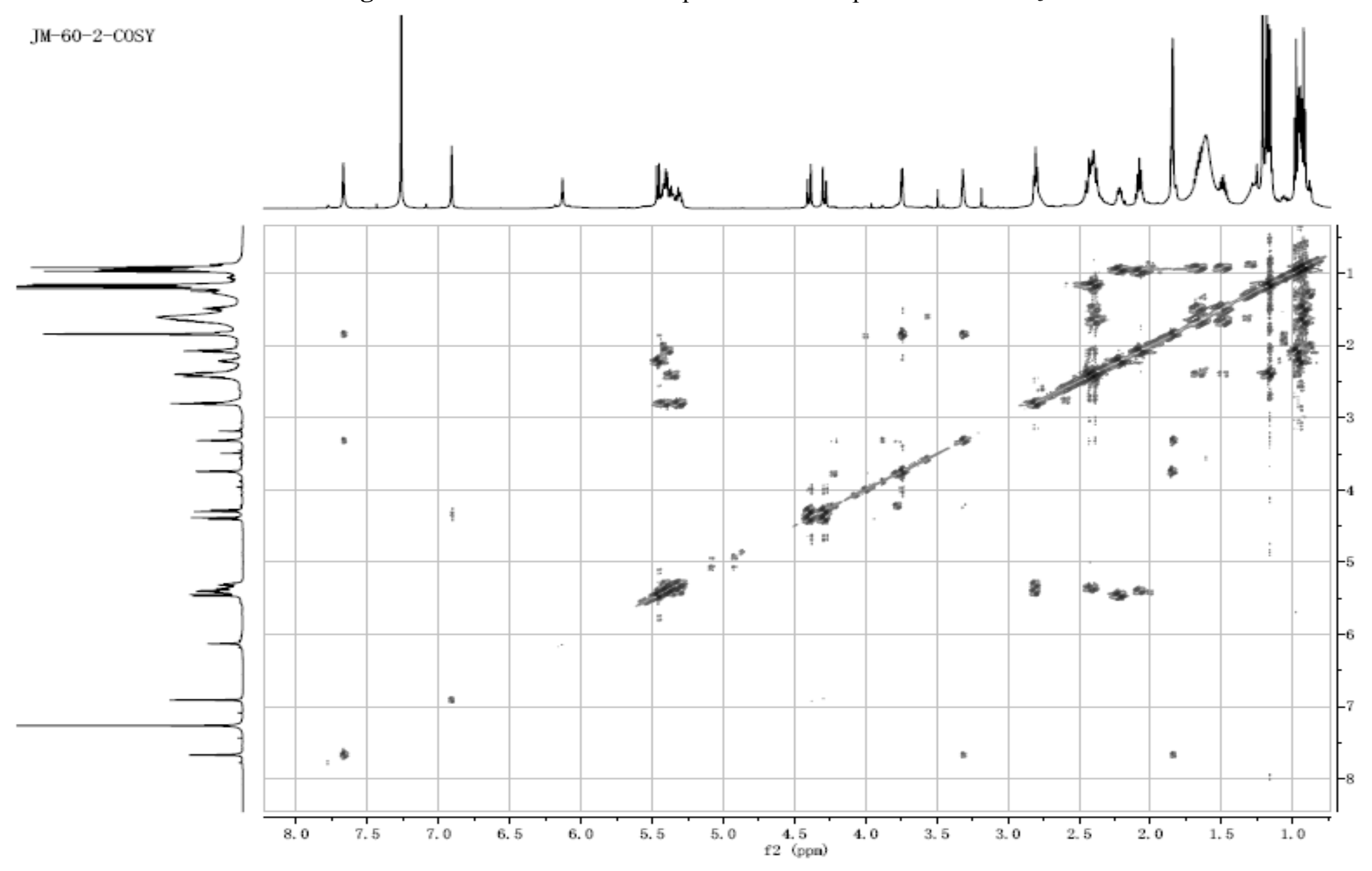


Figure S89. The ROESY spectrum of compound 9 in $\mathrm{CDCl}_{3}$.

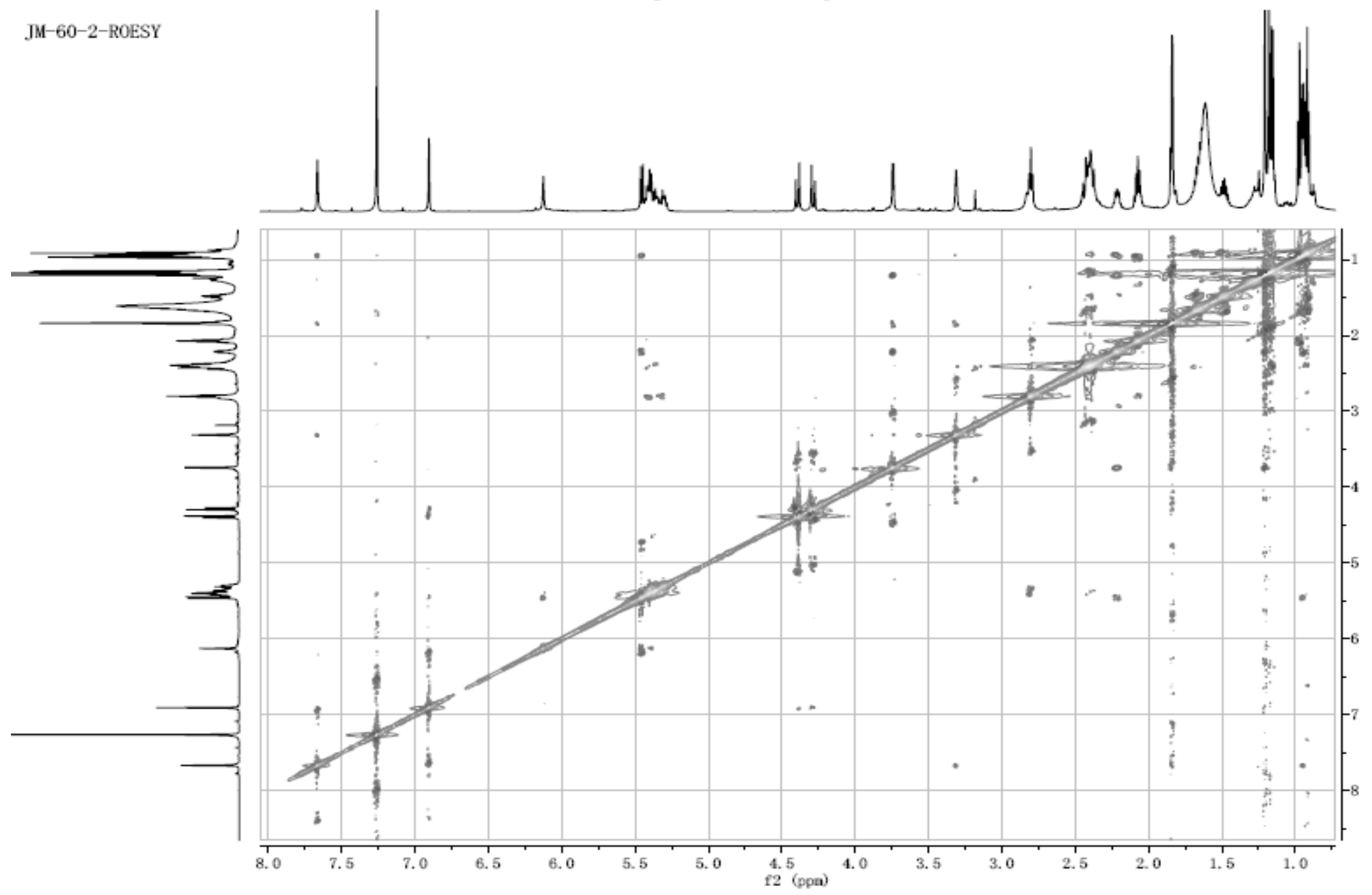


Figure S90. The HRESIMS (+) of compound $\mathbf{1 0}$.

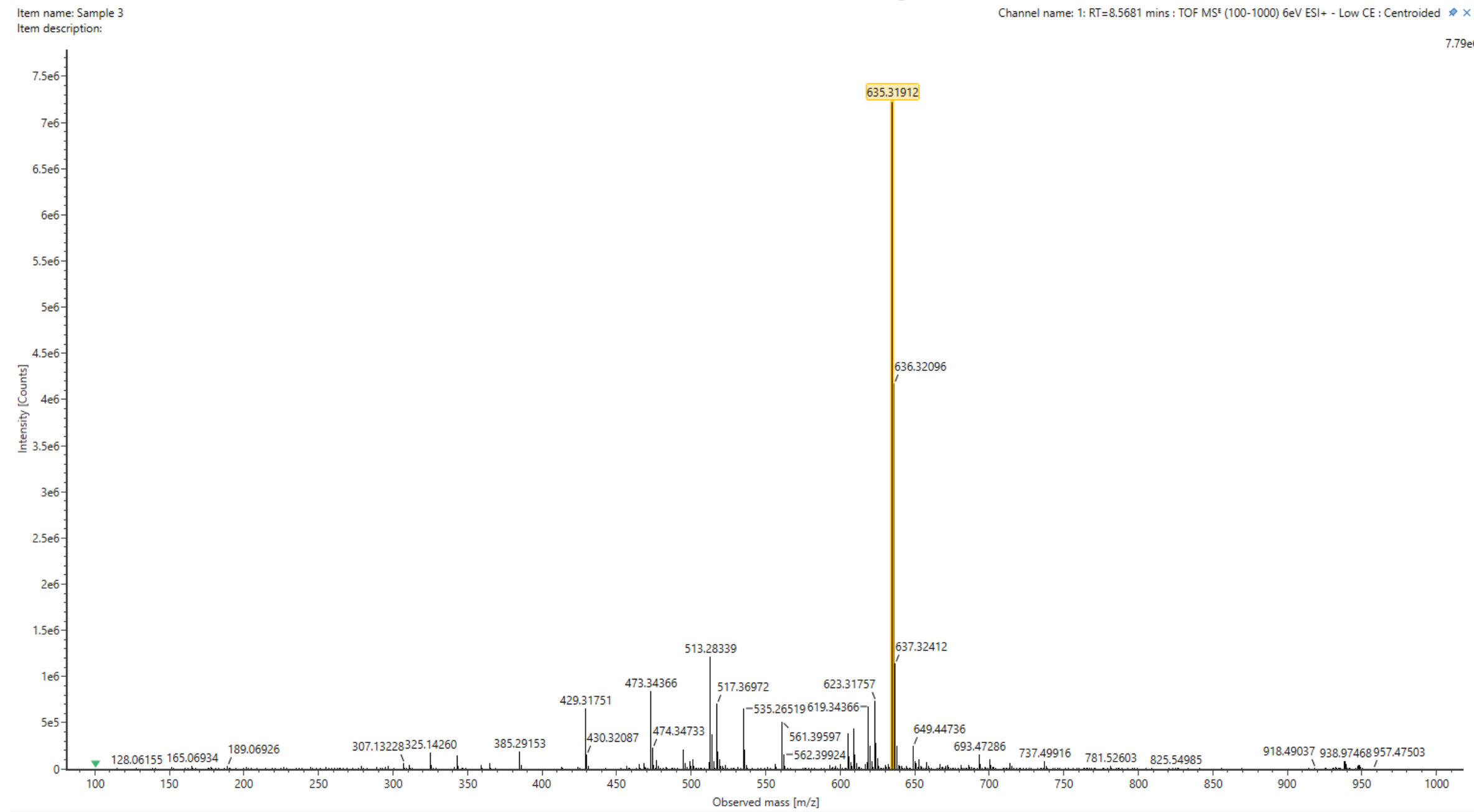




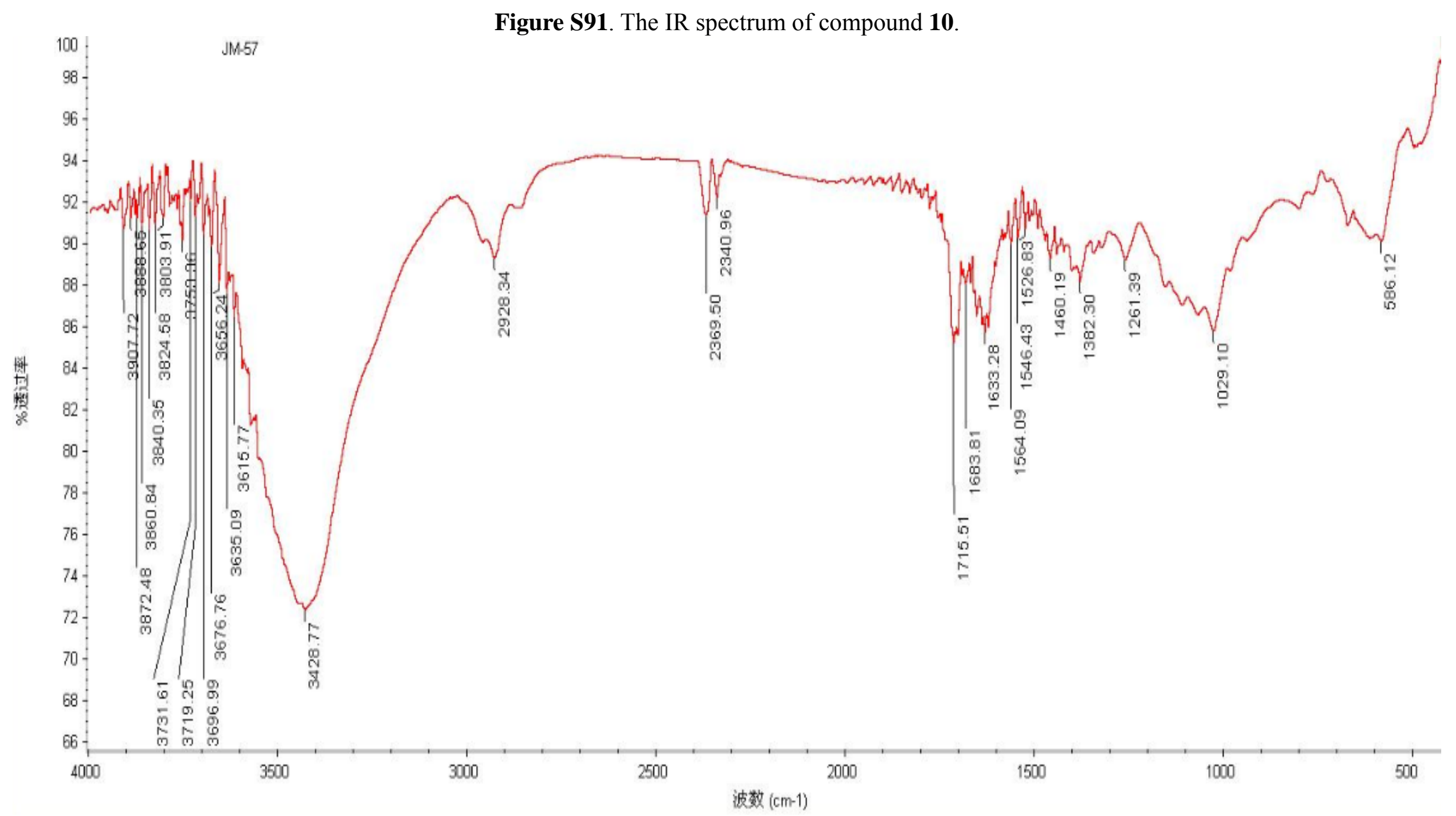


Figure S92. The CD spectrum of compound 10.

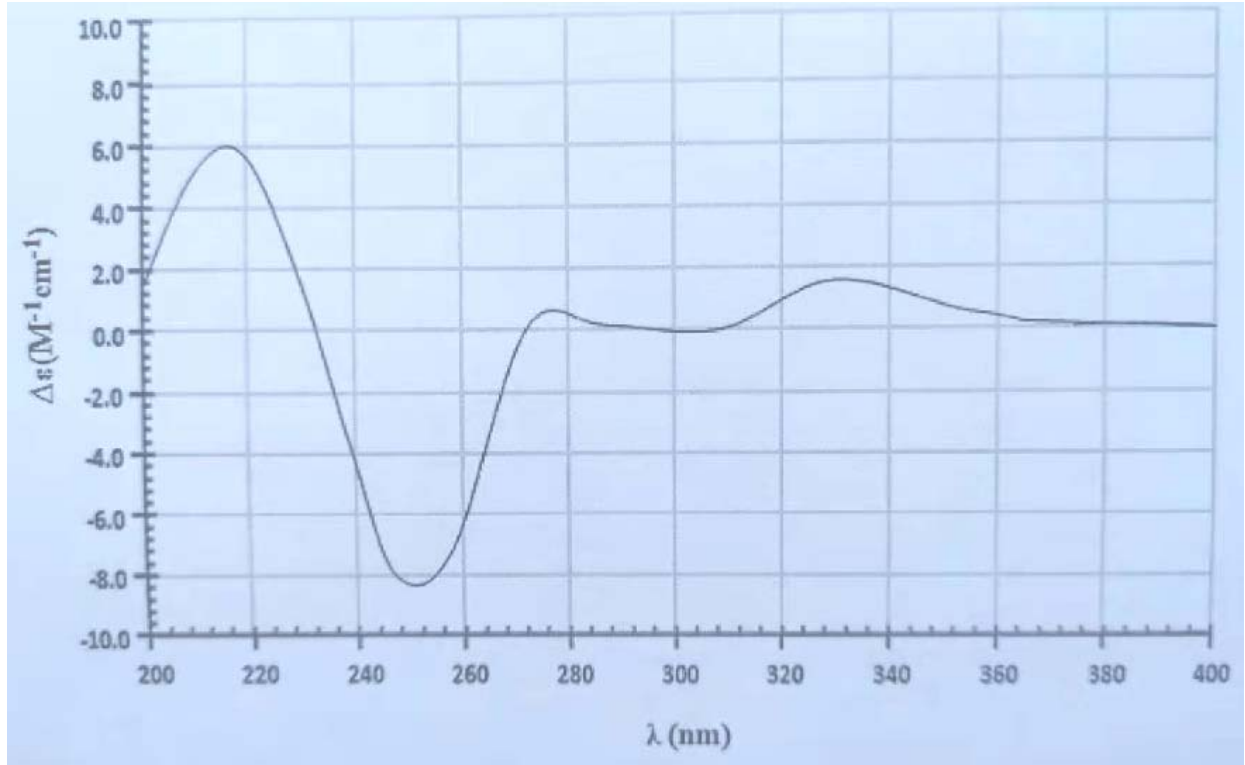


Figure S93. The ${ }^{1} \mathrm{H}$ NMR (400 MHz) spectrum of compound 10 in $\mathrm{CDCl}_{3}$.

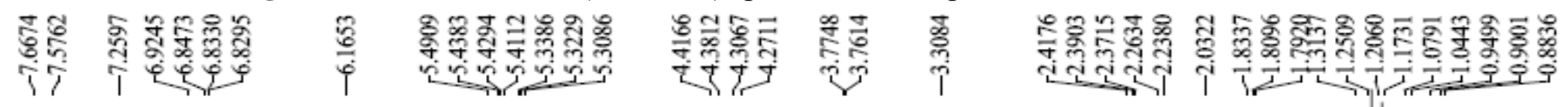

$\mathrm{JM}-57-\mathrm{H}$

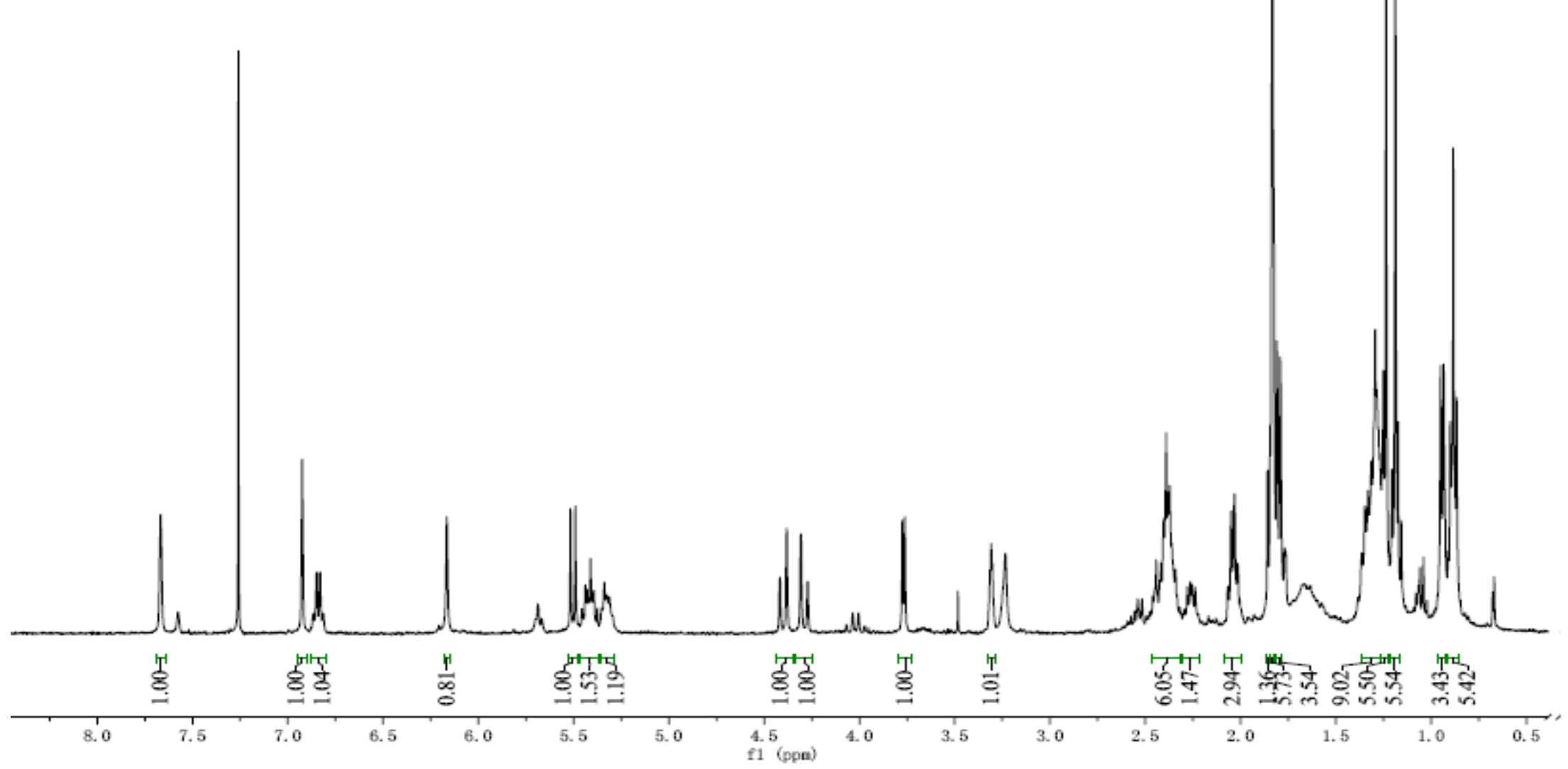


Figure S94. The ${ }^{13} \mathrm{C}$ NMR (100 MHz) spectrum of compound 10 in $\mathrm{CDCl}_{3}$.
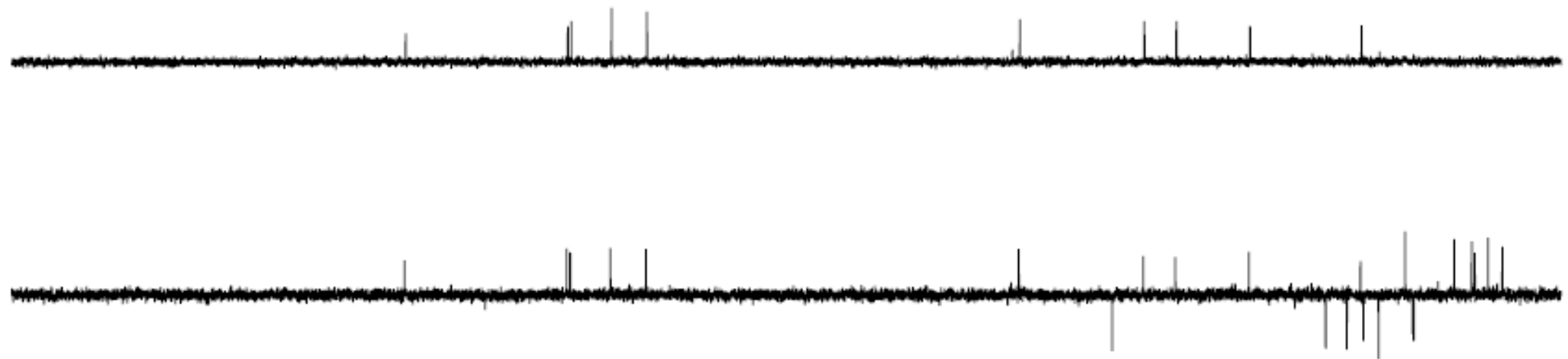

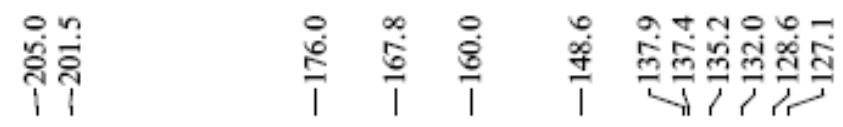

年年
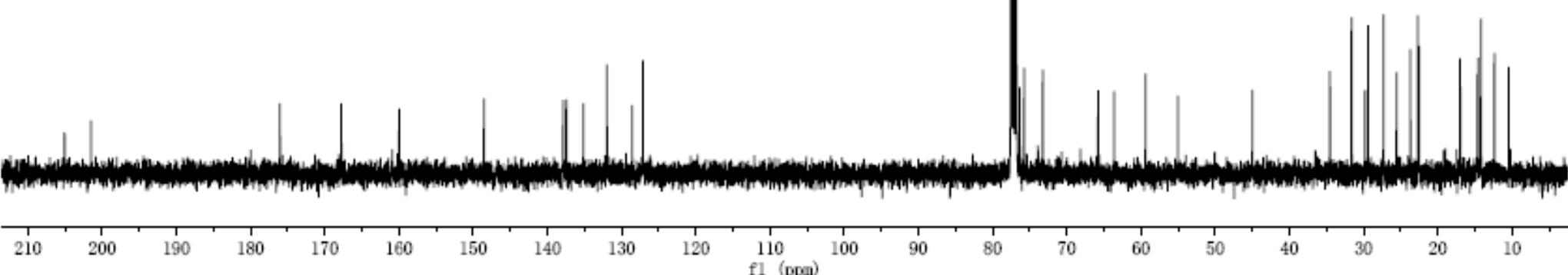
Figure S95. The enlarged ${ }^{13} \mathrm{C}$ NMR (100 MHz) spectrum of compound 10 in $\mathrm{CDCl}_{3}$.
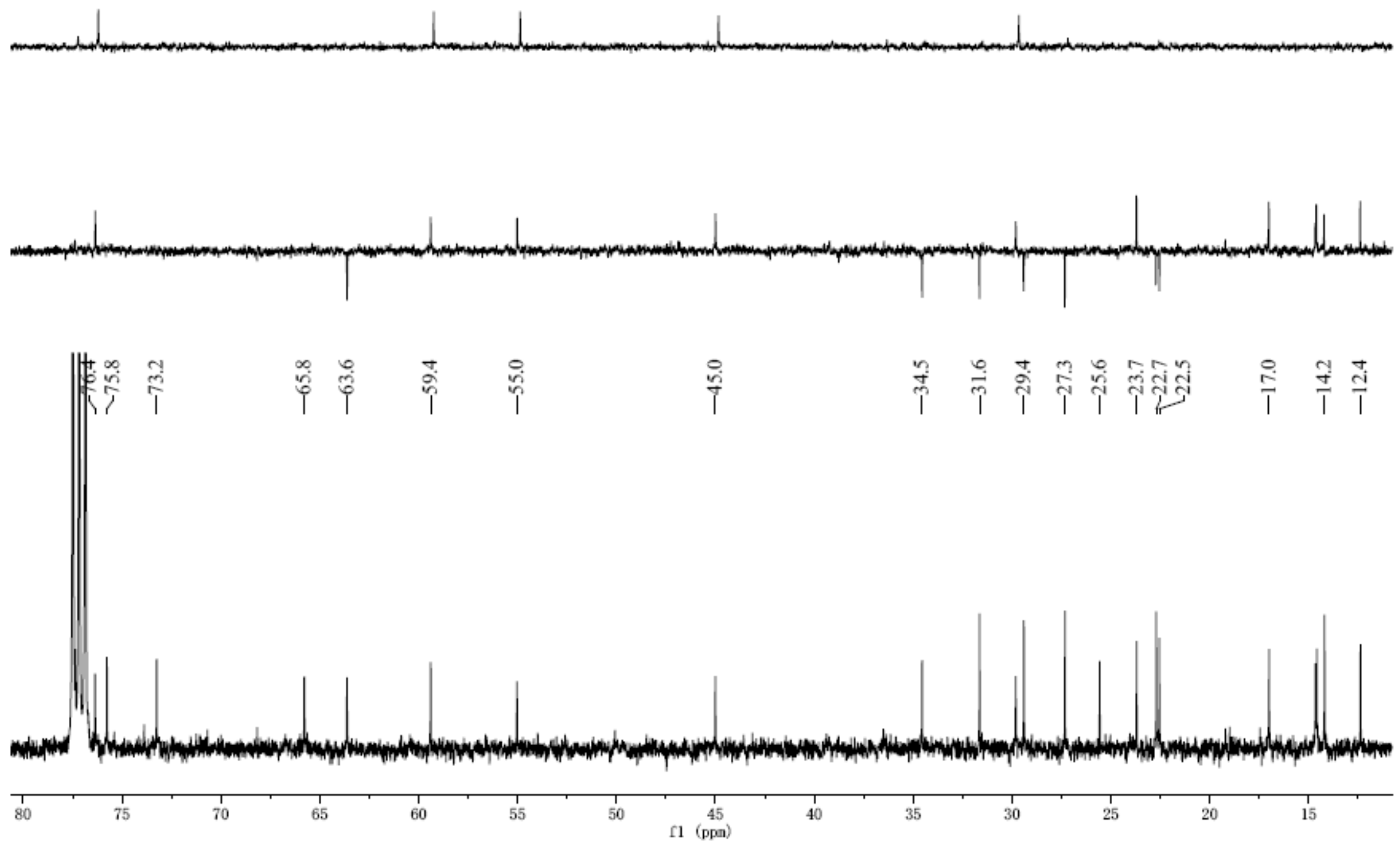
Figure S96. The HSQC spectrum of compound 10 in $\mathrm{CDCl}_{3}$.

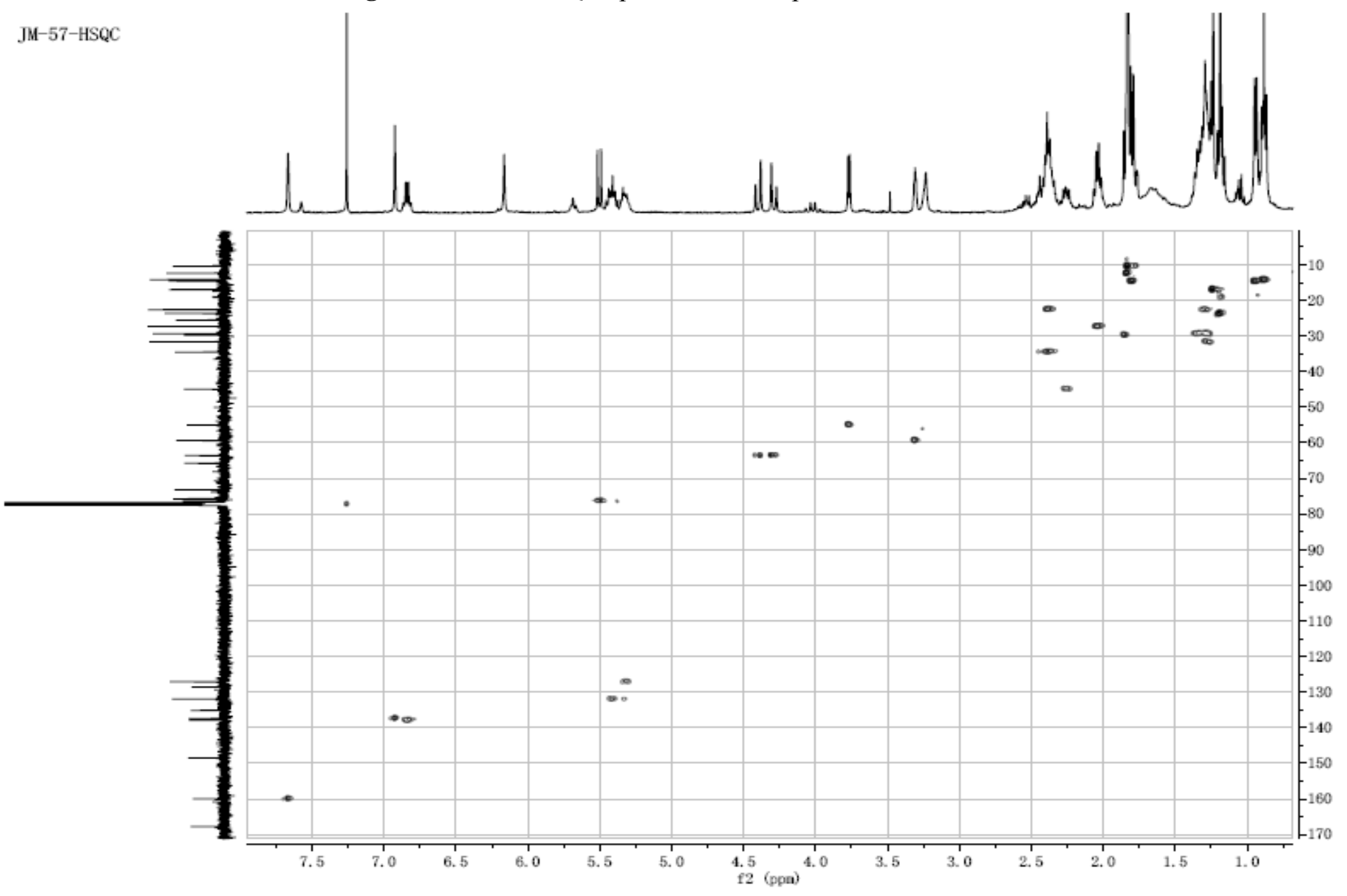


Figure S97. The HMBC spectrum of compound 10 in $\mathrm{CDCl}_{3}$.

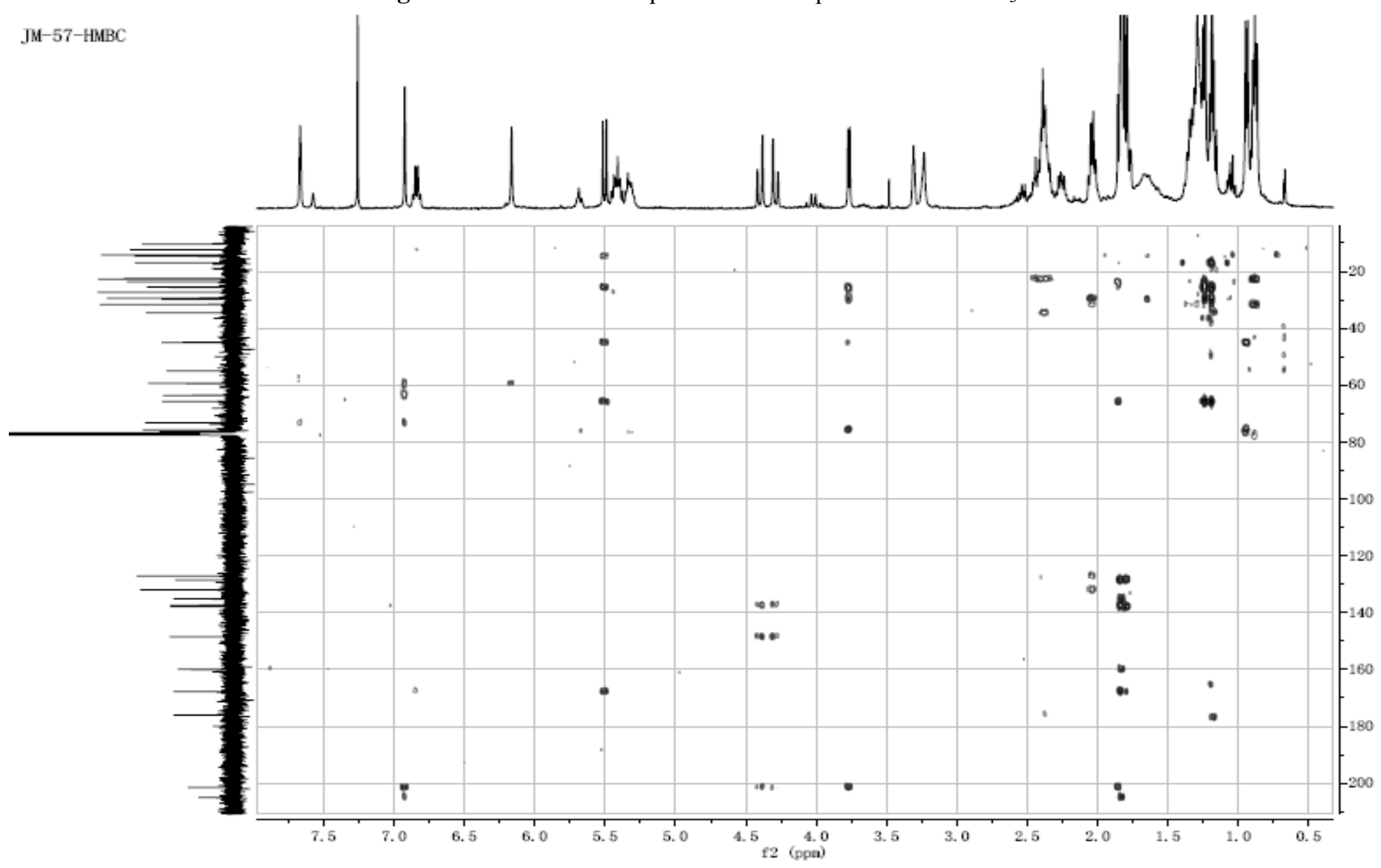


Figure S98. The ${ }^{1} \mathrm{H}-{ }^{1} \mathrm{H}$ COSY spectrum of compound 10 in $\mathrm{CDCl}_{3}$.

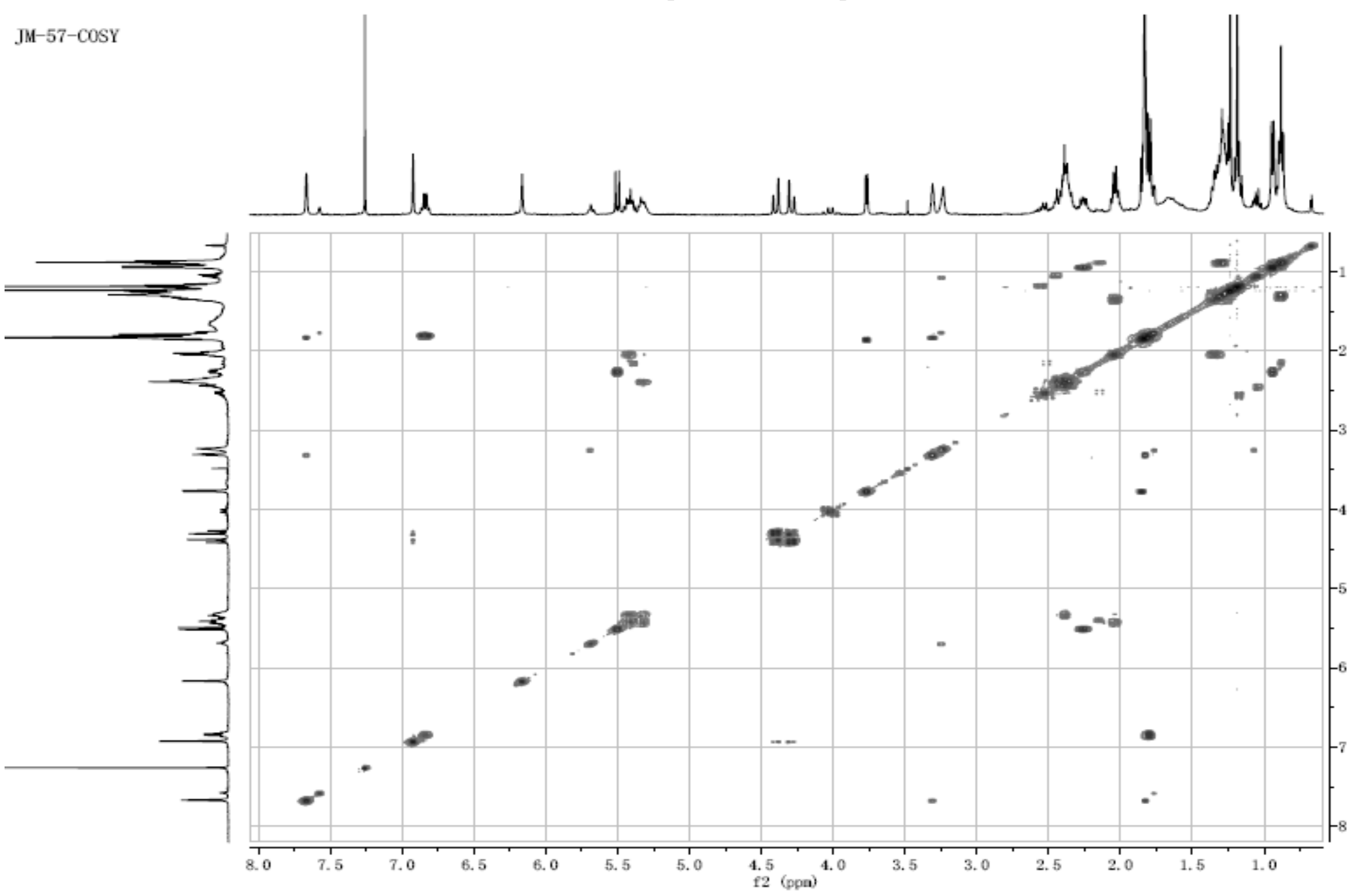


Figure S99. The ROESY spectrum of compound $\mathbf{1 0}$ in $\mathrm{CDCl}_{3}$.

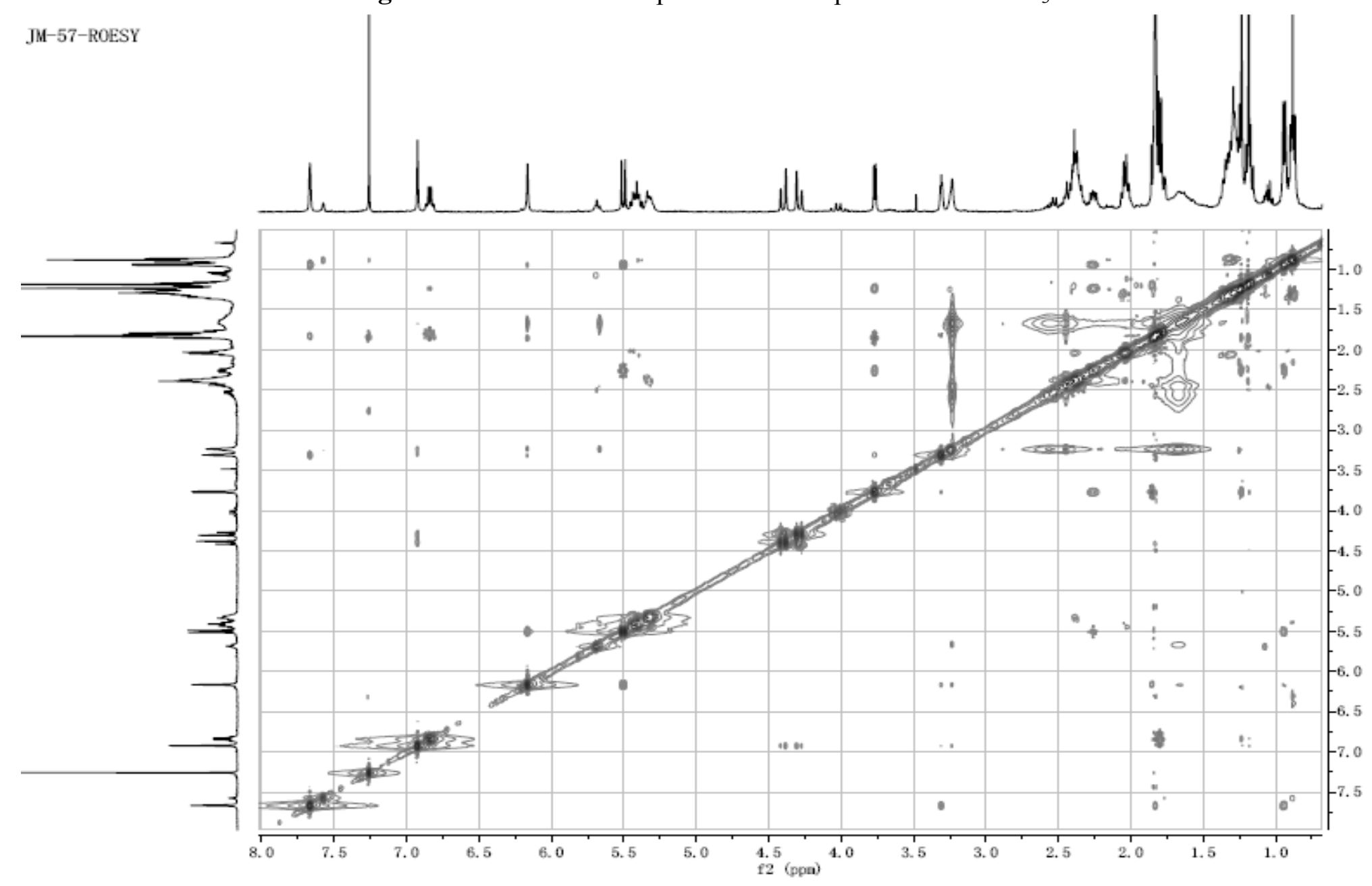

